\title{
Synthesis and Optimization of Mechanical Networks with Inerters in Landing Gear for Improved Landing Performance and Vibration Control at Touchdown Considering Airframe Flexibility
}

by

\author{
Terrin Stachiw
}

A Thesis submitted to the Faculty of Graduate and Postdoctoral Affairs in partial fulfilment of the requirements for the degree of

\author{
Master of Applied Science \\ in \\ Aerospace Engineering
}

\author{
Carleton University \\ Ottawa, Ontario
}

(C) Copyright

Terrin Stachiw, 2020 


\section{Abstract}

The landing impact case results in the development of significant loads and accelerations within the airframe. Accurate knowledge of the landing loads is not only necessary for the stress analysis and design of the airframe, but also for designing strategies to mitigate the vibratory loads and improve the ride quality. Perceived passenger comfort is dependent both on the magnitude of the acceleration experienced by the passengers and on the frequency content of the vibrations. Using a flexible airframe model of a 150-passenger regional jet with cantilevered landing gear in a tricycle configuration, this study optimizes various single-port (two-terminal) passive mechanical networks that consist of an arrangement of springs, dampers, and inerters to minimize passenger discomfort and peak forces applied to the aircraft. The performance of the mechanical networks is compared to a baseline oleopneumatic shock absorber. First, the importance of including airframe flexibility effects was demonstrated as the peak landing gear loads, the loading regime, and the frequency response of the structure were altered when compared to the equivalent rigid model. Next,

eight candidate layouts were optimized, then the observations from this exercise were used to synthesize a mechanical network with a desired frequency response. All considered mechanical networks demonstrated the ability to control the frequency content of the input loading, thus resulting in a reduction in accelerations and an improvement in all comfort parameters used in this study over the oleo-pneumatic baseline. 
To my family 


\section{Acknowledgments}

First and foremost, my thanks goes out to my thesis supervisors: Dr. Fidel Khouli, Dr. Robert Langlois, and Dr. Fred Afagh. Their wealth of knowledge and experience brought support and guidance that exceeded my expectations.

To my family and friends, I am thankful for their support and tolerance during stressful times. I am forever indebted to my family for their relentless support in every way through my education process-and through my lifetime for that matter.

This research was financially supported in part by the Natural Sciences and Engineering Research Council of Canada both by the Canada Graduate Scholarship-Master's and Discovery Grants. In addition, entrance scholarships to the Mechanical and Aerospace Engineering department, and Teaching Assistantships helped fund my research.

-Terrin Stachiw 


\section{Contents}

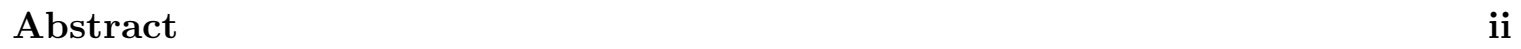

Acknowledgments

Table of Contents $\quad$ iv

List of Tables viii

List of Figures $\quad x$

Nomenclature xii

List of Abbreviations $\quad$ xvii

1 Introduction 1

1.1 Motivation . . . . . . . . . . . . . . . . . . . . . . . . . . 1

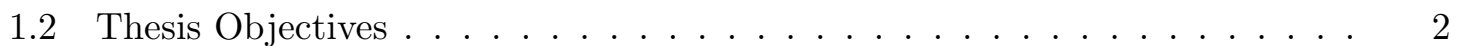

1.3 Document Organization $\ldots \ldots \ldots \ldots \ldots$

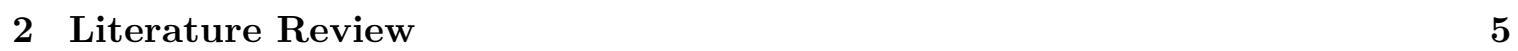

$2.1 \quad$ Simulation Model Requirements . . . . . . . . . . . . . . . . . . . . . 5

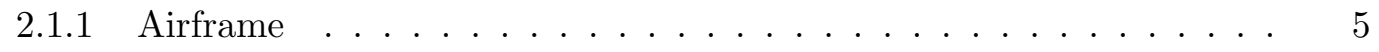

2.1 .2 Landing Gear . . . . . . . . . . . . . . . . 8

2.1 .3 Aerodynamics $\ldots \ldots \ldots \ldots$

2.2 Vibration Control and Human Comfort . . . . . . . . . . . . . . . . . 16

2.2 .1 Vibration Control $\ldots \ldots \ldots \ldots$ 
$2.2 .2 \quad$ Human Comfort Parameters $\ldots \ldots \ldots \ldots \ldots$

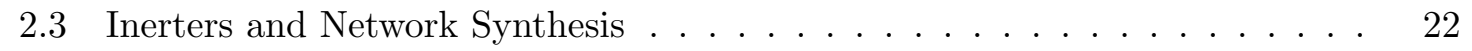

$\begin{array}{lll}3 & \text { Aircraft Simulation Model and Problem Setup } & 27\end{array}$

$3.1 \quad$ Aircraft Model . . . . . . . . . . . . . . . . . . . . . . . . . . . . . . 28

$3.2 \quad$ Aircraft Geometry $\ldots \ldots \ldots \ldots \ldots$

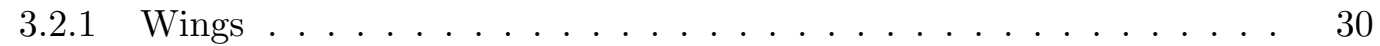

3.2 .2 Horizontal Tail . . . . . . . . . . . . . . . . . . . 30

3.2 .3 Vertical Tail . . . . . . . . . . . . . . . . . . . . . . 30

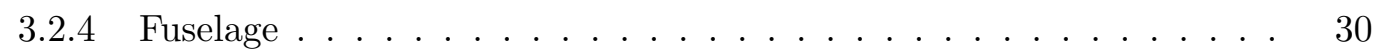

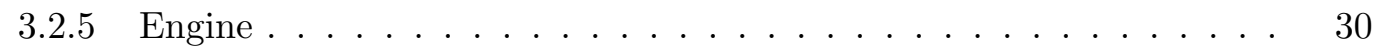

$3.2 .6 \quad$ Landing Gear Geometry . . . . . . . . . . . . . . . . . 31

3.3 Mass Distribution . . . . . . . . . . . . . . . . . . . . . . . . . . 32

$3.3 .1 \quad$ Landing Gear Mass $\ldots \ldots \ldots \ldots . \ldots \ldots$

$3.3 .2 \quad$ Passenger Mass and Position $\ldots \ldots \ldots \ldots \ldots$

$3.3 .3 \quad$ Fuel Mass and Arrangement. . . . . . . . . . . . . . . . . . 37

3.4 Airframe Beam and Stiffness Properties $\ldots \ldots \ldots \ldots$

$3.4 .1 \quad$ Wings $\ldots \ldots \ldots \ldots \ldots$

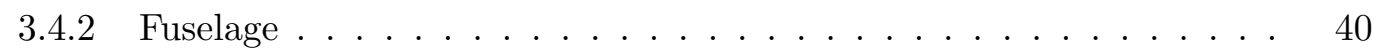

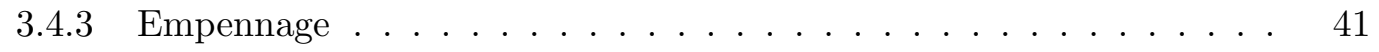

$3.4 .4 \quad$ Structural Damping $\ldots \ldots \ldots \ldots \ldots \ldots$. . . . . . . . . . . 41

$3.5 \quad$ Modal Analysis . . . . . . . . . . . . . . . . . . . . . . . . . . 41

$3.6 \quad$ Mesh Convergence $\ldots \ldots \ldots \ldots \ldots$. . . . . . . . . . . . . . . . . 42

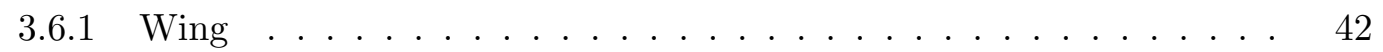

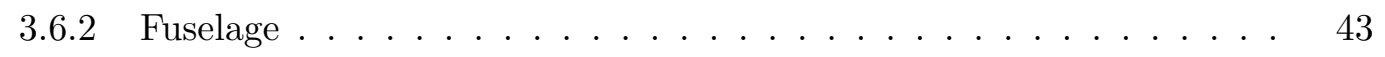

3.6 .3 Horizontal Tail . . . . . . . . . . . . . . . . . . . 43

3.6 .4 Vertical Tail . . . . . . . . . . . . . . . . . . . 43

3.7 Landing Gear Attachment . . . . . . . . . . . . . . . . . . . . . . 44

3.8 Multibody Dynamics Model . . . . . . . . . . . . . . . . . . . . . . 44

3.8.1 Shock Absorber Force Model . . . . . . . . . . . . . . . . . . 44 
3.8 .2 Tire Model . . . . . . . . . . . . . . . . . . . . . . 44

$3.8 .3 \quad$ Number of Airframe Flexibility Modes Required for Simulation . . . 49

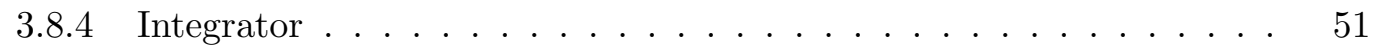

3.9 Initial Conditions: Landing Cases $\ldots \ldots \ldots \ldots \ldots \ldots$

3.10 Optimization Problem Setup $\ldots \ldots \ldots \ldots$

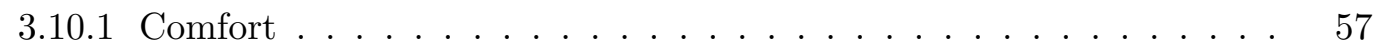

3.10 .2 Shock-Strut Performance $\ldots \ldots \ldots \ldots \ldots \ldots$

3.10 .3 Cost Function $\ldots \ldots \ldots \ldots \ldots \ldots \ldots$

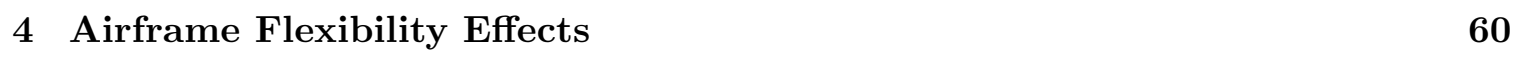

$4.1 \quad$ Flexibility Effects at Landing $\ldots \ldots \ldots$. . . . . . . . . . . . . . 60

$4.1 .1 \quad$ Airframe Flexibility $\ldots \ldots \ldots \ldots \ldots$

$4.1 .2 \quad$ Landing Gear Attachment Flexibility. . . . . . . . . . . . . 63

$4.2 \quad$ Frequency Analysis $\ldots \ldots \ldots \ldots \ldots$

4.3 Observations and Conclusions . . . . . . . . . . . . . . . . . 66

\begin{tabular}{|lll}
5 & Design and Synthesis of Shock Absorbers & 68
\end{tabular}

5.1 Baseline Oleo-pneumatic Performance $\ldots \ldots \ldots$. . . . . . . . . 68

5.1 .1 Observations . . . . . . . . . . . . . . . . . . . . . 69

$5.2 \quad$ Optimization of Candidate Layouts $\ldots \ldots \ldots \ldots \ldots \ldots \ldots \ldots$

$5.2 .1 \quad$ Optimization Algorithm $\ldots \ldots \ldots \ldots \ldots \ldots \ldots$

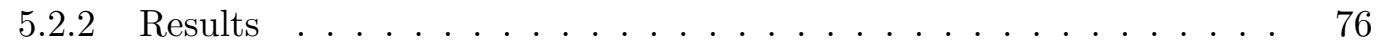

5.2 .3 Observations $\ldots \ldots \ldots \ldots \ldots \ldots \ldots \ldots \ldots \ldots \ldots$

5.3 Synthesis of Mechanical Network with Idealized Response . . . . . . . . . 81

$5.3 .1 \quad$ Optimization $\ldots \ldots \ldots \ldots \ldots \ldots \ldots \ldots \ldots$

5.3 .2 Results $\ldots \ldots \ldots \ldots \ldots \ldots \ldots \ldots \ldots \ldots$

$\begin{array}{lll}6 & \text { Results and Discussion } & 87\end{array}$

6.1 Results. . . . . . . . . . . . . . . . . . . . . . . . 87

$6.1 .1 \quad$ Converged Points . . . . . . . . . . . . . . . . . . 87

6.1 .2 Comfort Parameters $\ldots \ldots \ldots \ldots \ldots \ldots$ 
$6.1 .3 \quad$ Strain Energy $\ldots \ldots \ldots$. . . . . . . . . . . . . . . . . . 90

6.2 Discussion . . . . . . . . . . . . . . . . . . . . . . . . . . . . 91

$6.2 .1 \quad$ Airframe Flexibility Effects $\ldots \ldots \ldots$. . . . . . . . . . . 91

$6.2 .2 \quad$ Optimized Mechanical Networks . . . . . . . . . . . . . . . 92

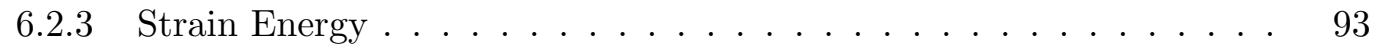

6.2 .4 Passenger and Crew Comfort . . . . . . . . . . . . . . 95

\begin{tabular}{lll}
\hline 7 & Conclusions & 96
\end{tabular}

7.1 Contributions . . . . . . . . . . . . . . . . . . . . . . . . . . 97

7.2 Publications . . . . . . . . . . . . . . . . . . . . . . . 98

7.3 Future Work $\ldots \ldots \ldots \ldots$

\begin{tabular}{lr}
\hline Bibliography & 100
\end{tabular}

\begin{tabular}{|l|l|}
\hline Appendix A Tire and Road Property Files & 109
\end{tabular}

A.1 Nose Landing Gear . . . . . . . . . . . . . . . . . . . . . . . . . . . . . . . . . . 109

A.2 Main Landing Gear . . . . . . . . . . . . . . . . . . . . . . . . . . . 110

A.3 Road Property File . . . . . . . . . . . . . . . . . . . . . . . . . . . 111 


\section{List of Tables}

2.1 Mechanical and electrical analogies . . . . . . . . . . . . . . . . 23

$3.1 \quad$ Relevant specifications of the Airbus A220-300. . . . . . . . . . . . . . . . 29

3.2 Landing gear attachment and tire locations. . . . . . . . . . . . . . . . 31

$3.3 \quad$ Lengths of landing gear structural components. . . . . . . . . . . . . . . . . 32

3.4 Reference component mass fractions for Boeing 737-200. . . . . . . . . . . . 32

$3.5 \quad$ Final component masses. . . . . . . . . . . . . . . . . . . . . . 33

3.6 Reference A220 tire and wheel properties. . . . . . . . . . . . . . . . 35

3.7 Masses of landing gear structural components. . . . . . . . . . . . . . 36

3.8 Al $7075-\mathrm{T} 6$ properties $\ldots \ldots \ldots \ldots$

$3.9 \quad$ Final wing and fuselage cross-sectional parameter distribution values. . . . . 41

3.10 Final empennage cross-sectional parameter distribution values. . . . . . . . 41

3.11 Eigenmodes of the aircraft model at OEM and MLM. . . . . . . . . . . . . 42

3.12 Percent change in modal frequency compared to the previous refinement level for a beam representation of a single wing. . . . . . . . . . . . . . . . . . . 42

3.13 Percent change in modal frequency compared to the previous refinement level for a beam representation of the fuselage. . . . . . . . . . . . . . . . 43

3.14 Percent change in modal frequency compared to the previous refinement level for a beam representation of a single horizontal tail. . . . . . . . . . . . 43

3.15 Percent change in modal frequency compared to the previous refinement level for a beam representation of a vertical tail. . . . . . . . . . . . . . . 43

3.16 Root mean square errors compared to simulation with all modes up to $150 \mathrm{~Hz}$ with corresponding simulation time. $\ldots \ldots \ldots$. . . . . . . . . . 51 
3.17 Root mean square errors compared to simulation with a $1 \times 10^{-5}$ integration error tolerance with corresponding simulation time. . . . . . . . . . . 54

3.18 Initial aircraft velocities and attitude. . . . . . . . . . . . . . . . 56

3.19 Locations used to assess comfort . . . . . . . . . . . . . . . . . . . . 57

4.1 Comfort parameters in the cockpit for varying airframe flexibility levels. . . $\quad 62$

4.2 Percent differences of various response parameters compared to the baseline LG attachment stiffness. . . . . . . . . . . . . . . . . . . . . . . 64

4.3 Acceleration at three fuselage stations in response to typical landing force for rigid airframe. . . . . . . . . . . . . . . . . . . . . . 65

$5.1 \quad$ Initial guesses for the optimization of the candidate mechanical networks. . $\quad 77$

6.1 Optimization results for candidate shock absorbers from both optimization algorithms. . . . . . . . . . . . . . . . . . . 88

6.2 Optimization results for candidate shock absorbers from best optimization algorithm. . . . . . . . . . . . . . . . . . . . 89

6.3 Average comfort parameters at three fuselage stations for optimized shock absorbers. . . . . . . . . . . . . . . . . . . 90

6.4 Sum of peak forces at each landing gear attachment and peak strain energy. $\quad 90$ 


\section{List of Figures}

$2.1 \quad$ Diagram of an oleo-pneumatic shock absorber. . . . . . . . . . . . . 9

2.2 Spin-up and spring-back motions. . . . . . . . . . . . . . . . . . 12

$2.3 \quad$ Equivalent spring-mass-damper system used to calculate the DRI. . . . . . 18

2.4 Bode magnitude diagram of seat vertical acceleration to spinal compression transfer function. . . . . . . . . . . . . . . . . . . . . 21

2.5 Schematics of various inerter types. . . . . . . . . . . . . . . 25

$3.1 \quad$ Stick model used in dynamic analyses. . . . . . . . . . . . . . . . . . . 28

$3.2 \quad 3$-view drawing of Airbus A220. . . . . . . . . . . . . . . . . 29

3.3 Global coordinate system. . . . . . . . . . . . . . . . . . . . . . . . . . 29

3.4 Local airfoil coordinate system. . . . . . . . . . . . . . . . . . . . . 39

$3.5 \quad$ Vertical tire force versus deflection with corresponding linear fits for MLG and NLG tires. . . . . . . . . . . . . . . . . . . . 46

$3.6 \quad$ Longitudinal tire force ratio versus slip ratio. . . . . . . . . . . . . . . . . . 49

$3.7 \quad$ Simulated main landing gear stroke with various flexible modes included. . 50

$3.8 \quad$ Simulated main landing gear force with various flexible modes included. . . 50

$3.9 \quad$ Simulated cockpit acceleration with various flexible modes included. . . . . 51

3.10 Simulated main landing gear stroke with various integration error tolerances. 52

3.11 Simulated main landing gear force with various integration error tolerances. 53

3.12 Simulated cockpit acceleration with various integration error tolerances. . . 53

$4.1 \quad$ MLG force with varying levels of flexibility. . . . . . . . . . . . . . 61

4.2 Cockpit acceleration with varying levels of flexibility. . . . . . . . . . . 62 
4.3 Translational acceleration magnitude FRF of excitation at MLG to various points along fuselage. . . . . . . . . . . . . . . . . . . . . . . . . 64

5.1 Response contour plots for OP shock absorber parameters. . . . . . . . . . 69

$5.2 \quad$ PSD of input force at the MLG for the OP baseline. . . . . . . . . . . 71

$5.3 \quad$ Candidate mechanical network arrangements. . . . . . . . . . . . . . . 73

5.4 Diagram of a dashpot. . . . . . . . . . . . . . . . 75

5.5 Bode magnitude plots of all shock absorbers at converged point. . . . . . . 80

5.6 Mechanical network layout of Syn1. . . . . . . . . . . . . . . . . . . 84

$6.1 \quad$ Bode magnitude plot of Syn1. . . . . . . . . . . . . . . . . . . . . . . 93 


\section{Nomenclature}

\section{Latin Characters}

\begin{tabular}{|c|c|c|}
\hline Symbol & Description & Units \\
\hline$A$ & Area & {$\left[\mathrm{m}^{2}\right]$} \\
\hline$A(s)$ & Laplace-transformed acceleration & {$\left[\mathrm{m} \mathrm{s}^{-2}\right]$} \\
\hline$A_{\text {fuselage }_{i}}$ & Cross-sectional area of fuselage section $i$ & {$\left[\mathrm{~m}^{2}\right]$} \\
\hline$A_{\text {wing }}$ & Cross-sectional area of a wing section & {$\left[\mathrm{m}^{2}\right]$} \\
\hline$A_{a}$ & Pneumatic area & {$\left[\mathrm{m}^{2}\right]$} \\
\hline$A_{h}$ & Hydraulic area, area of strut & {$\left[\mathrm{m}^{2}\right]$} \\
\hline$A_{n}$ & Orifice area & {$\left[\mathrm{m}^{2}\right]$} \\
\hline$a$ & Arbitrary constant & {$[-]$} \\
\hline$a_{i}$ & Constants of the wing property distribution & {$[-]$} \\
\hline$b_{i}$ & Inertance of element $i$ & {$[\mathrm{~kg}]$} \\
\hline$b_{i}$ & Constants of the fuselage property distribution & {$[-]$} \\
\hline$C$ & Capacitance & {$[\mathrm{F}]$} \\
\hline$C_{\alpha}$ & Tire cornering stiffness & {$[\mathrm{lbf}]$} \\
\hline$C_{\text {slip }}$ & Longitudinal tire stiffness & {$[\mathrm{lbf}]$} \\
\hline$C_{0}$ & Hydraulic damping coefficient & {$\left[\mathrm{N} \mathrm{s}^{2} \mathrm{~m}^{-2}\right]$} \\
\hline$C_{d}$ & Discharge coefficient & {$[-]$} \\
\hline$c_{i}$ & Damping coefficient of element $i$ & {$\left[\mathrm{~N} \mathrm{~s} \mathrm{~m}^{-1}\right]$} \\
\hline$c_{i}$ & Cord length of section $i$ & {$[\mathrm{~m}]$} \\
\hline$D$ & Nominal tire diameter & [in] \\
\hline
\end{tabular}




\begin{tabular}{|c|c|c|}
\hline Symbol & Description & Units \\
\hline$D(s)$ & Laplace-transformed denominator & {$[-]$} \\
\hline$d$ & Orifice diameter & {$[\mathrm{m}]$} \\
\hline$d_{i}$ & Arbitrary constant & {$[-]$} \\
\hline$E$ & Young's modulus & {$[\mathrm{Pa}]$} \\
\hline$F$ & Force & {$[\mathrm{N}]$} \\
\hline$F(s)$ & Laplace-transformed force & {$[-]$} \\
\hline$F_{0}$ & Air-spring pre-load force & {$[\mathrm{N}]$} \\
\hline$F_{a}$ & Pneumatic force & {$[\mathrm{N}]$} \\
\hline$F_{h}$ & Hydraulic force & {$[\mathrm{N}]$} \\
\hline$F_{x_{t}}$ & Longitudinal tire force & {$[\mathrm{N}]$} \\
\hline$F_{z_{t}}$ & Vertical tire force & {$[\mathrm{N}]$} \\
\hline$f$ & Cost function & {$[-]$} \\
\hline$G$ & Shear modulus & {$[\mathrm{Pa}]$} \\
\hline$g$ & Acceleration due to gravity & {$\left[\mathrm{ms}^{-2}\right]$} \\
\hline$h$ & Length of cylinder & {$[\mathrm{m}]$} \\
\hline$I$ & Area second moment of inertia & {$\left[\mathrm{m}^{4}\right]$} \\
\hline$I_{x x}, I_{y y}, I_{z z}$ & Mass moments of inertia in global aircraft coordinates & {$\left[\mathrm{kg} \mathrm{m}^{2}\right]$} \\
\hline$I_{x^{\prime} x^{\prime}}, I_{y^{\prime} y^{\prime}}, I_{z^{\prime} z^{\prime}}$ & Mass moments of inertia in local airfoil coordinates & {$\left[\mathrm{kg} \mathrm{m}^{2}\right]$} \\
\hline$I_{x x_{\mathrm{tire}}}, I_{y y_{\mathrm{tire}}}, I_{z z_{\mathrm{tire}}}$ & Mass moments of inertia in SAE Tire coordinates & {$\left[\mathrm{kg} \mathrm{m}^{2}\right]$} \\
\hline$i$ & Current & {$[\mathrm{A}]$} \\
\hline$J_{\text {avg }}$ & Jerk: average time derivative of acceleration-onset & {$\left[\mathrm{ms}^{-3}\right]$} \\
\hline$K_{1,2}$ & Residue of a pole & {$[-]$} \\
\hline$K_{3}$ & Constant & {$[-]$} \\
\hline$k_{1,2}$ & Residue of a pole & {$[-]$} \\
\hline$k_{e q}$ & Equivalent vertical tire stiffness & {$\left[\mathrm{N} \cdot \mathrm{m}^{-1}\right]$} \\
\hline$k_{a}$ & Equivalent static spring constant & {$\left[\mathrm{N} \mathrm{m}^{-1}\right]$} \\
\hline$k_{i}$ & Gain factor relating properties & {$[-]$} \\
\hline$k_{i}$ & Spring constant of element $i$ & {$\left[\mathrm{~N} \mathrm{~m}^{-1}\right]$} \\
\hline
\end{tabular}




\begin{tabular}{|c|c|c|}
\hline Symbol & Description & Units \\
\hline$L$ & Length & {$[\mathrm{m}]$} \\
\hline$L$ & Inductance & {$[\mathrm{H}]$} \\
\hline$m$ & Mass & {$[\mathrm{kg}]$} \\
\hline$m_{E}$ & Mass of engine & {$[\mathrm{kg}]$} \\
\hline$m_{E_{I}}$ & Class I method calculated engine mass & {$[\mathrm{kg}]$} \\
\hline$m_{f}$ & Fuel mass & {$[\mathrm{kg}]$} \\
\hline$m_{f_{\text {centre }}}$ & Fuel mass in centre fuel tank & {$[\mathrm{kg}]$} \\
\hline$m_{f_{i}}$ & Fuel mass in wing segment $i$ & {$[\mathrm{~kg}]$} \\
\hline$m_{f_{\text {tot }}}$ & Maximum fuel mass & {$[\mathrm{kg}]$} \\
\hline$m_{i}$ & Mass of component $i$ & {$[\mathrm{~kg}]$} \\
\hline$m_{p}$ & Total passenger mass & {$[\mathrm{kg}]$} \\
\hline$m_{S_{I}}$ & Class I method operating empty mass & {$[\mathrm{kg}]$} \\
\hline$m_{t_{\mathrm{MLG}}}$ & Mass of main landing gear tire & {$[\mathrm{kg}]$} \\
\hline$m_{t_{\mathrm{NLG}}}$ & Mass of nose landing gear tire & {$[\mathrm{kg}]$} \\
\hline$m_{t r}$ & Mass of trapped fuel & {$[\mathrm{kg}]$} \\
\hline$m_{S}$ & Operating empty mass & {$[\mathrm{kg}]$} \\
\hline$N(s)$ & Laplace-transformed numerator & {$[-]$} \\
\hline$N^{\prime}(s)$ & Laplace-transformed numerator of remainder function & {$[-]$} \\
\hline$p_{a}$ & Air pressure & {$[\mathrm{Pa}]$} \\
\hline$p_{a_{0}}$ & Pressure in fully extended strut & {$[\mathrm{Pa}]$} \\
\hline$p_{h}$ & Hydraulic pressure & {$[\mathrm{Pa}]$} \\
\hline $\mathrm{PSD}_{\text {input }}$ & Input power spectral density & {$[-]$} \\
\hline $\mathrm{PSD}_{\text {output }}$ & Output power spectral density & {$[-]$} \\
\hline$Q$ & Volumetric flow rate & {$\left[\mathrm{m}^{3} \mathrm{~s}^{-1}\right]$} \\
\hline$Q(s)$ & Laplace-transformed admittance & {$\left[\mathrm{kg}-\mathrm{s}^{-1}\right]$} \\
\hline$R$ & Radius & {$[\mathrm{m}]$} \\
\hline$R$ & Ratio of current vertical load to tire rated load & {$[-]$} \\
\hline$R$ & Resistance & {$[\Omega]$} \\
\hline
\end{tabular}




\begin{tabular}{|c|c|c|}
\hline Symbol & Description & Units \\
\hline$r_{t_{\mathrm{MLG}}}$ & Radius of gyration of MLG tire & {$[\mathrm{m}]$} \\
\hline$r_{t_{\mathrm{NLG}}}$ & Radius of gyration of NLG tire & {$[\mathrm{m}]$} \\
\hline$r_{w_{\mathrm{MLG}}}$ & Radius of gyration of MLG wheel assembly & {$[\mathrm{m}]$} \\
\hline$r_{w_{\mathrm{NLG}}}$ & Radius of gyration of NLG wheel assembly & {$[\mathrm{m}]$} \\
\hline$S$ & Tire slip ratio & {$[-]$} \\
\hline$S_{\text {crit }}$ & Critical tire slip ratio & {$[-]$} \\
\hline$s$ & Complex frequency variable & {$\left[\mathrm{s}^{-1}\right]$} \\
\hline$s$ & Stroke position & {$[\mathrm{m}]$} \\
\hline$s_{\text {static }}$ & Static stroke deflection & {$[\mathrm{m}]$} \\
\hline$s_{t}$ & Total stroke length & {$[\mathrm{m}]$} \\
\hline$t_{R}$ & Rise time & {$[\mathrm{s}]$} \\
\hline $\mathrm{TF}$ & Transfer function & {$[-]$} \\
\hline$V$ & Air volume in fully extended strut & {$\left[\mathrm{m}^{3}\right]$} \\
\hline$V$ & Voltage & {$[\mathrm{V}]$} \\
\hline$V(s)$ & Laplace-transformed velocity & {$[-]$} \\
\hline$V_{0}$ & Air volume in strut & {$\left[\mathrm{m}^{3}\right]$} \\
\hline$V_{\text {centre }}$ & Volume of centre fuel tank & {$\left[\mathrm{m}^{3}\right]$} \\
\hline$V_{f_{\mathrm{tot}}}$ & Total fuel tank volume & {$\left[\mathrm{m}^{3}\right]$} \\
\hline$V_{i}$ & Volume of segment $i$ & {$\left[\mathrm{~m}^{3}\right]$} \\
\hline$v$ & Speed & {$\left[\mathrm{ms}^{-1}\right]$} \\
\hline$W$ & Weight & {$[\mathrm{N}]$} \\
\hline$w$ & Distance between wing roots & {$[\mathrm{m}]$} \\
\hline $\mathrm{x}$ & Input parameter vector & {$[-]$} \\
\hline$x, y, z$ & Global aircraft coordinates & {$[-]$} \\
\hline$x^{\prime}, y^{\prime}, z^{\prime}$ & Local airfoil coordinates & {$[-]$} \\
\hline$x_{\mathrm{CG}}$ & $x$-position of the centre of gravity & {$[\mathrm{m}]$} \\
\hline$x_{\mathrm{ref}}$ & Reference $x$-position & {$[\mathrm{m}]$} \\
\hline$x_{f}$ & $x$-position of applied force & {$[\mathrm{m}]$} \\
\hline
\end{tabular}




\begin{tabular}{clc}
\hline Symbol & Description & Units \\
\hline$Z(s)$ & Laplace-transformed impedance & {$\left[{\left.\mathrm{s}-\mathrm{kg}^{-1}\right]}\right.$}
\end{tabular}

\section{Greek Characters}

\begin{tabular}{clc}
\hline Symbol & Description & Units \\
\hline$\gamma$ & Heat capacity ratio & {$[-]$} \\
$\Delta$ & Change in parameter & {$[-]$} \\
$\Delta(s)$ & Laplace-transformed spinal compression & {$[\mathrm{m}]$} \\
$\delta_{\max }$ & Maximum spinal compression & {$[\mathrm{m}]$} \\
$\delta \%$ & Percentage of maximum vertical tire compression & {$[-]$} \\
$\zeta$ & Damping ratio & {$[-]$} \\
$\eta$ & Normalized position along wing & {$[-]$} \\
$\eta_{s}$ & Stroke efficiency & {$[-]$} \\
$\mu$ & Coefficient of friction & {$[-]$} \\
$\mu$ & Dynamic viscosity & {$[\mathrm{Pa}-\mathrm{s}]^{2}$} \\
$\nu$ & Poisson's ratio & {$[-]$} \\
$\rho$ & Fluid density & {$\left[\mathrm{kg} \mathrm{m}^{-3}\right]$} \\
$\omega$ & Frequency & {$\left[\mathrm{rad} \mathrm{s}^{-1}\right]$} \\
$\omega_{i}$ & Frequency of the $i^{\text {th }}$ zero & {$\left[\mathrm{rad} \mathrm{s}^{-1}\right]$} \\
$\omega_{n}$ & Natural frequency & {$\left[\mathrm{rad} \mathrm{s}^{-1}\right]$}
\end{tabular}




\title{
List of Abbreviations
}

\author{
APP Airport planning publication \\ BL Bandwidth-limited \\ CARs Canadian Aviation Regulations \\ CG Centre of gravity \\ CSs Certification Specifications \\ dll Dynamic link library \\ DOE Design of experiment \\ DOF Degree-of-freedom \\ DRI Dynamic response index \\ EASA European Aviation Safety Agency \\ FARs $\quad$ Federal Aviation Regulations \\ FEM Finite element model \\ FRF Frequency response function \\ GSE General state equation \\ ISO International Organization for Standardization \\ LG Landing gear \\ MLG Main landing gear \\ MLM Maximum landing mass \\ MNF Modal neutral file \\ MTOM Maximum takeoff mass \\ NLG Nose landing gear \\ OEM Operating empty mass
}


OP Oleo-pneumatic

PSD Power spectral density

RMS Root-mean-square

SATP Standard atmosphere temperature and pressure

SI International System of Units

SI2 Stabilized-Index Two

TC AIM Transport Canada Aeronautical Information Manual 


\section{Chapter 1}

\section{Introduction}

\subsection{Motivation}

Landing is a critical phase in aircraft operation in which the airframe experiences high forces and accelerations as the aircraft impacts and comes to rest on the ground. In fact, the Transportation Safety Board of Canada reports that between 2008 and 2018, 41\% of all airplane accidents occurred at landing, followed by $17 \%$ occurring at take-off [1]. These high accelerations, especially in hard landing scenarios, are a source of passenger discomfort, and the impact may result in coupling between the aircraft and the pilot where an inadvertent activation of controls may occur. Accordingly, accurate prediction of the loads developed during landing is not only important for the stress analysis of the airframe, but also for assessing the frequency content of the loads throughout the structure for various system requirements and ride quality standards. The loads transferred from the landing gear (LG) to the aircraft structure are commonly determined by representing the aircraft as a rigid body. This assumption is manifested in a LG drop test where the LG is attached to a structure that represents the aircraft as a rigid mass. With the advent of highly-optimized structures and composite materials, aircraft are lighter than ever and this comes at the cost of increased airframe flexibility, which not only alters the loads developed at the LG, but also affects the attenuation of these loads throughout the structure to subsystems, passengers, and crew.

The inerter is a passive force element that completes the analog between mechanical and 
electrical systems. Since its invention by Malcolm C. Smith in 2002 [2], it has gained attention for use in vehicle suspensions as it allows one to prescribe the frequency response of the mechanical network and this has been shown to improve the suspension's performance [3]. The use of mechanical networks in aircraft suspensions presents unique differences between road vehicles with the larger load range experienced by LG and resonance of an aircraft's flexible structure. With an understanding of the loading and the frequency response of the structure and subsystems, one can design a strategy to alter the loads that can be realized by a passive mechanical network. This can have several implications including reduced landing loads, reduced stressing of the airframe, and improved comfort of passengers and crew.

\subsection{Thesis Objectives}

This Thesis uses passive mechanical networks to demonstrate the ability to control vibrations in a flexible aircraft at landing. The objectives of the Thesis are as follows:

1. Develop a model of a flexible aircraft using information available in the public domain;

2. Demonstrate the significance of airframe flexibility in the analysis of landing loads;

3. Demonstrate the ability to passively control vibrations in a flexible airframe at landing as characterized by passenger comfort; and

4. Establish the baseline performance of a conventional oleo-pneumatic (OP) shock absorber and compare its performance to

(a) Mechanical network layouts available in literature (candidate layouts); and

(b) A custom mechanical network that is synthesized to have a prescribed frequency response.

Corresponding to each item in the previous enumeration, the following provides a discussion of the novelty of each objective:

1. The aircraft models used in landing simulations are typically reduced versions of a detailed finite element model (FEM). However, this detailed model is not always avail- 
able such as in preliminary aircraft design phases. This Thesis outlines a process to develop a representative flexible aircraft model for landing simulations when detailed information is not known.

2. Literature often neglects airframe flexibility effects during the design of shock absorbers. However, the frequency response of a flexible structure can be significantly different than that of the rigid equivalent. This Thesis demonstrates the significance of airframe flexibility effects in terms of the structural dynamic response at landing.

3. Studies on the design of various shock absorbers generally focus on the optimization of the shock-strut performance and, as a result of the improved performance, accelerations in the rigid aircraft are reduced, which is hypothesized to improve comfort. However, the studies either do not quantify the comfort using appropriate parameters or neglect the airframe flexibility effects. This Thesis develops a novel cost function for use in the optimization of shock absorbers to simultaneously optimize for shock-strut performance and for passenger comfort.

4. Mechanical networks have gained recent attention for use in aircraft landing gear suspensions for improved landing performance but have not been demonstrated to control the structural dynamic response. This Thesis is the first to demonstrate the ability of passive mechanical networks to control the structural dynamic response in a flexible aircraft. Further, to the best of the author's knowledge, the work of this Thesis is the first to synthesize a custom mechanical network for the simultaneous improvement of shock-strut performance and passenger comfort in a flexible aircraft.

\subsection{Document Organization}

This document contains 7 chapters. A description of each chapter follows.

Chapter 1: Introduction - The introduction provides motivations and objectives for this research. The organization of the document is provided.

Chapter 2: Literature Review - A review of literature is provided to explore previous work in the field, and to develop requirements for the simulation model. The 
previous work in the field is necessary to establish a novel direction of the research project. The fields of flexible aircraft landing simulation, vibration control for human comfort at landing, and mechanical network synthesis including inerters are explored. The conclusions of the previous work in these fields establish requirements for the simulation model.

Chapter 3: Aircraft Simulation Model and Problem Setup - The development process of the flexible aircraft model for the multibody dynamic simulation is described. The simulation conditions and the setup of the optimization problem, including the cost function, are also provided.

Chapter 4: Airframe Flexibility Effects - The effect of airframe flexibility in terms of the parameters of interest during landing simulations is explored. A frequency analysis of the flexible aircraft model is provided.

Chapter 5: Design and Synthesis of Shock Absorbers - Baseline OP shock absorber performance is established. The parameters of eight candidate mechanical networks are optimized. Lessons learned from that exercise are used to synthesize a custom one-port (two-terminal) mechanical network, and its corresponding parameters are optimized.

Chapter 6: Results and Discussion - The results from the optimizations of the oleo-pneumatic shock absorber, candidate mechanical networks, and synthesized mechanical network are given. The results include the converged points, and the cost function and comfort parameter values corresponding to the converged point. A discussion of the results is provided, including discussion of the optimizer behaviour, implications of the results on structural deformation, and human comfort during landing.

Chapter 7: Conclusion - Conclusions of the research project are drawn and the contributions to the field are enumerated. Suggestions for future work are provided. 


\section{Chapter 2}

\section{Literature Review}

\subsection{Simulation Model Requirements}

This section presents background on the state of the art in dynamic landing simulations necessary to develop a set of requirements for the simulation model.

\subsubsection{Airframe}

The loads transferred from the LG to the aircraft structure are commonly determined by representing the aircraft as a rigid body. Modern aircraft are now lighter than ever and this comes at the cost of increased airframe flexibility, which not only alters the loads developed at the LG, but also affects the attenuation of these loads throughout the structure to subsystems, passengers, and crew. In fact, the inclusion of airframe flexibility effects is, in some cases, a regulatory requirement. The Canadian Aviation Regulations (CARs) Section 525.473(c)(4) states that the method of analysis of LG loads must consider the "structural dynamic response of the airframe, if significant" [4].

The importance of including airframe flexibility was investigated in 1956 by Cook and Milwitzky, who found that the interaction between the LG and the flexible structure could either reduce or increase the loads when compared to a completely rigid airframe as a result of dynamic magnification effects [5]. The Advisory Group for Aerospace Research and Development in the Conference on Landing Gear Design Loads [6], as well as reviews of landing dynamics conducted by Krüger et al. [7] and by Pritchard [8] indicate the importance 
of including aircraft flexibility effects in the modelling of ground dynamics for simulation. The work by Pritchard focuses on the importance of airframe flexibility in predicting and managing LG instabilities, such as shimmy; the work by Krüger covers the requirements for the simulation of various cases, including the shimmy problem, and the dynamics at touchdown and ground-roll.

There are various methods of capturing airframe flexibility effects in the simulation with varying levels of complexity. Early investigations of airframe flexibility effects represented the airframe as an equivalent $n$ degree-of-freedom (DOF) system of springs, masses and dampers to capture the first $n-1$ airframe flexible modes [5]. Since the advent of dynamic substructuring methods, such as the Craig-Bampton method in 1968 [9], modal representations of the airframe have been the dominant method presented in literature to date. Another possible method is explicit finite element simulation; however, this is generally reserved for highly-nonlinear models such as for crash landing or highly-flexible aircraft [10, 11].

Simple simulations assume that the landing impact force is independent of the structural response. In this case, simulations apply the loads at the LG attachment points for a rigid airframe model with a nonlinear LG model, which are subsequently applied a posteriori to a flexible airframe model to develop the internal stresses, such as in the study by Lee et al. [12]. This method more closely represents the loads obtained during LG drop tests but is understood to give conservative loads with increasing differences in peak loads for more flexible airframes [13. However, the preferred method for landing simulation is a coupled approach wherein both the nonlinear LG model and linear flexible airframe model are included in the development of landing loads [6, 7, 8, 13, 14, 15, 16].

The reduction of a flexible airframe in a global finite element model stems from aeroelastic analysis. Perhaps the most common reduced model is a stick model, which simplifies the major aircraft components to equivalent bar elements and point masses such that the distribution of properties is both statically and dynamically equivalent. A review of model order reduction methods for aeroelastic analysis by Thomas et al. found that although a stick model with equivalent static properties provides poor results, component mode synthesis of reduced order models give good results compared to a full FEM for aeroelastic 
analysis [17. Thus, it can be concluded that a reduced model that accurately represents the component modes of the airframe is both necessary and adequate for dynamic landing analysis.

A stick model with dynamic substructuring completed using the Craig and Bampton method is regularly used in dynamic landing simulations, such as in references [18, 19, 20]. The authors used their stick models to perform landing and other ground dynamic simulations. For early aircraft development, where detailed geometry and other features may not be known, Krüger used a reduced model made up of concentrated mass elements connected by torsional springs to capture only the bending of the structure [16. Krüger used this model to compare loads developed during landing simulations based on the flexible airframe and an equivalent rigid model.

For a lower computational cost method of evaluating stresses in aircraft components due to landing loads, Lee et al. [12] used a rigid representation of the aircraft to develop landing loads during hard landing cases and then applied these loads to a FEM to evaluate the stresses in the detailed representation of the structural components. Recent investigations by Bronstein et al. 21], and Cumnuantip and Krüger [22] used a flexible stick model to develop dynamic landing loads, which were subsequently applied to a full FEM for transient analysis.

Several authors have made conclusions on the required number of flexible modes for landing simulations and this number has generally increased through time, perhaps as computational power has increased or as aircraft become more flexible. Cook and Milwitzky found that airframe flexibility effects in the form of the first 2 flexible modes must be included [5]. Ijff states that flexible modes up to at least $20 \mathrm{~Hz}$ must be included [14], and more recently Castrichini et al. used modes up to $30 \mathrm{~Hz}$ [23] and Cumnuantip and Krüger conclude that there is no appreciable improvement in landing load fidelity when including eigenmodes with a frequency greater than $50 \mathrm{~Hz}[22$.

An accurate estimation of structural damping is important for the estimation of internal stresses [18, 21]. It has been found by Ghiringhelli and Boschetto that underestimating the damping will result in an increase in the internal loads, and that overestimation will underestimate the internal loads. Despite this, the authors found that structural damping 
has a small effect on the ground loads and kinematic motions at landing [18].

In summary, the following conclusions can be drawn for transport-category aircraft:

1. Airframe flexibility effects must be included in dynamic landing simulations;

2. The inclusion of airframe flexibility effects may reduce the magnitude of vertical loads and increase the magnitude of torsional loads at the wing-root;

3. The inclusion of airframe flexibility effects may increase the accelerations throughout the fuselage due to dynamic magnification effects;

4. Airframe flexibility effects are best captured by representing the aircraft as a dynamicallysimilar stick model consisting of bar elements and point masses with flexible modes matching that of the full aircraft model; and

5. A modal representation of the airframe in simulation is sufficient if component modes of the stick model up to at least $50 \mathrm{~Hz}$ are included.

\subsubsection{Landing Gear}

As LG are the intermediary between the ground and the aircraft, their representation has consequential effects on the loads developed in the aircraft during landing and other ground operations. This subsection develops a set of requirements for the representation of the LG. It first begins with the development of the force model in an OP shock absorber, explores the physical representation of the LG in a dynamic model, and reviews tire models for landing simulations.

\section{Oleo-Pneumatic Force Model}

The OP shock absorber is the most widely used shock absorber as it has the highest efficiency and best energy dissipation compared to other conventional models [24]. A schematic of an example oleo-pneumatic design without a metering pin is shown in Figure 2.1. The forces in an OP model consist of three parts: hydraulic resistance, gas-compression, and friction from the journal and seal bearings [25, 26]. 


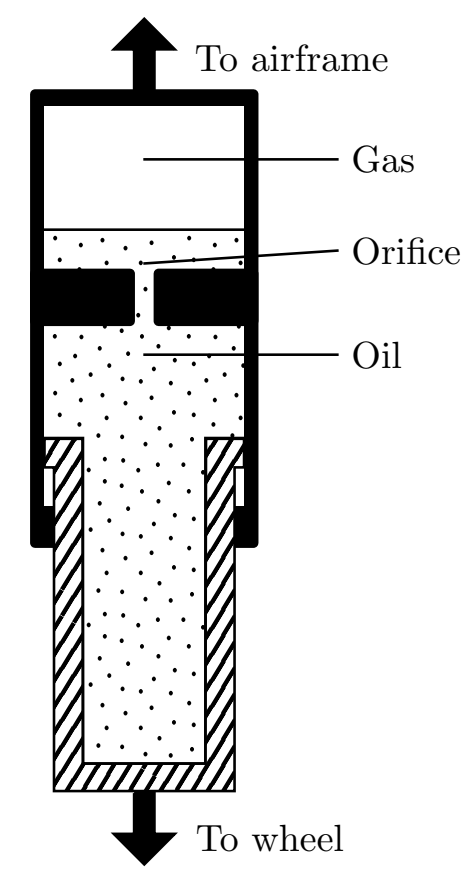

Figure 2.1: Diagram of an oleo-pneumatic shock absorber.

\section{Hydraulic Resistance}

The hydraulic damping is a result of the pressure drop associated with turbulent flow through an orifice. Note that this model does not consider the effect of a metering pin, which varies the orifice size as a function of the stroke position and allows additional control of the LG performance. The volumetric flow rate, $Q$, is the product of the stroke rate, $\dot{s}$, and the hydraulic area, or area of the strut, $A_{h}$

$$
Q=A_{h} \dot{s}
$$

The equation for discharge through an orifice is from Milwitzky and Cook [25]

$$
Q=C_{d} A_{n} \sqrt{\frac{2}{\rho}\left(p_{h}-p_{a}\right)}
$$

where $C_{d}$ is the discharge coefficient, $A_{n}$ is the orifice area, $p_{h}$ is the hydraulic pressure, $p_{a}$ is the gas pressure, and $\rho$ is the fluid density. Equating Eq. (2.1) and Eq. (2.2), and realizing the hydraulic force, $F_{h}$, is given by the product of the differential pressure $\left(p_{h}-p_{a}\right)$ and 
the hydraulic area, one obtains the following expression for the hydraulic force:

$$
F_{h}=\frac{\rho A_{h}^{3}}{2\left(C_{d} A_{n}\right)^{2}}|\dot{s}| \dot{s}
$$

The hydraulic damping coefficient, $C_{0}$, is defined as

$$
C_{0}=\frac{\rho A_{h}^{3}}{2\left(C_{d} A_{n}\right)^{2}}
$$

Therefore, the hydraulic resistance force simplifies to

$$
F_{h}=C_{0}|\dot{s}| \dot{s}
$$

\section{Pneumatic Force}

The pneumatic force is determined in accordance with polytropic compression/expansion of a gas

$$
p_{a}=p_{a_{0}}\left(\frac{V_{0}}{V}\right)^{\gamma}
$$

where $p_{a_{0}}$ is the pressure in the fully-extended strut, $V$ is the volume of gas in the strut with volume $V_{0}$ when fully extended, and $\gamma$ is the heat capacity ratio for a gas, which is commonly set to a value of 1.4 for commercial aircraft [22]. The instantaneous gas volume is the difference between the initial gas volume and the product of the stroke and pneumatic area, $A_{a}$, and the pneumatic force, $F_{a}$, is the product of the pneumatic pressure and the pneumatic area. Thus, the pneumatic force is

$$
F_{a}=p_{a_{0}} A_{a}\left(\frac{V_{0}}{V_{0}-A_{a} s}\right)^{\gamma}
$$

which simplifies to

$$
F_{a}=F_{0}\left(1-\frac{s}{s_{t}}\right)^{-\gamma}
$$

where $F_{0}$ is the air-spring pre-load force and $s_{t}$ is the total stroke length.

\section{Friction Force}

The friction force in the shock absorber consists of the bearing friction in the journal, and 
the friction in the seals. There are three cases of friction that may exist. The first is dry friction, where the friction force is proportional to the normal force and approximately independent of the velocity when in motion; the static friction is slightly greater than the kinetic friction. The second is under perfect lubrication where the force is proportional to the velocity and approximately independent of the normal force. The condition of perfect lubrication is rarely seen in practice, so there exists a third type of friction, which is a hybrid of the first two and is under a case of imperfect lubrication.

Due to the poor lubricating properties of hydraulic fluid and the shape of the bearing surfaces in the shock absorber, it can be assumed that the shock-strut is under a dry friction condition with a coefficient of friction typically between 0.05 to 0.1 [25, 14]. The friction forces are thus proportional to the drag loads at the tire (due to friction between the tire and the runway) and are a function of the stroke length. In a shock-strut, the friction forces are usually of concern in conditions of high normal forces (i.e. during the spin-up phase, as discussed in Section 2.1.2 and low sliding velocities [25, 7]. It has been found that the inclusion of friction forces in the model generally decreases the peak loads by a few percent as it serves to absorb and dissipate energy stored in the shock absorber during the initial stroke [14]. The friction forces have a small effect near the point of maximum vertical force because the tire has completed its spin-up and the shock absorber is at maximum compression, which corresponds to a case with minimum normal force in the journal and the seal, and thus minimum frictional forces. Therefore, neglecting friction forces results in a small loss of accuracy and leads to a slightly conservative estimate of the peak loads [14].

Other authors have found that the inclusion of friction in the journal and seals has a significant effect on the LG dynamics in conditions under high loads and low velocities, such as the stick friction during taxi [7, 27]. Krüger and Morandini found that the inclusion of friction is important for modelling the free play in LG components in order to develop stability margins [27]. However, the friction models are often difficult to implement into multibody code and this may result in ill-posed problems. As such, the friction models used in practice are often proprietary in nature [27]. Due to the small effect that the inclusion of friction forces has on forces at the landing impact, it is concluded that friction can be neglected for a comparative study of LG designs. 


\section{Landing Gear Flexibility and Attachment}

LG are slender structures subject to significant loads at touchdown. Immediately prior to touchdown, the LG has a large forward velocity and the tires have zero rotational velocity. Upon touchdown, there is a frictional drag force between the tire and the ground as the rotational velocity of the tire increases to match the forward speed of the aircraft. This phase is known as spin-up and the drag forces cause the LG to flex in the aft direction. The drag forces reduce as the rotational velocity begins to match the forward velocity, resulting in spring-back of the LG. The fore-aft motion of the LG is referred to as gear-walk. These phenomena are displayed schematically in Figure 2.2 .

The spin-up and spring-back phenomena are significant and introduce additional forces on the airframe and, as such, are required in landing loads analysis by CARs 525.473(c)(2) [4]. The spin-up forces must be captured by appropriate modelling of the tire, which is discussed in Section 2.1.2. The spring-back and gear-walk motions must be captured by incorporating a model of the LG flexibility [7].

The inclusion of LG flexibility in the model has been found to affect the loads developed in the airframe versus a rigid model of the LG [18, 7, 28, 27, 29, 30]. The bending of the LG in the aft-direction furthers the distance between the contact patch of the tire and the centre of gravity (CG) of the aircraft, which consequently increases the torsional moment at the

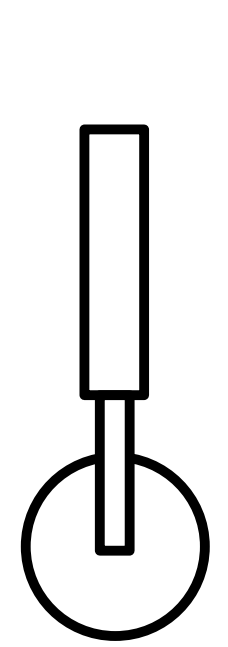

a) Prior to touchdown

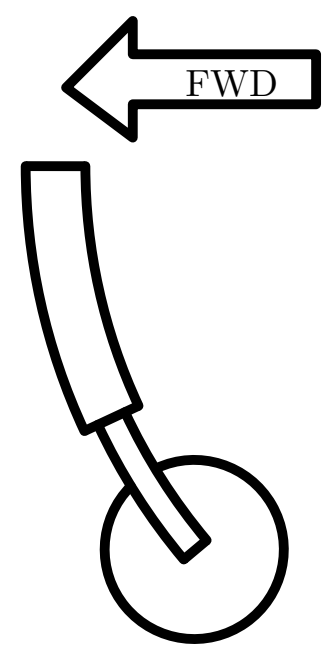

b) Spin-up

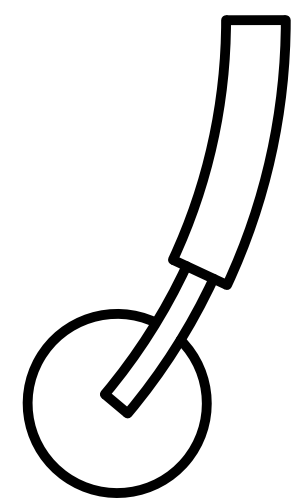

c) Spring-back

Figure 2.2: Spin-up and spring-back motions. 
LG attachment and at the wing-root. The additional motion due to gear-walk also alters the motion of the tire, which may affect the performance of anti-skid braking systems [28]. Further, there are increased normal loads in the shock absorber introduced by bending of the LG that have been found to have a significant effect on the frictional forces developed in the shock-strut [29, 30]. The inclusion of LG flexibility effects has been found by Wei et al. to affect the peak vertical loads by approximately $1 \%$ [29, 30] and it can be concluded that these effects are not needed for analysis of the vertical loads [27] but they may be necessary for other structural dynamic analyses.

The flexibility of the LG can generally be represented either by a modal representation of the LG, by capturing the equivalent flexibility at the LG attachment, or through an explicit FEM of the LG. The modal representation can be accomplished by representing major LG components as beam or bar elements, as in references [19, 31, 32]. The modal representation is appropriate for leaf-spring type LG but is not preferred for shock-strut type designs because as the LG is compressed, the stiffness increases, thus altering the frequencies and mode shapes. An alternate modelling approach by Lernbeiss and Plöchl deals with this phenomenon by representing the shock-strut as two Euler-Bernoulli beams with two points of sliding contact [28] and has been used by other authors [29, 30]. A modal representation of leaf-spring type LG is appropriate if the displacements are assumed linear, as in references [33, 34]. When the displacements are large and nonlinear, an explicit FEM was used in references [35, 32]. The introduction of a flexible joint with a torsional spring representing the equivalent stiffness of the LG can be used as a lower computational cost method to capture the LG flexibility effects [27]. This approach, however, assumes that the stiffness of the LG is constant throughout the stroke.

The way in which the LG interfaces with the aircraft has been found to have an impact on the LG dynamics at landing and on the forces developed at landing [27, 22, 36]. The node to which the LG attaches in the multibody simulation can interface with one or several nodes using various element types. The authors, however, do not recommend a preferred attachment model, and thus the model of the LG attachment can be explored when validating a simulation model to test data and is outside of the scope of this work.

It can be concluded that LG flexibility effects must be included in the multibody simu- 
lation as this may affect the loading regime experienced by the airframe and the dynamics at landing. LG flexibility effects are best captured by a sliding beam model or explicit FEM, but a constant flexibility assumption is sufficient by representing flexibility at the attachment by using an equivalent rotational spring.

\section{Tire Models}

The tires of an aircraft are the interface between the LG and the ground and accordingly play a significant roll in the dynamics at landing. Not only is sufficient grip required to slow down the aircraft during braking, but their deformation is not insignificant compared to the shock stroke and accordingly plays a role in energy absorption during landing [24]. As previously mentioned, the spin-up and spring-back loads generated by the tire also have a significant effect on the LG dynamics.

There are generally two unstable modes associated with LG: shimmy and gear-walk (or leg-walk). Shimmy is a lateral/torsional motion of the LG leg caused by the interactions between the tire and the LG structure and is commonly observed on the nose landing gear (NLG) [7. Gear-walk is a fore/aft bending oscillation of the LG and can be induced by braking or uneven runway conditions. Accurate tire modelling is important for predicting and modelling these LG instabilities [7, 37, 8, 27].

Most tire models are intended for road vehicles. Aircraft tire modelling is particularly difficult as the load range of the tires can be up to fifteen times larger than road vehicles with the initial loads being zero [27, 38]. Typical dedicated aircraft tire models or reduced versions of more complex models focus on the critical effects for the intended study while holding other parameters constant [27]. Prior to the 1990s, aircraft generally used bias-ply tires but since then, radial ply tires have been used by most commercial aircraft [24, 39]. Thus, tire models from before the 1990s are generally based on bias-ply tires, such as the popular TR64 model of Smiley and Horne [40], and are not applicable to modern aircraft. Daugherty provides test data of radial aircraft tires and empirical equations describing the characteristics of these tires [39].

Tire models can be categorized by physical models, semi-empirical models, and empirical models. Physical models use physical properties of the tire, such as friction characteristics, 
normal pressures, and compliance of the carcass, to model the displacement in the contact patch [41]. Semi-empirical and empirical models require tire test data to form the model parameters and thus the simulation should be similar to the test conditions, but the mathematical structure in semi-empirical models have some origins in the physical model [41]. Empirical models are not often found in practice [41]. Besides mathematically-based models, Nguyen et al. use a FEM of their tire in their study of loads at touchdown. The tire was modelled using hydrostatic fluid elements with the tire carcass constructed using hyperelastic elements [35]. The use of a FEM of the tire, however, is not suitable for multibody dynamic simulation as this requires an explicit solution and thus is significantly more costly.

Kiébré provides a review of aircraft tire models with guidelines for the selection of an appropriate model [41]. Of all tire models, the Fiala tire model [42] is commonly used in industrial practice and is a physically-based tire model [41]. The Fiala tire model provides reasonable results for simple manoeuvres where inclination angle is not a major factor and where longitudinal and lateral slip effects may be considered unrelated [43]. The Pacejka "Magic Formula" [4] is often used in the shimmy analysis of LG as it produces accurate results for lateral tire force characteristics. However, van Slagmaat found that this model is not suitable for the fast dynamics at landing since it is an algebraic equation fitted to steady-state observations and not a first order differential equation [45]. Further, this model has a large number of input parameters and the force output is sensitive to these values [38].

The present study is concerned with the landing impact case, which generally is limited to the first stroke of the LG after touchdown. Modelling and prediction of instability onset is out of scope of the present study. Further, as outlined in the CARs [4], there is not a need for unsymmetrical landing analysis as lateral landing loads are applied statically as a scaled percentage of the vertical loads in a symmetric landing (i.e. without initial lateral velocity or roll angle). Therefore, the tire model for touchdown simulation in this study must model the vertical force, longitudinal force, rolling resistance moment, and inertial characteristics; lateral characteristics (lateral force, aligning torque, and oversteer moment) can be neglected. Therefore, it is concluded that a Fiala tire model is sufficient for analysis at landing touchdown. 


\subsubsection{Aerodynamics}

The representation of aerodynamics at landing and during the subsequent ground-roll influences the forces developed in the LG. Immediately prior to touchdown, the aircraft is initially in a steady-state descent where the lift is equal and opposite to the weight of the aircraft; this condition is prescribed in CARs 525.473(b) [4]. As the aircraft begins to slow and during the subsequent ground-roll, the lift force reduces, and the LG must support the increased load.

The simulation of aerodynamic effects at landing in multibody simulations can be accomplished by concentrating the aerodynamic loads at the CG of the aircraft, such as in reference [20]. In this study, Khapane developed stability and control derivatives from a vortex lattice method code and applied the forces and moments at the CG to capture the rigid body response. This approach, however, does not capture the aeroelastic effects resulting from the wing deformation at landing impact. In order to capture the aeroelastic effects at landing, aerodynamic strip theory [16, 46] or a doublet lattice method [23] can be used in the simulation. However, in the short duration of landing impact, which is less than one second, Ijff concludes that the lift forces in a flexible aircraft will experience minor changes [14]. Therefore, it is concluded that the lift shall equal the weight during the simulation and remain constant, as permitted in the CARs [4].

\subsection{Vibration Control and Human Comfort}

This section explores vibration control and attempts to improve human comfort due to vibrational loading in an aircraft upon landing and ground movement. It then explores various metrics to quantify human comfort.

\subsubsection{Vibration Control}

There have been various attempts in literature for vibration control in aircraft using active or semi-active shock absorbers [47, 48, 49, 50, 51, 52]. In 2002, Krüger [47] developed various semi-active LG models for the reduction of peak vertical accelerations throughout a fuselage subject to input loads from an uneven runway model using a flexible airframe model. Since 
that time, studies have neglected the flexibility effects where various suspension systems were tuned to minimize the vertical displacements and accelerations of a rigid aircraft model, as well as the time to return to equilibrium, which authors hypothesized will improve passenger comfort, such as in Refs. [48, 49, 50, 51, 52. Yazici and Sever [53] considered human response to vibrational loading in an aircraft. In this study, the authors developed an active LG suspension to minimize motion of the centre of gravity of a rigid multi-DOF aircraft model and the acceleration of a pilot's head under random runway vibrations and bump excitations. The pilot's head was modelled using a Wan and Schimmels biodynamic model, with model parameters optimized by Abbas et al. to have a peak seat-to-head transmissibility near $5 \mathrm{~Hz}$ [54]. Ciloglu in a Master's Thesis and Ciloglu et al. replicated flight test acceleration data measured during takeoff, landing, and turbulent cruise on a multi-axis shaker table [55, 56]. These studies investigated various seat properties and their effects on passenger comfort quantified using the weighted acceleration and vibration dose value from International Organization for Standardization (ISO) standard 2631-1 [57].

Li et al. optimized mechanical networks for improved shock-strut performance at touchdown and hypothesized that a reduction in peak shock-strut force will improve the comfort of passengers and crew at touchdown [58, 59]. The authors, however, used a rigid representation of the airframe in their studies, which fails to capture the true loading of the LG and the attenuation of forces through the aircraft, and it does not consider passenger perception of the loads. Human comfort and perception of loads and vibrations is dependent both on the magnitude and frequency of the applied loading [57.

In conclusion, a literature survey has revealed that it is commonplace to neglect airframe flexibility effects in vibration control problems despite the observations of Krüger [47]. In order to control vibrations at another point in a flexible body, the frequency response function (FRF) must be known as there may exist resonance or anti-resonance, which may have a significant effect on the response parameters.

\subsubsection{Human Comfort Parameters}

Studies of vibration control in an aircraft often hypothesize that a reduction in the amplitude or duration of vibration will improve human comfort [48, 49, 50, 51, 52]. Human comfort is 
not only dependent on the amplitude of vibration, but also on the frequency of vibration. In order to design strategies to improve passenger comfort, one must understand the timeand frequency-domain responses of comfort parameters of interest.

Comfort parameters in literature generally focus on low-amplitude vibrations occurring over a longer duration. However, the landing impact case is a short-duration loading with a high amplitude that resembles a shock loading. There exist several parameters to assess injury risk arising from shock loading but due to the short duration, comfort or human perception is not often mentioned. However, the level of discomfort shall be assumed proportional to the injury risk. Peterson and Bass [60] and De Alwis [61] provide reviews of the various impact injury risk parameters applied to high-speed watercraft. The following parameters considered in the study are explained and derived in the subsequent sections: dynamic response index (DRI), peak seat acceleration, peak lumbar acceleration (from ISO 2631-5 [62]), bandwidth-limited (BL) power-spectral density (PSD), and the average acceleration onset derivative (average jerk).

\section{Dynamic Response Index}

The DRI is a non-dimensional measure of axial spinal compression subject to vertical loads in a seated position for a single shock event. It represents the head and spinal column as an equivalent single degree-of-freedom spring-mass-damper system, as illustrated in Figure 2.3 . with natural frequency $\omega_{n}=52.9 \mathrm{rad} \mathrm{s}^{-1}=8.4 \mathrm{~Hz}$ and damping ratio $\zeta=0.224$, as defined in MIL-DTL-9479E 63.

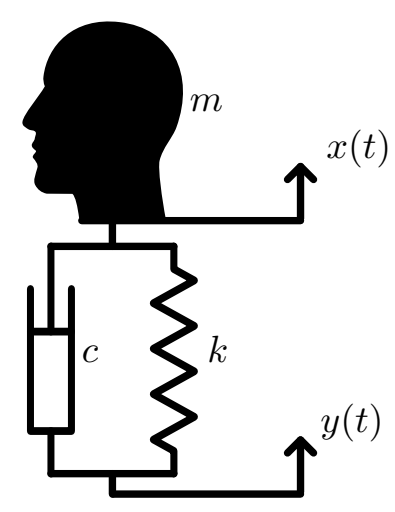

Figure 2.3: Equivalent spring-mass-damper system used to calculate the DRI. 
The DRI is calculated from the maximum compression of the spine, $\delta_{\max }$, using the following equation:

$$
\mathrm{DRI}=\frac{\omega_{n}^{2}}{g} \delta_{\max }=285.3 \delta_{\max }
$$

The differential equation for the system is:

$$
m \ddot{x}(t)+c(\dot{x}(t)-\dot{y}(t))+k(x(t)-y(t))=0
$$

Alternatively, this can be arranged as

$$
\frac{m}{k} \ddot{x}(t)+\frac{c}{k} \dot{x}(t)+x(t)=\frac{c}{k} \dot{y}(t)+y(t)
$$

Making the following substitutions:

$$
\begin{aligned}
\omega_{n} & =\sqrt{\frac{k}{m}} \\
\zeta & =\frac{c}{2 \sqrt{k m}}
\end{aligned}
$$

Eq. 2.11) reduces to

$$
\frac{1}{\omega_{n}^{2}} \ddot{x}(t)+\frac{2 \zeta}{\omega_{n}} \dot{x}(t)+x(t)=\frac{2 \zeta}{\omega_{n}} \dot{y}(t)+y(t)
$$

Multiplying through by $\omega_{n}^{2}$ and taking the Laplace transform, assuming zero initial conditions:

$$
X(s)\left(s^{2}+2 \zeta \omega_{n} s+\omega_{n}^{2}\right)=Y(s)\left(2 \zeta \omega_{n} s+\omega_{n}^{2}\right)
$$

The Laplace-transformed seat-displacement is $Y(s)$ and the Laplace-transformed headdisplacement is $X(s)$. The transfer function of the seat-displacement to head-displacement, $\frac{X(s)}{Y(s)}$, is

$$
\frac{X(s)}{Y(s)}=\frac{2 \zeta \omega_{n} s+\omega_{n}^{2}}{s^{2}+2 \zeta \omega_{n} s+\omega_{n}^{2}}
$$

For a passenger seated in a vehicle, it is difficult to measure the position of the seat relative to the inertial frame. Alternatively, accelerations at the seat are measured. The Laplace- 
transformed seat-acceleration, $A(s)$, is

$$
A(s)=s^{2} Y(s)
$$

Therefore, both sides of Eq. 2.16 can be multiplied through by $\frac{1}{s^{2}}$ resulting in

$$
\frac{X(s)}{A(s)}=\frac{2 \zeta \omega_{n} s+\omega_{n}^{2}}{s^{4}+2 \zeta \omega_{n} s^{3}+\omega_{n}^{2} s^{2}}
$$

The spinal compression, $\delta(t)$, and its Laplace transform, $\Delta(s)$, are

$$
\begin{gathered}
\delta(t)=x(t)-y(t) \\
\Delta(s)=X(s)-Y(s)
\end{gathered}
$$

Finally, the seat-acceleration to spinal compression transfer function is given by

$$
\Delta(s)=A(s) \frac{2 \zeta \omega_{n} s+\omega_{n}^{2}}{s^{4}+2 \zeta \omega_{n} s^{3}+\omega_{n}^{2} s^{2}}-\frac{1}{s^{2}} A(s)
$$

which can be simplified to

$$
\frac{\Delta(s)}{A(s)}=\frac{-1}{s^{2}+2 \zeta \omega_{n} s+\omega_{n}^{2}}
$$

Substituting the previously-defined values of $\omega_{n}$ and $\zeta$

$$
\frac{\Delta(s)}{A(s)}=\frac{-1}{s^{2}+23.6992 s+2798.41}
$$

This relation can be used to determine the spinal compression time-history, from which $\delta_{\max }$ can be obtained. The Bode magnitude diagram of the transfer function is shown in Figure 2.4.

\section{Peak Seat Acceleration}

The peak seat acceleration, $a_{\text {peak }}$, is the maximum value of the acceleration at the seat in the vertical (upward) direction after removing the acceleration due to gravity bias [63] and neglects the floor-to-seat transfer function. 


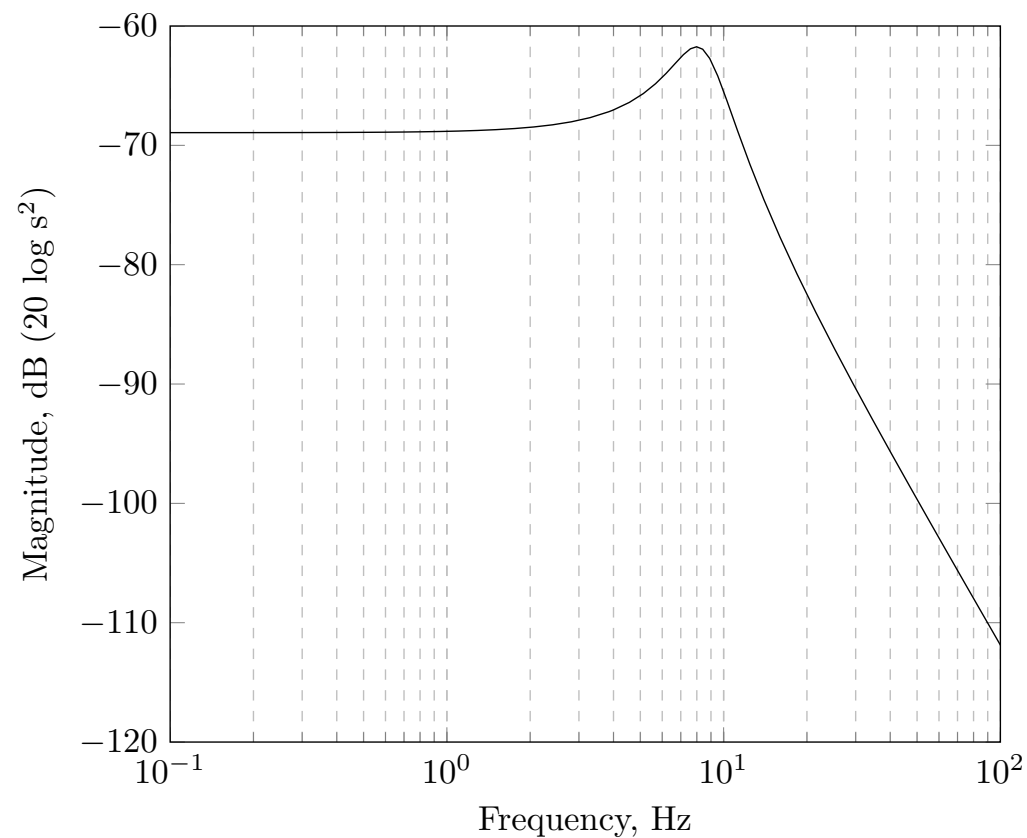

Figure 2.4: Bode magnitude diagram of seat vertical acceleration to spinal compression transfer function.

\section{Peak Lumbar Acceleration}

ISO 2631-5 provides a method to evaluate human injury risk when exposed to repeated shock loading and is not intended to evaluate health effects from single shock events, as is the case for landing. However, the Standard gives a method to determine the spinal response as a function of the accelerations measured at the seat. This analysis observes the spinal response in the vertical direction, which is represented by a recurrent neural network given for data sampled at $160 \mathrm{~Hz}$ [62]. Data sampled at a higher frequency shall be down-sampled by first applying an anti-aliasing filter using a forward-backward second order low-pass Butterworth filter having an $80 \mathrm{~Hz}$ cut-off frequency. The data then are resampled to a new $160 \mathrm{~Hz}$ time vector using linear interpolation of the filtered data. Using the formulation in ISO 2631-5, the lumbar acceleration time-history is determined, and the peak positive value is taken as this corresponds to lumbar compression. For the purpose of this study, the vertical lumbar acceleration will be assumed proportional to the level of discomfort. 


\section{Bandwidth-Limited PSD}

The BL PSD method was introduced by Peterson and Bass at the Naval Surface Warfare Centre - Panama City [60. The BL PSD is calculated as the average PSD value in the $4 \mathrm{~Hz}$ to $8 \mathrm{~Hz}$ bandwidth using a 4096-point Hamming window with $50 \%$ overlap. This method can be modified to use a more appropriate frequency range and window function. A force window is the preferred window for a response to an impact [64] and is more appropriate for the landing impact. Further, the average PSD value in the range of $4 \mathrm{~Hz}$ to $10 \mathrm{~Hz}$ is taken, as the biodynamic response is not insignificant in the $8 \mathrm{~Hz}$ to $10 \mathrm{~Hz}$ range and must be considered [63, 57, 54].

\section{Acceleration Onset: Average Jerk}

The average jerk provides a measurement of the acceleration-onset. The rise-time, $t_{R}$, and peak acceleration are determined using the method of MIL-DTL-9479E 63]. The average onset jerk, $J_{\mathrm{avg}}$, is defined as

$$
J_{\mathrm{avg}}=\frac{a_{\mathrm{peak}}}{t_{R}}
$$

\subsection{Inerters and Network Synthesis}

The concept of prescribing a frequency response of an electrical system is fundamental in the study of electronics. Analogies between electrical and mechanical systems can be drawn such that an arrangement of springs, dampers and masses can have a prescribed frequency response. Analogies between mechanical and electrical systems can be summarized as follows:

$$
\begin{aligned}
\text { Force }(F) & \leftrightarrow \text { Current }(I) \\
\text { Velocity }(v) & \leftrightarrow \text { Voltage }(V) \\
\text { Spring }(k) & \leftrightarrow \text { Inductor }(L) \\
\text { Damper }(c) & \leftrightarrow \text { Resistor }(R) \\
\text { Mass }(m) & \leftrightarrow \text { Grounded Capacitor }(C) \\
\text { Kinetic Energy } & \leftrightarrow \text { Electrical Energy } \\
\text { Potential Energy } & \leftrightarrow \text { Magnetic Energy } \\
\text { Lever } & \leftrightarrow \text { Transformer }
\end{aligned}
$$

One limitation is the requirement that the capacitor be grounded in order to be anal- 
Table 2.1: Mechanical and electrical analogies

$\underset{\substack{\text { Mechanical } \\ \longrightarrow}}{\longrightarrow}$

ogous to mass. This is because the force from a mass is proportional to the acceleration relative to the inertial frame, thus implying the mass is grounded. The inerter, invented by Smith [2], overcomes this limitation. The inerter is a force element in which the output force is proportional to the relative acceleration between its two terminals. Thus, the analogy between mechanical and electrical systems is complete and is summarized in Table 2.1 with the definition of the admittance, $Q(s)$, of each element. The admittance is the transfer function of the input variable, such as the velocity, $V(s)$, to the output, such as the force, $F(s)$, as in

$$
Q(s)=\frac{F(s)}{V(s)}
$$

An ideal inerter exerts a force proportional to the relative acceleration between its terminals with a constant of proportionality, $b$, called the inertance

$$
F=b\left(\dot{v}_{2}-\dot{v}_{1}\right)
$$


The following are properties of an ideal inerter, reproduced from [2]

1. It must have a small mass that is independent of the value of $b$;

2. There must not be a requirement that it is attached to the ground;

3. It must have a finite travel; and

4. It must function in any orientation.

There are various possible inerter designs. One such design by Smith consists of a flywheel, rack-and-pinion, and a gear train and has a mass to inertance ratio of $1: 300$ [2, 3]. Other designs include a ball-screw design and a fluid inerter [65]. Schematics of these designs are in Figure 2.5 .

The inerter is starting to gain attention for use in LG suspensions. It was initially proven to provide performance improvements in vehicle suspensions [3, 66]. Dong et al. 67] first demonstrated the use of an inerter in a LG to improve the shimmy stability; and Li et al. 68 demonstrated that the inerter properties can be selected such that no shimmy occurs at any speed in the operating envelope. Mechanical networks with inerters were shown to improve touchdown performance by Li et al. [58, 59]. In these studies, the authors demonstrated potential improvements in strut efficiency, maximum loads, and maximum strut stroke when including an inerter in the shock-strut versus a conventional OP shock absorber baseline.

There are two general approaches to the development of mechanical networks. The first approach is to start from previously-designed candidate layouts of stiffness, damping, and inertance elements then optimize the parameters of each with respect to a given cost function. This is the most common approach and was used by Li et al. to optimize for landing performance [58, 59]. The second approach is to develop a desired frequency response of the shock absorber and synthesize a mechanical network with that response. This approach requires detailed knowledge of the frequency response of the parameters of interest in order to synthesize a network with that response.

The concept of network synthesis is rooted in the study of electronics where a circuit designer can design a network with a prescribed frequency response. Perhaps the most 


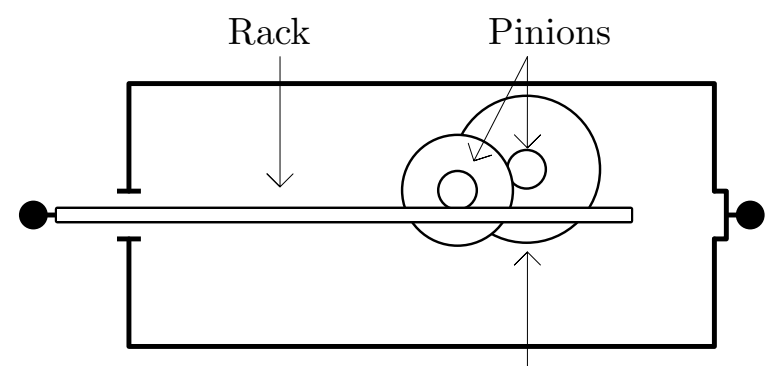

Flywheel

(a) Flywheel-type inerter.

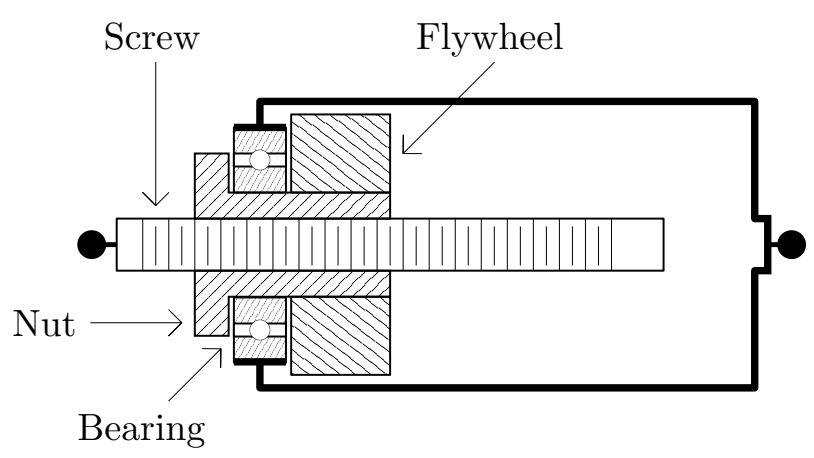

(b) Ball screw-type inerter.

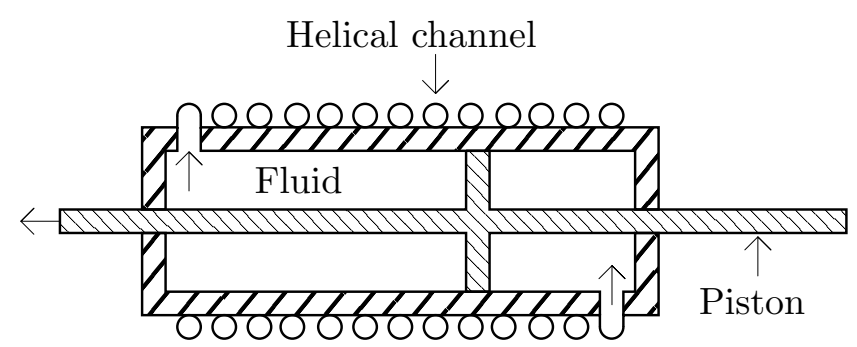

(c) Fluid inerter.

Figure 2.5: Schematics of various inerter types. 
commonly-used approach is the work of Brune and the methodology referred to as Brune's synthesis [69]. There have been various works on the synthesis of passive one-port (twoterminal) electrical and mechanical networks, but the methods of Brune generally form the first step in the network synthesis process [70, 71, 72].

A survey of literature has only discovered studies wherein mechanical networks in aircraft suspensions are optimized from a candidate arrangement. To the best of the author's knowledge, there does not exist a study wherein a mechanical network is synthesized for a LG suspension from a prescribed impedance that is developed from knowledge of the frequency content of the input and the frequency response of parameters of interest. 


\section{Chapter 3}

\section{Aircraft Simulation Model and Problem Setup}

It is common industrial practice to begin with a full FEM of an aircraft then reduce it to an equivalent model using various dynamic reduction techniques or by the development of an equivalent stick model using unitary loads, as introduced by Elsayed et al. [73]. The reduced model represents the elastic axis of the wings, fuselage, and vertical and horizontal stabilizers as bar elements (CBAR in NASTRAN). Ideally, these bar elements retain the same bulk stiffness properties such that they are statically equivalent, and the stiffness and mass distributions allow for equivalent natural mode shapes and frequencies such that they are dynamically equivalent.

In the present investigation, a full FEM was not available so a stick model was developed directly from the aircraft geometry. The methods applied herein represent those found in common industrial practices and in literature. The mass and stiffness distributions were derived from typical values available in literature and then were tuned in order to match natural frequencies of similar aircraft also available in literature. The major elements of the stick model are shown in Figure 3.1a. In order to allow for better visualization of the structural dynamics, especially for torsional modes, plotting elements (PLOTEL in NASTRAN) were used, as shown in Figure $3.1 \mathrm{~b}$. 


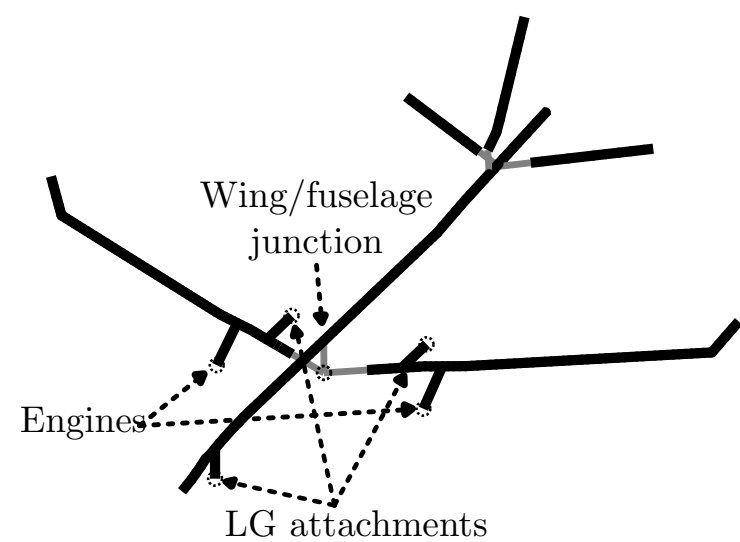

(a) Annotated stick model.

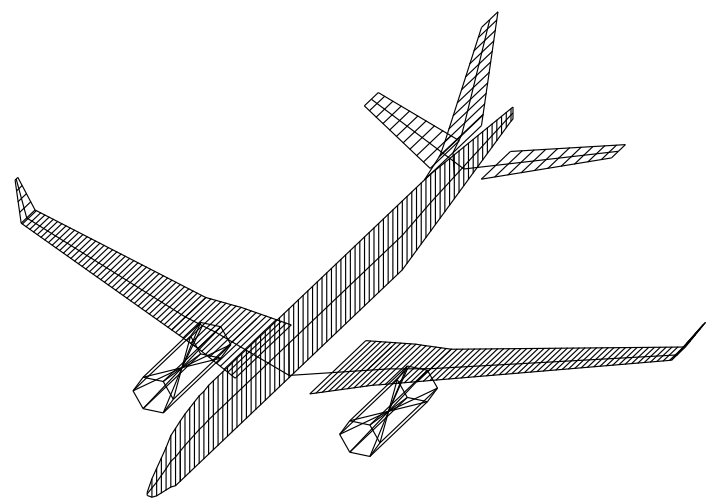

(b) Stick model with plotting elements.

Figure 3.1: Stick model used in dynamic analyses.

\subsection{Aircraft Model}

The aircraft used in this study is an Airbus A220-300 regional jet with a capacity of 150 passengers. It has cantilevered shock-strut type LG in a tricycle configuration. The masses, reference dimensions, and relevant performance data used in this study are given in Table 3.1. The masses and the angle for simultaneous ground contact of the main landing gear (MLG) and tail structure were retrieved from the Airport Planning Publication (APP) [74.

\subsection{Aircraft Geometry}

The geometry of the aircraft was retrieved from a 3-view drawing from IHS Jane's All The World's Aircraft, as given in Figure 3.2 . The global aircraft coordinate system is given in

Figure 3.3 . In the global coordinate system, the $x$ coordinate begins at the nose, the $y$ coordinate begins at the aircraft centre line, and the $z$ coordinate begins at the lowest point of the fuselage. 
Table 3.1: Relevant specifications of the Airbus A220-300. Retrieved from [74, 75].

\begin{tabular}{cc}
\hline \hline Parameter & Value \\
\hline Span & $35.08 \mathrm{~m}$ \\
Length & $11.51 \mathrm{~m}$ \\
Operating Empty Mass (OEM) & $37081 \mathrm{~kg}$ \\
Maximum Takeoff Mass (MTOM) & $61000 \mathrm{~kg}$ \\
Maximum Landing Mass (MLM) & $58740 \mathrm{~kg}$ \\
Trapped Fuel & $100 \mathrm{~kg}$ \\
Fuel Capacity & $17214 \mathrm{~kg}$ \\
Fuel Volume & $21505 \mathrm{~L}$ \\
Unusable Fuel & $100 \mathrm{~kg}$ \\
Number of Passengers & 150 \\
Engines & Pratt \& $\mathrm{Whitney} \mathrm{PW1500}$ \\
Engine Nominal Diameter & $2.006 \mathrm{~m}$ \\
Engine Length & $3.184 \mathrm{~m}$ \\
Single Engine Mass & $2177 \mathrm{~kg}$ \\
Simultaneous MLG and Tail ground Contact Angle & $11.3 \mathrm{deg}$ \\
\hline \hline
\end{tabular}

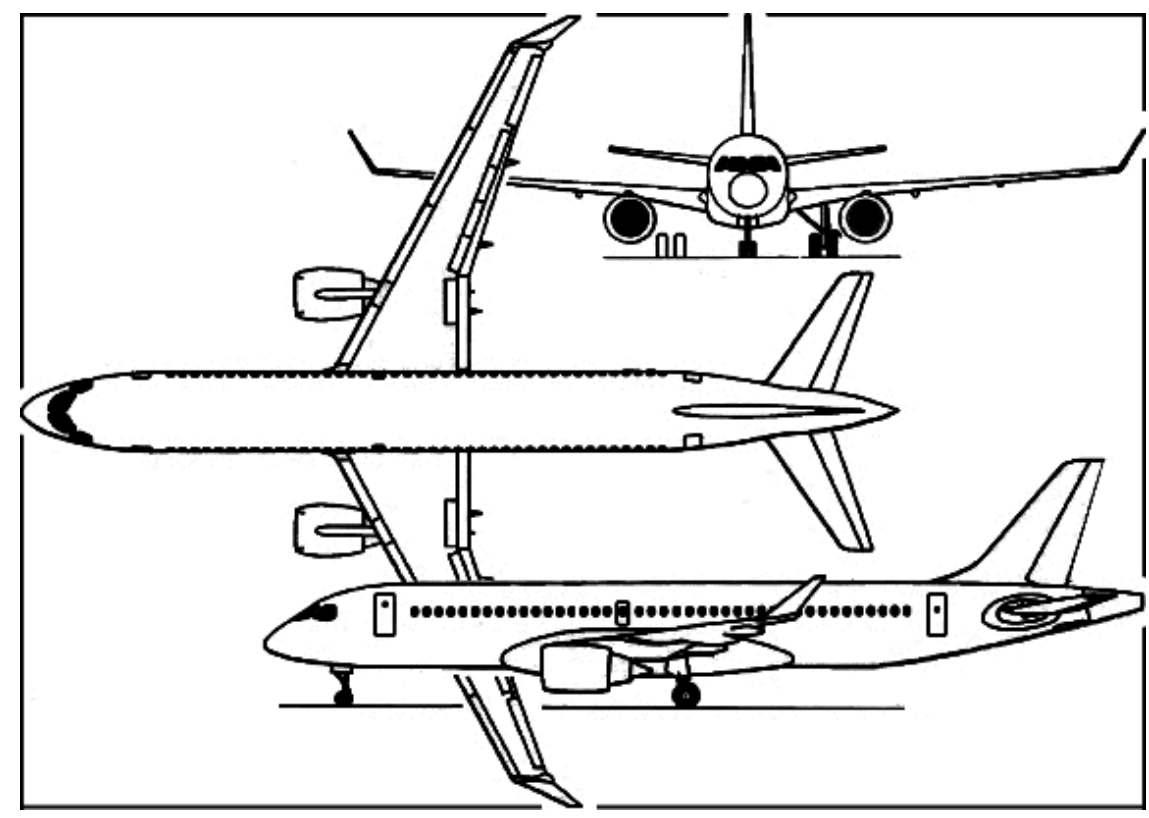

Figure 3.2: 3-view drawing of Airbus A220. Modified from [76].

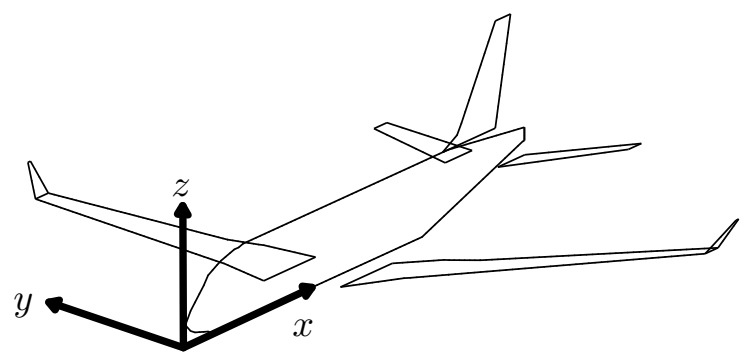

Figure 3.3: Global coordinate system. 


\subsubsection{Wings}

The $x$ and $y$ coordinates of the leading and trailing edges of the wings were taken from the top view and the corresponding $z$ coordinates were retrieved from the front view. The elastic axis was assumed to lie at $40 \%$ of the cord-wise distance between the leading and trailing edges and $50 \%$ of the way between the top and bottom surfaces.

\subsubsection{Horizontal Tail}

The $x$ and $y$ coordinates of the leading and trailing edges of the horizontal tail were taken from the top view and the corresponding $z$ coordinates were retrieved from the front view. The elastic axis was assumed to lie at $40 \%$ of the cord-wise distance between the leading and trailing edges and $50 \%$ of the way between the top and bottom surfaces.

\subsubsection{Vertical Tail}

The $x$ and $z$ coordinates of the leading and trailing edges of the vertical tail were taken from the side view and the corresponding $y$ coordinates were taken to be zero. The elastic axis was assumed to lie at $40 \%$ of the cord-wise distance between the leading and trailing edges and on the aircraft $x z$ plane.

\subsubsection{Fuselage}

The $x$ and $z$ coordinates of the top and bottom of the fuselage were taken from the side view and the corresponding $y$ coordinates were taken to be zero. The elastic axis was assumed to lie at $50 \%$ of the vertical distance between the top and bottom and on the aircraft $x z$ plane.

\subsubsection{Engine}

An equivalent cylinder was used to represent the engine with the same nominal diameter and overall length as given in Table 3.1 . 


\subsubsection{Landing Gear Geometry}

Table 3.2 gives the $x$ and $y$ positions of the tires and the LG attachments. Currey 24] gives typical values for the ratios of the LG static stroke position to the total stroke length, $\frac{s_{\text {static }}}{s_{t}}$, which were used as guides in choosing the LG geometry. The total strokes were taken to be $0.5 \mathrm{~m}$ for both the MLG and NLG. A constraint of $0.8 \leq \frac{s_{\text {static }}}{s_{t}} \leq 0.9$ was derived from the reference values in Currey [24] and is used in selecting shock absorber parameters.

The NLG tires of the Airbus A220-300 are type 27x8.5R12 with a 16 ply rating inflated to 10 bar and the MLG has type H42x15.0R21 tires with a 26 ply rating at 14.7 bar [74].

The length specifications of LG consist of three main components: main body, piston, and axle. The length of the piston was assumed to be the same as the stroke length. The length of the axle was assumed to be the distance between the tires. The length of the body was chosen such that it gives the same minimum engine and body ground clearances when the LG is fully compressed, as specified in [74]. The length of the LG components are given in Table 3.3. Note that the length of the LG body is longer than the true size. The MLG would typically attach to the bottom surface of the wing but the planar representation of the wing has zero thickness with the planar surface $50 \%$ of the way between the true top and bottom surfaces. Thus, the LG body length in the model is the true LG body length plus $50 \%$ of the wing thickness.

Table 3.2: Landing gear attachment and tire locations. Retrieved from [74.

\begin{tabular}{ccc}
\hline \hline & $x$ coordinate & $y$ coordinate \\
& {$[\mathrm{m}]$} & {$[\mathrm{m}]$} \\
\hline NLG Attachment & 3.5 & 0 \\
NLG Right Tire & 3.5 & 0.235 \\
NLG Left Tire & 3.5 & -0.235 \\
\hline Right MLG Attachment & 18.74 & 3.36 \\
Right MLG Right Tire & 18.74 & 3.81 \\
Right MLG Left Tire & 18.74 & 2.92 \\
\hline Left MLG Attachment & 18.74 & -3.36 \\
Left MLG Right Tire & 18.74 & -2.92 \\
Left MLG Left Tire & 18.74 & -3.81 \\
\hline \hline
\end{tabular}


Table 3.3: Lengths of landing gear structural components.

\begin{tabular}{ccc}
\hline \hline & $\begin{array}{c}\text { Nose Landing Gear } \\
{[\mathrm{m}]}\end{array}$ & $\begin{array}{c}\text { Main Landing Gear } \\
{[\mathrm{m}]}\end{array}$ \\
\hline Body & 1.26 & 2.27 \\
Piston & 0.50 & 0.50 \\
Axle & 0.47 & 0.89 \\
\hline \hline
\end{tabular}

\subsection{Mass Distribution}

The masses of components were found using the Class I Method from Roskam, which were derived from historical mass fraction values [77]. The mass fractions used in this study are the same as a Boeing 737-200, as given in [77] and are reproduced in Table 3.4. According to Roskam, the nacelle consists of the structural mass of external ducts, cowls, and pylon mass [77]; this was added to the mass of the power plant. Fixed equipment includes the flight control system, hydraulic and pneumatic systems, instrumentation, avionics, electronics, the environmental control system, anti- and de-icing, auxiliary power unit, furnishings, baggage and cargo-handling equipment, operational items, and paint. Fixed equipment will be assumed to be included in the mass of the fuselage [77. The empennage consists of the horizontal and vertical tails [77.

The actual mass of the engine and the OEM are known and given in Table 3.1. Since there are discrepancies between the actual values and the values calculated using mass fractions, the difference was distributed between the components as a function of their mass fraction compared to the OEM. This ensures that the Class I method matches the actual OEM. Let the mass adjustment, $\Delta m_{i}$, of component $i$ with initial Class I calculated

Table 3.4: Reference component mass fractions for Boeing 737-200. Retrieved from [77].

\begin{tabular}{cc}
\hline \hline & Component mass / MTOM \\
\hline Power Plant & 0.074 \\
Fixed Equipment & 0.129 \\
Wings & 0.092 \\
Empennage & 0.024 \\
Fuselage & 0.105 \\
Nacelle & 0.012 \\
Landing Gear & 0.038 \\
\hline \hline
\end{tabular}


mass, $m_{i_{I}}$, be calculated as follows

$$
\Delta m_{i}=\frac{m_{i_{I}}}{m_{S_{I}}-m_{E_{I}}-m_{t r}}\left(m_{S}-m_{S_{I}}-\left(m_{E}-m_{E_{I}}\right)\right)
$$

where $m_{S_{I}}$ is the initial Class I calculated OEM, $m_{S}$ is the actual OEM, $m_{t r}$ is the mass of trapped fuel, $m_{E_{I}}$ is the initial Class I calculated engine mass, and $m_{E}$ is the actual engine mass. The initial component masses, adjustment, and final estimated masses are given in Table 3.5 .

The distribution of mass along the length of the components is required so concentrated mass elements (CONM2 in NASTRAN) can be assigned to nodes in the stick model. For the wings and the empennage, the mass at node $i$ is the ratio of the projected area of the wing section to the total projected area of the wing multiplied by the total wing mass. One section begins halfway between the current node and the preceding node and ends halfway between the current node and the following node. Similarly, the equivalent concentrated mass element for a fuselage section was calculated as the ratio of the volume of the fuselage section to the total fuselage volume multiplied by the total fuselage mass.

The mass moments of inertia of fuselage elements were calculated in the global coordinate system by treating the discretized fuselage element as a uniform solid cylindrical section centred at the elastic axis with mass $m$, the average radius of the section $R$, and

Table 3.5: Final component masses.

\begin{tabular}{ccc|c}
\hline \hline & Class I Method & $\begin{array}{c}\text { Adjustment } \\
{[\mathrm{kg}]}\end{array}$ & $\begin{array}{c}\text { Final Adjusted Value } \\
{[\mathrm{kg}]}\end{array}$ \\
\hline Power Plant & 4331 & +23 & 4354 \\
Fixed Equipment & 7869 & +2653 & 10522 \\
Wing & 5612 & +1892 & 7504 \\
Empennage & 1464 & +494 & 1958 \\
Fuselage & 6405 & +2160 & 8565 \\
Nacelle & 732 & +247 & 979 \\
Landing Gear & 2318 & +782 & 3100 \\
\hline OEM & 28831 & +8250 & 37081 \\
\hline \hline
\end{tabular}


length $l$. The mass moment of inertia of a cylinder is given by

$$
\begin{gathered}
I_{x x}=\frac{1}{2} m R^{2} \\
I_{y y}=I_{z z}=\frac{1}{12}\left(3 R^{2}+l^{2}\right)
\end{gathered}
$$

The mass moments of inertia of wing elements (main wings, vertical and horizontal tails) were determined in the local wing coordinate system (see Figure 3.4 by treating each wing section as a flat trapezoid. The area moments of inertia and centroids were calculated using the MATLAB function polygeom. The mass moment of inertia was then calculated as the area moment of inertia multiplied by the area density.

The engines were modelled as concentrated mass elements with corresponding inertias in the global coordinate system that are rigidly attached to the wings. The mass was taken to be that of a representative engine and the moments of inertia were calculated as the inertia of a uniform cylinder with equivalent dimensions to those of a representative engine, as in Eqs. 3.2 to 3.3 .

\subsubsection{Landing Gear Mass}

According to the APP, approximately $90 \%$ of the total aircraft weight is supported by the MLG [74]. Accordingly, it was assumed that the MLG will account for $90 \%$ of total LG mass. Using the results from Table 3.5, the LG has a total mass of $3100 \mathrm{~kg}$. Thus, each MLG has a mass of $1395 \mathrm{~kg}$ and the NLG has a total mass of $310 \mathrm{~kg}$.

The Airbus 220-300 uses 27x8.5R12 tires with 16 ply rating for the NLG and H42x15.0R21 tires with a 26 ply rating for the MLG [74]. Alroqi and Wang quote the mass of a Boeing 747 tire to be $110 \mathrm{~kg}$ and rim to be $74.4 \mathrm{~kg}$ [38]. The tire mass was not known for Airbus A220 tires but it is known for the Boeing 737-300/400/500 with MLG tire type H42x16.0-19 with ply rating of 26 to be $75.7 \mathrm{~kg}$ and NLG tire type $27 \times 7.75 \mathrm{R} 15$ with 12 ply rating has mass $17 \mathrm{~kg}$ [78]. The mass of Boeing 737-300 tires was assumed to be the same as the Airbus A220. The mass of the tire and rim were assumed to scale linearly from those of the Boeing 


$$
\begin{aligned}
& m_{r_{\mathrm{NLG}}}=17 \frac{74.4}{110}=11.5 \mathrm{~kg} \\
& m_{r_{\mathrm{MLG}}}=75.7 \frac{74.4}{110}=51.2 \mathrm{~kg}
\end{aligned}
$$

Goodyear gives the following formulae to calculate the radius of gyration of the tire, $r_{t}$, and the wheel assembly including brakes, $r_{w}$, with error of $\pm 5 \%$ and $\pm 20 \%$ respectively [79].

$$
\begin{aligned}
r_{t} & =\frac{\operatorname{Max} \mathrm{OD}+\mathrm{Min} \mathrm{OD}}{5.12} \\
r_{w} & =0.4 D
\end{aligned}
$$

where the radii of gyration are given in inches, $D$ is the rim ledge diameters and the maximum and minimum outside diameters (OD) were obtained from [79]:

$$
\begin{aligned}
& r_{t_{\mathrm{NLG}}}=\frac{27+26.3}{5.12}=10.4 \mathrm{in}=0.264 \mathrm{~m} \quad r_{w_{\mathrm{NLG}}}=0.4(15)=6.0 \mathrm{in}=0.152 \mathrm{~m} \\
& r_{t_{\mathrm{MLG}}}=\frac{42+41.1}{5.12}=16.2 \mathrm{in}=0.411 \mathrm{~m} \quad r_{w_{\mathrm{MLG}}}=0.4(19)=7.6 \mathrm{in}=0.193 \mathrm{~m}
\end{aligned}
$$

The wheel rotational mass moments of inertia in the SAE Tire coordinate system from [80] were then calculated as

$$
I_{y y_{\mathrm{tire}}}=m r^{2}
$$

The reference tire values are summarized in Table 3.6 .

To determine the moments of inertia about the non-rotational axes $\left(I_{x x_{\text {tire }}}\right.$ and $\left.I_{z z_{\text {tire }}}\right)$,

Table 3.6: Reference A220 tire and wheel properties.

\begin{tabular}{ccc}
\hline \hline & Nose Landing Gear & Main Landing Gear \\
\hline Max Outer Diameter & $0.686 \mathrm{~m}$ & $1.07 \mathrm{~m}$ \\
Min Outer Diameter & $0.668 \mathrm{~m}$ & $1.05 \mathrm{~m}$ \\
Rim Diameter & $0.381 \mathrm{~m}$ & $0.482 \mathrm{~m}$ \\
Tire Mass & $17 \mathrm{~kg}$ & $75.7 \mathrm{~kg}$ \\
Rim Mass & $11.5 \mathrm{~kg}$ & $51.2 \mathrm{~kg}$ \\
Tire Inertia & $1.18 \mathrm{~kg} \mathrm{~m}^{2}$ & $12.81 \mathrm{~kg} \mathrm{~m}^{2}$ \\
Rim Inertia & $0.268 \mathrm{~kg} \mathrm{~m}^{2}$ & $1.908 \mathrm{~kg} \mathrm{~m}^{2}$ \\
\hline \hline
\end{tabular}


the tire was approximated as a flat disc. Thus, the moments of inertia are half of the moment of inertia along the rotational axis.

$$
I_{x x_{\text {tire }}}=I_{z z_{\text {tire }}}=\frac{1}{2} I_{y y_{\text {tire }}}
$$

In the absence of a rational method for determining the mass of the LG components, $50 \%$ of the mass of each LG (minus tire and rim mass) was assigned to the main body, $25 \%$ to the axle, and $25 \%$ to the piston. The masses are given in Table 3.7

In the aircraft structural model used in NASTRAN SOL 103 to determine the eigenmodes, the LG was represented by point masses at their attachment points defined in Table 3.2 . When creating the modal neutral file (MNF) from NASTRAN, the mass of the LG was omitted as the $M S C$ Adams model contains the LG with their corresponding masses.

Table 3.7: Masses of landing gear structural components.

\begin{tabular}{ccc}
\hline \hline & $\begin{array}{c}\text { Nose Landing Gear } \\
{[\mathrm{kg}]}\end{array}$ & $\begin{array}{c}\text { Main Landing Gear } \\
{[\mathrm{kg}]}\end{array}$ \\
\hline Body & 126.5 & 570.6 \\
Piston & 63.23 & 285.3 \\
Axle & 63.23 & 285.3 \\
\hline \hline
\end{tabular}

\subsubsection{Passenger Mass and Position}

The Transport Canada Aeronautical Information Manual (TC AIM) defines the standard passenger masses for summer and winter months for both males and females. The reference passenger mass used in this study was $84.1 \mathrm{~kg}$, which is the average of both male and female masses across summer and winter months.

The positions of passengers were calculated assuming a 150-passenger cabin arrangement. There are 30 rows total, each 5 seats wide with 3 seats on the starboard side and 2 on the port side separated by an aisle width of $0.5 \mathrm{~m}$ and total cabin width of $3.28 \mathrm{~m}$ [74]. The $x$ position of the first and last row was calculated from the cabin drawing with a 150-passenger arrangement, as given in [74]. These values correspond to the first row at $x=6.62 \mathrm{~m}$ and last row at a position of $x=29.07 \mathrm{~m}$. Rows were assumed to be distributed evenly between these values. 
The vertical position of the passenger was calculated assuming their centre of mass is situated at half of the maximum cabin diameter. Therefore, the position is $z=1.85 \mathrm{~m}$. Each passenger was represented as a point mass with zero mass moments of inertia connected to the nearest node on the fuselage stick model with an offset corresponding to the passenger position.

\subsubsection{Fuel Mass and Arrangement}

The locations of the fuel tanks were estimated from a cutaway drawing of the Airbus A220 [81]. The aircraft has fuel tanks in the wing with a centre tank between the two wings. The fuel tank in the wings was estimated to have a chord-wise length of $75 \%$ of the local cord length, $c_{i}$, and that it extends to $75 \%$ of the wing's span. The tanks were all approximated as having a rectangular cross section with a local wing $y$ dimension of $8.5 \%$ of the local cord length, which gives a total volume, $V_{f_{\text {tot }}}$, of 21.511 .

The fuel tank was discretized to have $n$ mass elements, which is the same number of elements as the wing in the stick model. Each tank segment begins halfway between the current node, $i$, and the preceding node, $i-1$, and ends halfway between the current node and the following node, $i+1$. The volume of each segment, $V_{i}$, is

$$
V_{i}= \begin{cases}\left(0.5^{2}\right)(0.75)(0.085)\left(c_{i+1}^{2}+c_{i}^{2}\right)\left(Y_{i+1}-Y_{i}\right), & i=1 \\ \left(0.5^{2}\right)(0.75)(0.085)\left[\left(c_{i-1}^{2}+c_{i}^{2}\right)\left(Y_{i}-Y_{i-1}\right)+\left(c_{i+1}^{2}+c_{i}^{2}\right)\left(Y_{i+1}-Y_{i}\right)\right], & 1<i<n \\ \left(0.5^{2}\right)(0.75)(0.085)\left(c_{i-1}^{2}+c_{i}^{2}\right)\left(Y_{i}-Y_{i-1}\right), & i=n\end{cases}
$$

where $c_{i}$ is the cord length of segment $i$. The volume of the centre tank is given by

$$
V_{\text {centre }}=(0.75)(0.085) c_{1}^{2} w
$$

where $c_{1}$ is the root cord length and $w$ is the distance between wing roots. For simplicity, the fuel was assumed to burn uniformly from all tanks. The fuel arrangements for the MLM and MTOM configurations were calculated assuming maximum passenger capacity (150 passengers) for a total passenger mass, $m_{p}$, of $12615 \mathrm{~kg}$. Thus, the required fuel mass, 
$m_{f}$ to obtain a total mass equal to the MLM or MTOM, $m_{x}$, is

$$
m_{f}=m_{x}-m_{E}-m_{p}
$$

The mass of fuel in each tank segment, $m_{f_{i}}$, that is required to obtain the desired mass is given by

$$
m_{f_{i}}=\frac{m_{f}}{V_{f_{\mathrm{tot}}}} V_{i}
$$

where $V_{f_{\text {tot }}}$ is the total fuel tank volume and is given in Table 3.1. The mass elements along the span of the wing were approximated as point masses with no offset from the node to which the mass element is attached. The centre tank was approximated as a rectangularbased prism with associated rotational inertias given by:

$$
\begin{aligned}
I_{x x} & =\frac{1}{12} m_{f_{\text {centre }}}\left(w^{2}+\left(0.085 c_{1}\right)^{2}\right) \\
I_{y y} & =\frac{1}{12} m_{f_{\text {centre }}}\left(\left(0.75 c_{1}\right)^{2}+\left(0.085 c_{1}\right)^{2}\right) \\
I_{z z} & =\frac{1}{12} m_{f_{\text {centre }}}\left(w^{2}+\left(0.75 c_{1}\right)^{2}\right)
\end{aligned}
$$

The centre of mass of the centre tank was assumed to be located at the wing-fuselage junction.

\subsection{Airframe Beam and Stiffness Properties}

Various sources give example distributions of the cross-sectional properties for the equivalent beams of reference wings, fuselages and empennages [16, 73, 82] and their corresponding natural frequencies [83, 82, 46, 17], with some expected values presented in Table 3.11. The properties include the second moments of area $\left(I_{z^{\prime} z^{\prime}}, I_{y^{\prime} y^{\prime}}\right.$, and $\left.I_{y^{\prime} z^{\prime}}\right)$, the torsional constant, $I_{x^{\prime} x^{\prime}}$, the reference cross-sectional area, $A$, and the area factors for shear, $K_{1}$ and $K_{2}$. The properties along the fuselage are given in the global coordinate system, as in Figure 3.3 . and the properties along wing segments are in the local airfoil coordinate system shown in Figure 3.4. In all analyses, the Young's modulus, shear modulus, and Poisson's ratio were assumed to be those of $\mathrm{Al} 7075$-T6, which are given in Table 3.8 . 


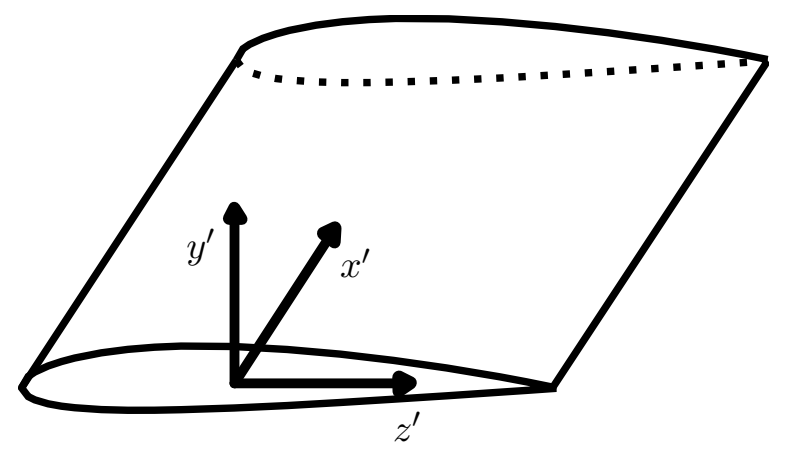

Figure 3.4: Local airfoil coordinate system. The $x$ axis is oriented along the elastic axis, which is assumed at $40 \%$ of the local wing cord length.

\subsubsection{Wings}

A smooth curve representing the distribution of cross-sectional properties can be formed from the reference distributions. The coefficients of these curves can then be tuned to give expected natural frequencies that match typical values. Airfoil sections are given according to the local coordinate system in Figure 3.4 with $\eta$ representing the non-dimensional position along the wing in the global $y$ axis with zero at the wing root and 1 at the wing tip. The out-of-plane bending area moment of inertia distribution of the wing, $I_{z^{\prime} z^{\prime} \text { wing }}$, was assumed to follow an exponential relationship:

$$
I_{z^{\prime} z_{\text {wing }}^{\prime}}=a_{1} e^{a_{2} \eta}+a_{3}
$$

where $a_{1}, a_{2}$, and $a_{3}$ are unknown coefficients. In order to reduce the number of coefficients required for tuning, the in-plane bending area moment of inertia, $I_{y^{\prime} y_{\text {wing }}^{\prime}}$, and polar moment

Table 3.8: Al 7075-T6 properties 84].

\begin{tabular}{cc}
\hline \hline Parameter & Value \\
\hline Young's modulus, $E$ & $71.7 \mathrm{GPa}$ \\
Poisson's ratio, $\nu$ & 0.33 \\
Shear modulus, $G$ & $26.9 \mathrm{GPa}$ \\
\hline \hline
\end{tabular}


of inertia, $I_{x^{\prime} x_{\text {wing }}^{\prime}}$, were assumed to be related to each other by a gain factor, $k_{i}$

$$
\begin{gathered}
I_{y^{\prime} y_{\text {wing }}^{\prime}}=k_{1} I_{z^{\prime} z_{\text {wing }}^{\prime}} \\
I_{x^{\prime} x^{\prime} \text { wing }}=k_{2} I_{z^{\prime} z_{\text {wing }}^{\prime}}
\end{gathered}
$$

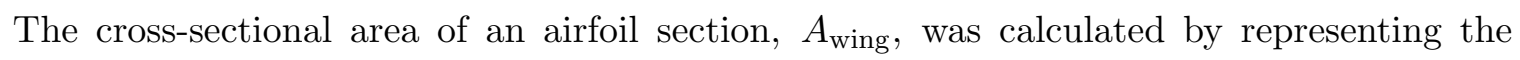
airfoil as a rectangular section with a wall thickness of $0.015 c$ and a height of $0.1 c$.

$$
A_{\text {wing }}=0.033 c^{2}
$$

\subsubsection{Fuselage}

The stiffness properties of the fuselage were assumed to follow a Gaussian distribution. The area moment of inertia distribution of the fuselage, $I_{\text {fuselage }}$, is given by:

$$
I_{z z_{\text {fuselage }}}=b_{1} e^{-\left(\frac{x-b_{2}}{b_{3}}\right)^{2}}+b_{4}
$$

where $b_{1}$ through $b_{4}$ are unknown coefficients that were tuned such that the fuselage natural frequencies matched expected values. The area moments of inertia were related by a gain factor and the polar moment of area was assumed that of a uniform cylinder.

$$
\begin{aligned}
& I_{y y_{\text {fuselage }}}=k_{3} I_{z z_{\text {fuselage }}} \\
& I_{x x_{\text {fuselage }}}=I_{z z_{\text {fuselage }}}+I_{y y_{\text {fuselage }}}
\end{aligned}
$$

The area of a fuselage section was calculated using the average radius of the fuselage section and assuming an average wall-thickness of $0.1 \mathrm{~m}$.

$$
A_{\text {fuselage }_{i}}=(2)(0.1) \pi R
$$

The final parameter values, in SI units, were selected as they most closely yield the desired modal frequencies and shapes and are provided in Table 3.9. 
Table 3.9: Final wing and fuselage cross-sectional parameter distribution values. The parameters return a value with units of $\mathrm{m}^{4}$.

\begin{tabular}{ll|ll}
\hline \hline \multicolumn{2}{c|}{ Wing } & \multicolumn{2}{c}{ Fuselage } \\
\hline$a_{1}$ & 0.0001 & $b_{1}$ & 0.035 \\
$a_{2}$ & -7 & $b_{2}$ & 17.8 \\
$a_{3}$ & 0.0022 & $b_{3}$ & 12.8 \\
$k_{1}$ & 10 & $b_{4}$ & 0.0055 \\
$k_{2}$ & 3.5 & $k_{3}$ & 1 \\
\hline \hline
\end{tabular}

\subsubsection{Empennage}

The cross-sectional properties of the empennage were assumed to vary linearly along the length. The desired natural frequencies and starting cross-sectional properties were found in [82] and these values were tuned to give the desired natural frequencies. The sections were all assumed symmetric and thus $I_{y^{\prime} z^{\prime}}=0$. The root and tip cross-sectional properties are given in Table 3.10 .

Table 3.10: Final empennage cross-sectional parameter distribution values.

\begin{tabular}{rl|rl}
\hline \hline \multicolumn{2}{c|}{ Horizontal Tail } & \multicolumn{2}{|c}{ Vertical Tail } \\
\hline Root $I_{z^{\prime} z^{\prime}}=0.003 \mathrm{~m}^{4}$ & Root $I_{z^{\prime} z^{\prime}}=0.003 \mathrm{~m}^{4}$ \\
$\operatorname{Tip} I_{z^{\prime} z^{\prime}}=0.0001 \mathrm{~m}^{4}$ & Tip $I_{z^{\prime} z^{\prime}}=0.0005 \mathrm{~m}^{4}$ \\
Root $I_{y^{\prime} y^{\prime}}=0.02 \mathrm{~m}^{4}$ & Root $I_{y^{\prime} y^{\prime}}=0.06 \mathrm{~m}^{4}$ \\
$\operatorname{Tip} I_{y^{\prime} y^{\prime}}=0.001 \mathrm{~m}^{4}$ & $\operatorname{Tip} I_{y^{\prime} y^{\prime}}=0.005 \mathrm{~m}^{4}$ \\
Root $I_{x^{\prime} x^{\prime}}=0.002 \mathrm{~m}^{4}$ & $\operatorname{Root} I_{x^{\prime} x^{\prime}}=0.01 \mathrm{~m}^{4}$ \\
$\operatorname{Tip} I_{x^{\prime} x^{\prime}}=0.00005 \mathrm{~m}^{4}$ & $\operatorname{Tip} I_{x^{\prime} x^{\prime}}=0.0005 \mathrm{~m}^{4}$ \\
$\operatorname{Root} A=1 \mathrm{~m}^{2}$ & $\operatorname{Root} A=1 \mathrm{~m}^{2}$ \\
$\operatorname{Tip} A=0.5 \mathrm{~m}^{2}$ & $\operatorname{Tip} A=0.5 \mathrm{~m}^{2}$ \\
\hline \hline
\end{tabular}

\subsubsection{Structural Damping}

A constant structural damping ratio of 0.05 was assumed, which agrees with the values found in references [18, 21].

\subsection{Modal Analysis}

A modal analysis was performed in NASTRAN using SOL 103 to get the modes and mode shapes. The frequencies of the eigenmodes and a description of the mode shapes for the 
OEM and MLM configurations are given in Table 3.11.

Table 3.11: Eigenmodes of the aircraft model at OEM and MLM.

\begin{tabular}{lcc}
\hline \hline & \multicolumn{2}{c}{ Frequency (Hz) } \\
Mode Description & OEM & MLM \\
\hline Symmetric wing 1st bending & 2.29 & 1.99 \\
Anti-symmetric wing 1st bending & 3.59 & 3.25 \\
Anti-symmetric fuselage 1st bending & 4.69 & 4.13 \\
Symmetric fuselage 1st bending & 4.79 & 4.38 \\
Symmetric wing in-plane 1st bending & 7.13 & 6.18 \\
Anti-symmetric wing in-plane 1st bending & 7.65 & 6.92 \\
Symmetric wing 1st torsion & 8.25 & 7.93 \\
Anti-symmetric wing 1st torsion & 9.72 & 9.19 \\
Symmetric wing 2nd bending & 13.2 & 11.0 \\
Anti-symmetric wing 2nd bending & 13.4 & 13.4 \\
\hline \hline
\end{tabular}

\subsection{Mesh Convergence}

An $h$-convergence approach was completed on each major component of the stick model to determine the number of nodes necessary such that there is a small change in the first three eigenmodes resulting from the modal frequencies approaching an asymptotic value. In each refinement step, the spacing between nodes was halved. It shall be noted that this does not necessarily correspond to doubling the number of nodes as some nodes have a fixed location where there is a geometrical discontinuity.

\subsubsection{Wing}

The $h$-convergence of the wing is shown in Table 3.12 . From the table, it is concluded that 64 nodes along a single wing (128 nodes total) are sufficient.

Table 3.12: Percent change in modal frequency compared to the previous refinement level for a beam representation of a single wing.

\begin{tabular}{cccc}
\hline \hline Number of Nodes & Mode 1 & Mode 2 & Mode 3 \\
\hline 19 & - & - & - \\
33 & $-7.5 \%$ & $1.0 \%$ & $-1.7 \%$ \\
64 & $8.9 \%$ & $-0.1 \%$ & $-0.3 \%$ \\
147 & $-0.1 \%$ & $0.0 \%$ & $0.1 \%$ \\
\hline \hline
\end{tabular}




\subsubsection{Fuselage}

The $h$-convergence of the fuselage is shown in Table 3.13. From the table, it is concluded that 79 nodes along the fuselage are sufficient.

Table 3.13: Percent change in modal frequency compared to the previous refinement level for a beam representation of the fuselage.

\begin{tabular}{cccc}
\hline \hline Number of Nodes & Mode 1 & Mode 2 & Mode 3 \\
\hline 21 & - & - & - \\
40 & $6.8 \%$ & $2.9 \%$ & $5.5 \%$ \\
79 & $0.3 \%$ & $0.3 \%$ & $1.1 \%$ \\
156 & $0.1 \%$ & $0.1 \%$ & $-0.3 \%$ \\
\hline \hline
\end{tabular}

\subsubsection{Horizontal Tail}

The $h$-convergence of the horizontal tail is shown in Table 3.14 . From the table, it is concluded that 11 nodes along a single section (22 nodes total) are sufficient.

Table 3.14: Percent change in modal frequency compared to the previous refinement level for a beam representation of a single horizontal tail.

\begin{tabular}{ccccc}
\hline \hline Number of Nodes & Mode 1 & Mode 2 & Mode 3 & Mode 4 \\
\hline 6 & - & - & - & - \\
11 & $0.02 \%$ & $0.02 \%$ & $-0.002 \%$ & -0.02 \\
\hline \hline
\end{tabular}

\subsubsection{Vertical Tail}

The $h$-convergence of the vertical tail is shown in Table 3.15. From the table, it is concluded that 13 nodes are sufficient.

Table 3.15: Percent change in modal frequency compared to the previous refinement level for a beam representation of a vertical tail.

\begin{tabular}{cccc}
\hline \hline Number of Nodes & Mode 1 & Mode 2 & Mode 3 \\
\hline 5 & - & - & - \\
7 & $2.1 \%$ & $2.0 \%$ & $2.4 \%$ \\
13 & $0.9 \%$ & $1.4 \%$ & $1.1 \%$ \\
24 & $0.9 \%$ & $0.9 \%$ & $1.1 \%$ \\
\hline \hline
\end{tabular}




\subsection{Landing Gear Attachment}

As outlined in Section 2.1.2, a flexible joint attaching the LG to the aircraft is sufficient to capture flexibility effects of the LG. The LG body attaches to the aircraft via a revolute joint that allows motion about the aircraft global $y$ axis. The stiffness of the attachment was modelled using a torsional spring with stiffness $1 \times 10^{5} \mathrm{~N}-\mathrm{m} \mathrm{deg}^{-1}$, corresponding to a maximum spin-up deflection of approximately $1 \mathrm{deg}$ at the MLM. The effects and justifications of this flexible attachment are discussed further in Section 4.1.2.

\subsection{Multibody Dynamics Model}

\subsubsection{Shock Absorber Force Model}

The forces developed in the shock-strut were generated from a general state equation (GSE) that was computed by $M S C$ Adams. The force model for a shock absorber was programmed in a Simulink model, which was compiled to form a dynamic link library $(d l l)$ file. This dll file was imported to $M S C$ Adams, which was subsequently converted to a GSE by $M S C$ Adams for simulation.

\subsubsection{Tire Model}

The Airbus 220-300 uses 27x8.5R12 tires with 16 ply rating inflated to 10 bar for the NLG and H42x15.0R21 tires with a 26 ply rating inflated to 14.7 bar for the MLG [74] but the tire data is not available for the aircraft. Data on the Boeing $737-300 / 400 / 500$ tires is available and was used for this simulation since the aircraft is similar to the Airbus A220. The Boeing 737-300/400/500 has MLG tires of type H42x16.0-19 with 26 ply rating and NLG tires of type $27 \times 7.75 \mathrm{R} 15$ with 12 ply rating.

MSC Adams with Adams Tire contains the following three aircraft tire models: Aircraft Basic, Aircraft Enhanced, and TR-R64. The MSC Adams Aircraft Basic tire model was used and is described in [43]. Despite the Aircraft Enhanced tire model considering centre of pressure shifts, the Aircraft Basic tire model was chosen over the Aircraft Enhanced model as the Enhanced model requires test data for the longitudinal, lateral, and cornering 
stiffness values. The Aircraft Basic tire model uses a Fiala tire model with proprietary modifications necessary for aircraft LG analysis [43]. As discussed in Section 2.1.2, a Fiala model is appropriate for aircraft landing analysis. The Aircraft Basic Tire model has the following properties [43]:

- 2D contact for wheel bottoming;

- Single contact point with road profile (since there are no bumps and potholes);

- Disc representation of wheel and tire;

- No lateral, longitudinal, and twist deformation effects on tire centre moments; and

- First-order lag on longitudinal and lateral slip.

\section{Force-Deflection Characteristics}

Daugherty [39] developed the following non-dimensional empirical formula describing the tire deflection as a function of the rated load and the nominal tire diameter based on test data of Boeing 777 MLG and NLG and Boeing 737 NLG tires

$$
\% \delta=-7.18+38.85 R-5.10 R^{2}+0.20 D
$$

where $\% \delta$ is the deflection divided by the distance between the unloaded wheel radius and the wheel flange, $R$ is the ratio of the current load to the rated load, and $D$ is the nominal diameter in inches. Since data for the Airbus A220-300 tires were not known, they were approximated as being equal to those of the Boeing 737-300/400/500 tires. Thus, forcedeflection curves were generated using Eq. (3.23) and are plotted in Figure 3.5.

\section{Vertical Damping}

Damping of an aircraft tire can be estimated as 1000 times less than the stiffness value [43.

$$
c=\frac{1}{1000} k_{e q}
$$

Since Eq. (3.23) generates a nonlinear force-deflection curve, a linear curve-fit was used along the first $50 \%$ of the maximum deflection range of the tire to generate an equivalent vertical 
stiffness using a least-squares regression. The force-deflection curves and the least-squares fits are plotted in Figure 3.5. The vertical damping coefficients are as follows:

$$
\begin{aligned}
& c_{\mathrm{MLG}}=1558 \mathrm{~N} \mathrm{~s} \mathrm{~m}^{-1} \\
& c_{\mathrm{NLG}}=821.3 \mathrm{~N} \mathrm{~s} \mathrm{~m}^{-1}
\end{aligned}
$$

\section{Relaxation Length}

The relaxation length is used to model cornering forces. Since landing conditions in this study are symmetrical without lateral forces on the tire, this value was assumed inconsequential. Thus, the default value of $0.25 \mathrm{~m}$ was used.

\section{Low-Speed Damping and Threshold}

Since landing occurs at a large forward and vertical velocity, low-speed transient behaviour was neglected.

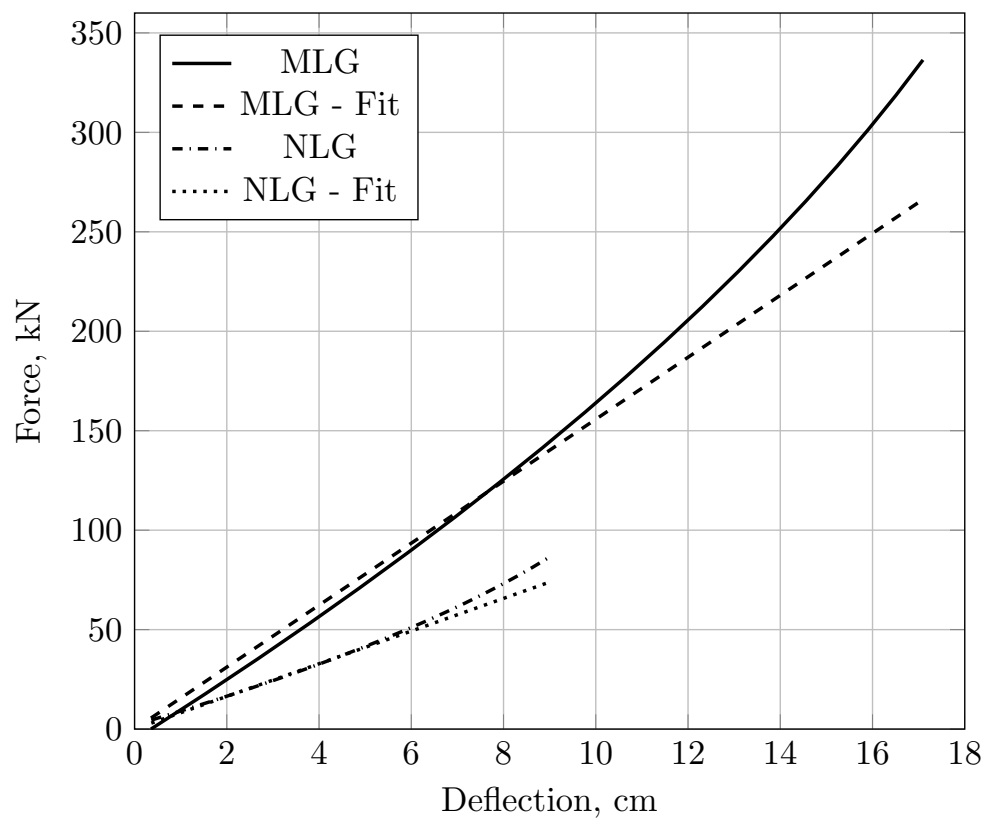

Figure 3.5: Vertical tire force versus deflection with corresponding linear fits for MLG and NLG tires. 


\section{Rolling Resistance}

The rolling resistance coefficient for radial aircraft tires can be conservatively estimated to be 0.015 [39].

\section{Tire Friction Model}

A linear slip-ratio-based friction model was used. The coefficient of friction, $\mu$, is a linear function of the slip ratio, $S$, as in

$$
\mu=\mu_{\max }+\left(\mu_{\min }-\mu_{\max }\right) S
$$

where the slip ratio is calculated for a tire that has rotational speed $\omega$ and forward speed $v_{x}$, as in

$$
S=\frac{v_{x}-\omega r_{t}}{v_{x}}
$$

The maximum coefficient of friction, $\mu_{\max }$ is 0.8 , as in [4, and at a slip ratio of 1 (locked tire), Yager and McCarty indicate a minimum coefficient of friction, $\mu_{\min }$, of approximately 0.2 over a range of tests [85].

\section{Stiffness Coefficients $\left(C_{\text {slip }}\right.$ and $\left.C_{\alpha}\right)$}

The longitudinal stiffness coefficient, $C_{\text {slip }}$, is defined as follows:

$$
C_{\text {slip }}=\left|\frac{\partial F_{x}}{\partial S_{L}}\right|_{S_{L}=0, S_{\alpha}=0}
$$

where $S_{L}$ is the longitudinal slip ratio and $S_{\alpha}$ is the lateral slip ratio. Similarly, for the lateral stiffness coefficient, $C_{\alpha}$,

$$
C_{\alpha}=\left|\frac{\partial F_{y}}{\partial S_{\alpha}}\right|_{S_{L}=0, S_{\alpha}=0}
$$


Using the tire friction model in Eq. (3.27), the values for $C_{\text {slip }}$ and $C_{\alpha}$ are as follows

$$
\begin{aligned}
C_{\text {slip }}=C_{\alpha} & =\frac{1}{\partial S}\left|F_{z}\left(\mu_{\max }+\left(\mu_{\min }-\mu_{\max }\right) S\right)\right| \\
& =0.6 F_{z}
\end{aligned}
$$

Assuming a normal load equal to the static load at the MLM, the longitudinal and lateral stiffness values are $17290 \mathrm{~N}$ for the NLG and $77800 \mathrm{~N}$ for the MLG.

The longitudinal force exerted on the tire, $F_{x_{t}}$, depends on the vertical tire force, $F_{z_{t}}$, the maximum available coefficient of friction from Eq. (3.27), and the slip ratio. The critical slip ratio, $S_{\text {crit }}$, is given in [43] as:

$$
S_{\text {crit }}=\frac{\mu F_{z_{t}}}{2 C_{\text {slip }}}
$$

The longitudinal tire force is given by:

$$
F_{x_{t}}= \begin{cases}C_{\text {slip }} S & S \leq S_{\text {crit }} \\ \mu F_{z_{t}}-\frac{\left(\mu F_{z_{t}}\right)^{2}}{4 S C_{\text {slip }}} & S>S_{\text {crit }}\end{cases}
$$

The ratio of the longitudinal tire force to vertical tire force, $F_{x_{t}} / F_{z_{t}}$, versus the slip ratio is given in Figure 3.6 .

\section{Rolling Radius Deflection Factor}

The effective rolling radius is given by the unloaded radius minus the scaled tire deflection (scaled by the rolling radius deflection factor). Currey gives this value to be $\frac{1}{3}[24$.

\section{Tire Bottoming Force-deflection Characteristics}

The bottoming loads for Boeing 737-300/400/500 NLG and MLG tires are over double the

rated loads [79]. Thus, bottoming was not expected to occur and was not included in the tire property file. 


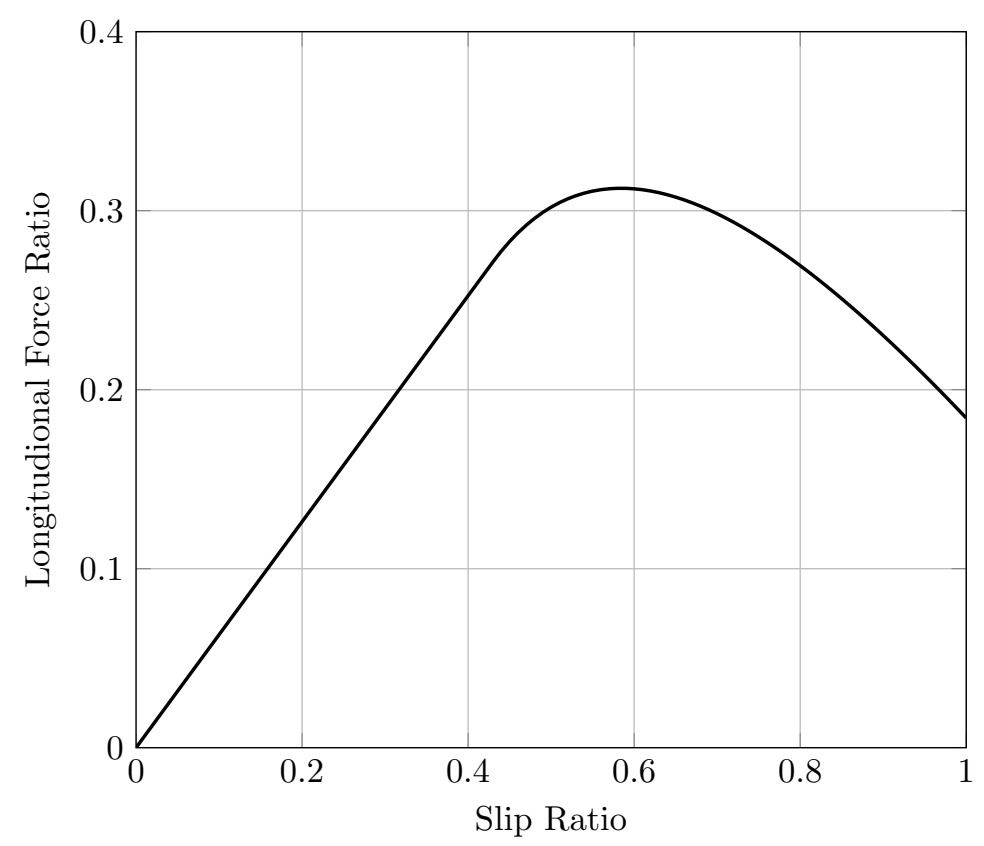

Figure 3.6: Longitudinal tire force ratio versus slip ratio.

\section{Road and Tire Property Files}

A flat 3D contact road file was used to represent the runway. The road data file is given in Appendix A.3. The tire property files used in simulations containing the values for the aforementioned parameters are given in Appendix $\mathrm{A}$.

\subsubsection{Number of Airframe Flexibility Modes Required for Simulation}

The following investigation was carried out using landing simulations at the MLM and in a tail-down orientation. It compares the force-displacement characteristics of the shock absorber, and acceleration in the cockpit when flexible modes up to and including the specified cut-off frequency are included in the modal representation of the airframe. The simulated MLG stroke, $s_{\mathrm{MLG}}$, and difference plots are shown in Figure 3.7. The simulated MLG force, $F_{\mathrm{MLG}}$, and difference plots are in Figure 3.8, and the simulated cockpit acceleration, $a_{c}$, and difference plots are in Figure 3.9. Difference plots are given with respect to the model with a $150 \mathrm{~Hz}$ cutoff and the difference plots comparing the rigid airframe case are not plotted as errors are large. Table 3.16 compares the RMS errors compared with the simulation with a $150 \mathrm{~Hz}$ cutoff. The table also includes the corresponding simulation time using an 
Intel $\AA$ Core $^{\mathrm{TM}}$ i5-6500 CPU at $3.20 \mathrm{GHz}$ and $16.0 \mathrm{~GB}$ of RAM.

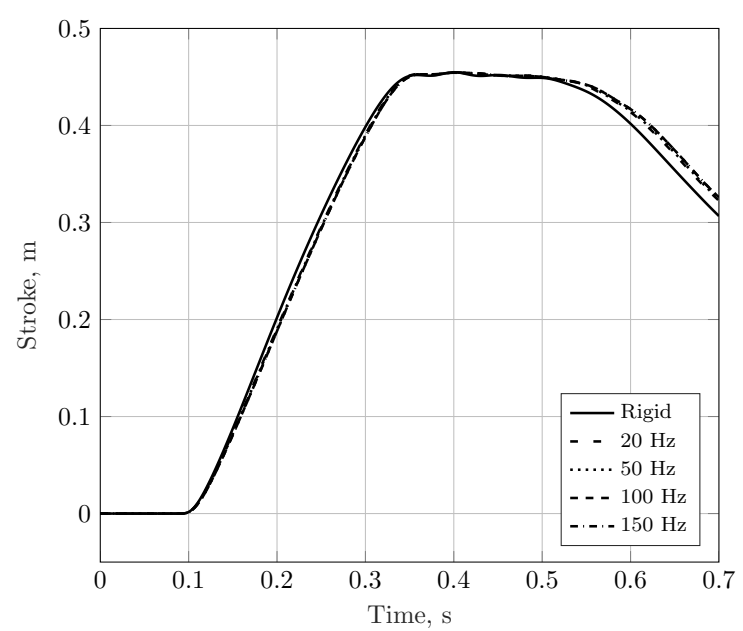

(a) Main landing gear stroke.

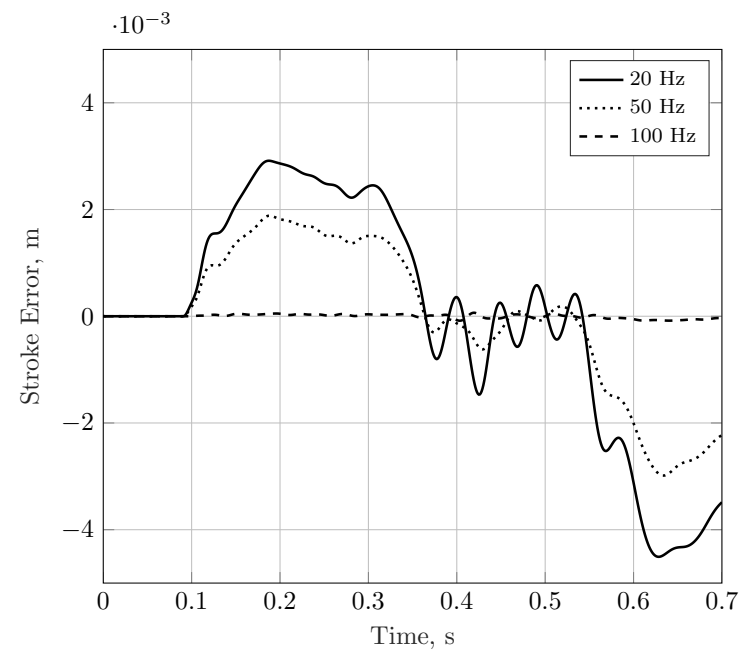

(b) Difference versus simulation with all modes up to $150 \mathrm{~Hz}$.

Figure 3.7: Simulated main landing gear stroke with various flexible modes included.

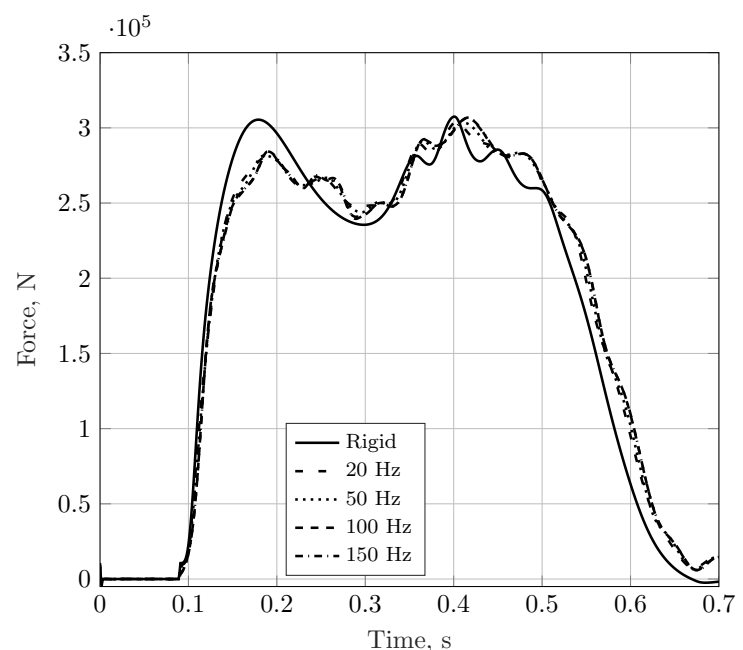

(a) Main landing gear force.

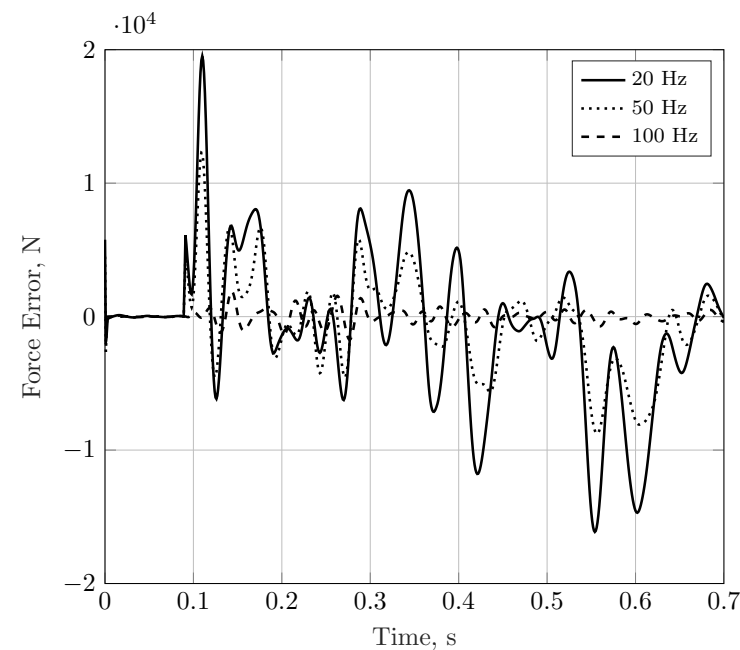

(b) Difference versus simulation with all modes up to $150 \mathrm{~Hz}$.

Figure 3.8: Simulated main landing gear force with various flexible modes included. 


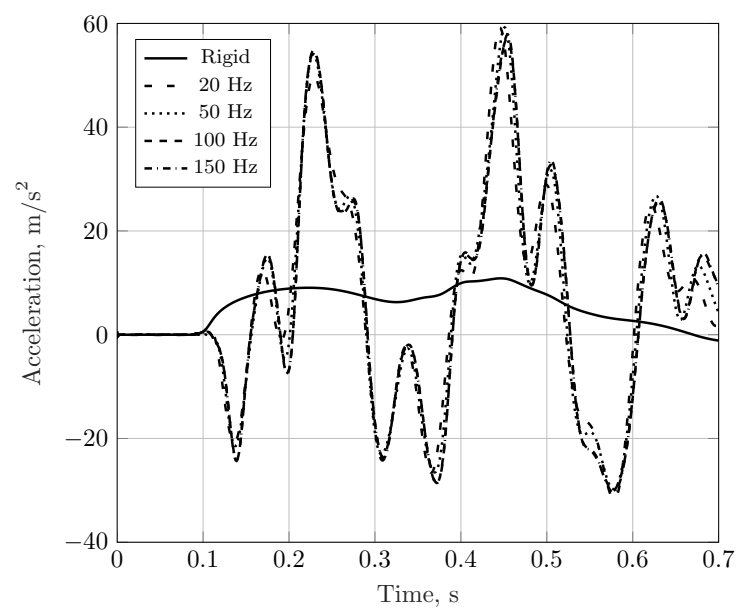

(a) Cockpit acceleration.

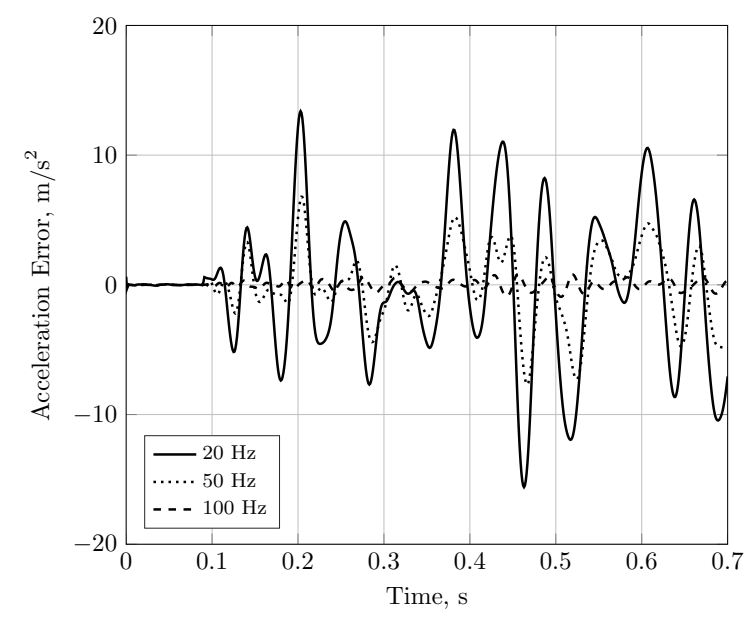

(b) Difference versus simulation with all modes up to $150 \mathrm{~Hz}$.

Figure 3.9: Simulated cockpit acceleration with various flexible modes included.

Table 3.16: Root mean square errors compared to simulation with all modes up to $150 \mathrm{~Hz}$ with corresponding simulation time.

\begin{tabular}{cccccc}
\hline \hline Cut-Off & Sim & No. & \multicolumn{3}{c}{ RMS Errors } \\
Freq. & Time [s] & Modes & Cockpit Accel. & MLG Stroke & MLG Force \\
\hline $0 \mathrm{~Hz}$ & 1.72 & 0 & $2.03 \mathrm{~g}$ & $10.1 \mathrm{~mm}$ & $20.2 \mathrm{kN}$ \\
$20 \mathrm{~Hz}$ & 1.67 & 17 & $0.562 \mathrm{~g}$ & $2.19 \mathrm{~mm}$ & $5.68 \mathrm{kN}$ \\
$50 \mathrm{~Hz}$ & 1.94 & 33 & $0.27 \mathrm{~g}$ & $1.38 \mathrm{~mm}$ & $3.47 \mathrm{kN}$ \\
$100 \mathrm{~Hz}$ & 2.05 & 57 & $0.0333 \mathrm{~g}$ & $0.037 \mathrm{~mm}$ & $0.499 \mathrm{kN}$ \\
$150 \mathrm{~Hz}$ & 2.38 & 73 & - & - & - \\
\hline \hline
\end{tabular}

It is concluded that modes up to $100 \mathrm{~Hz}$ must be included, with small gains in accuracy when including more modes at the cost of higher computational cost as quantified by the longer simulation time.

\subsubsection{Integrator}

The propagation of the numerical solution was accomplished using the GSTIFF integrator with SI2 formulation. The GSTIFF integrator uses a backwards difference formulation and is a variable-order, variable-step, multi-step integrator with maximum integration order of 6 [86]. The SI2 (Stabilized-Index Two) formulation gives more accurate results for velocities and accelerations, is more robust at the small step size needed to model ground impact, and tracks high-frequency oscillations very accurately [86]. 


\section{Integration Error Tolerance}

The following investigation was again carried out on simulations at MLM and tail-down. It compares the force-displacement characteristics of the shock absorber, and acceleration in the cockpit with various integration error tolerances. The simulated MLG stroke, $s_{\mathrm{MLG}}$, and difference plots are shown in Figure 3.10. The simulated MLG force, $F_{\text {MLG }}$, and difference plots are presented in Figure 3.11, and the simulated cockpit acceleration, $a_{c}$, and difference plots are in presented Figure 3.12. Difference plots are given with respect to the simulation with the lowest integration error tolerance $\left(1 \times 10^{-5}\right)$ and the simulation with an integration error tolerance of $1 \times 10^{-1}$ is not shown in the difference plot as the errors are much larger than the other simulations. Table 3.17 compares the RMS errors compared to the simulation with the maximum integration error tolerance $\left(1 \times 10^{-5}\right)$. The table also includes the corresponding simulation time using an Intel $\AA$ Core ${ }^{\mathrm{TM}}$ i5-6500 CPU at $3.20 \mathrm{GHz}$ and $16.0 \mathrm{~GB}$ of RAM.

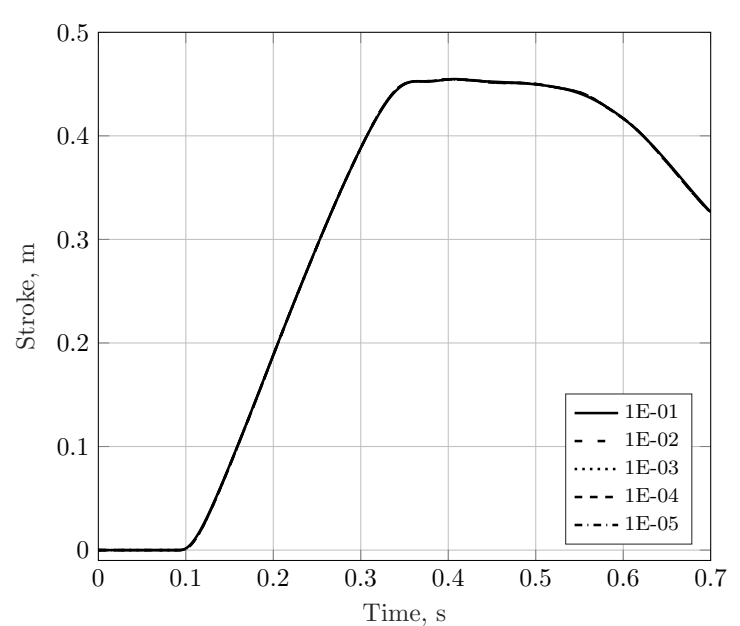

(a) Main landing gear stroke.

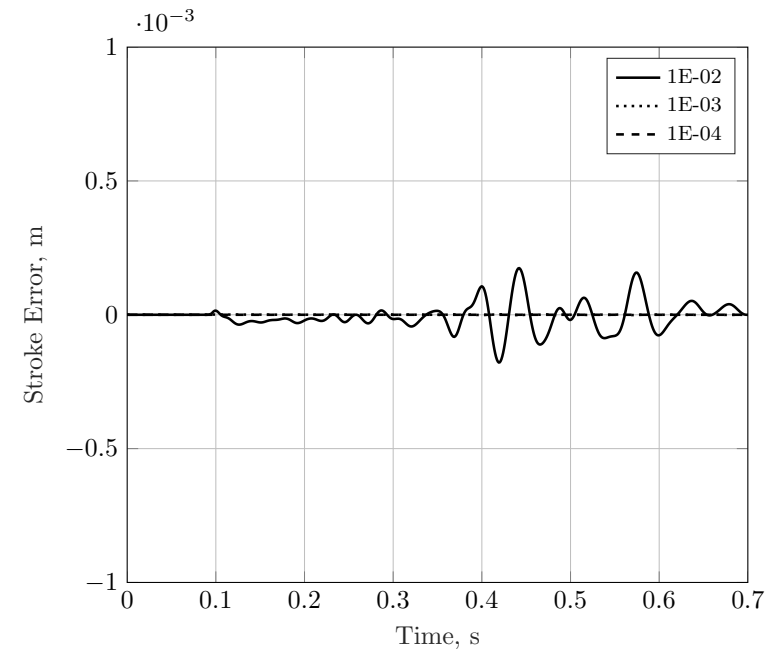

(b) Difference plot compared to the simulation with an integration error tolerance of $1 \times 10^{-5}$.

Figure 3.10: Simulated main landing gear stroke with various integration error tolerances. 


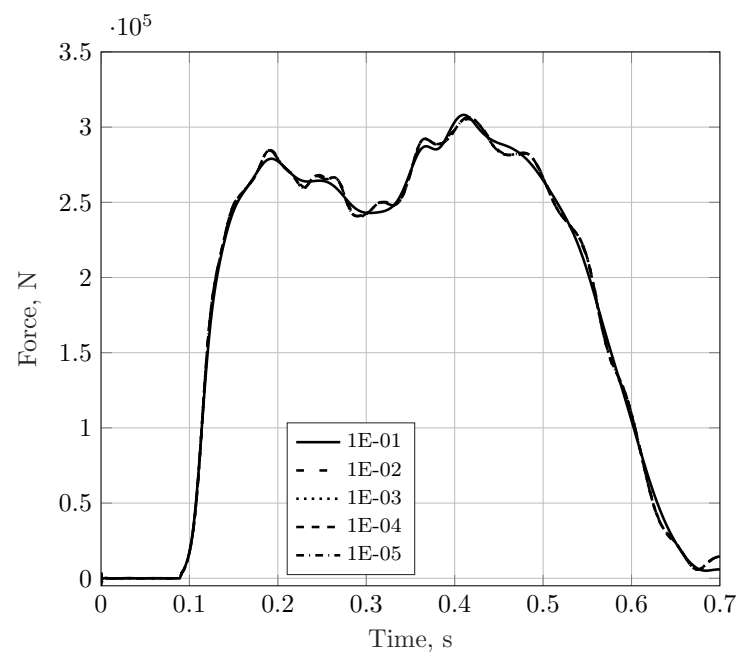

(a) Main landing gear force.

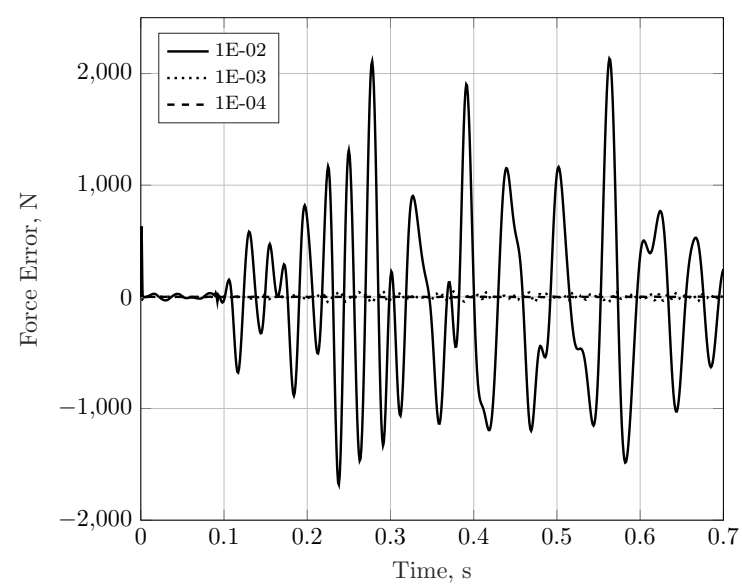

(b) Difference plot compared to the simulation with an integration error tolerance of $1 \times 10^{-5}$.

Figure 3.11: Simulated main landing gear force with various integration error tolerances.

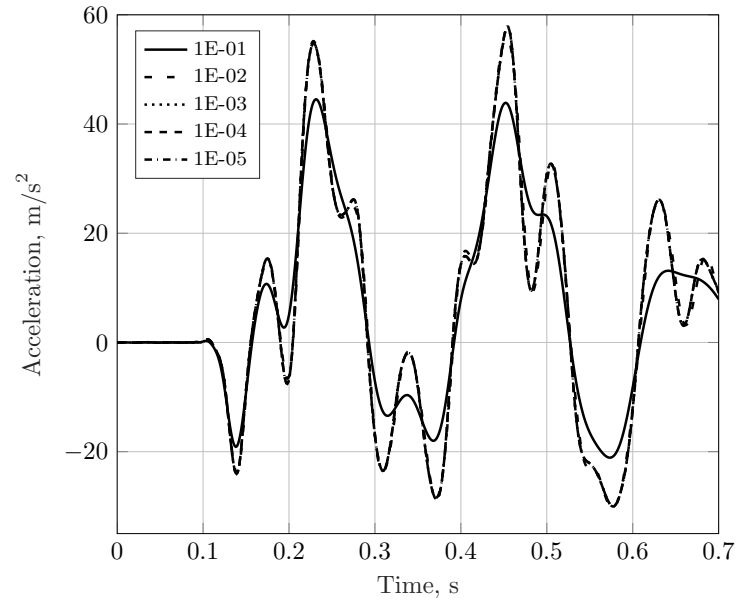

(a) Cockpit acceleration.

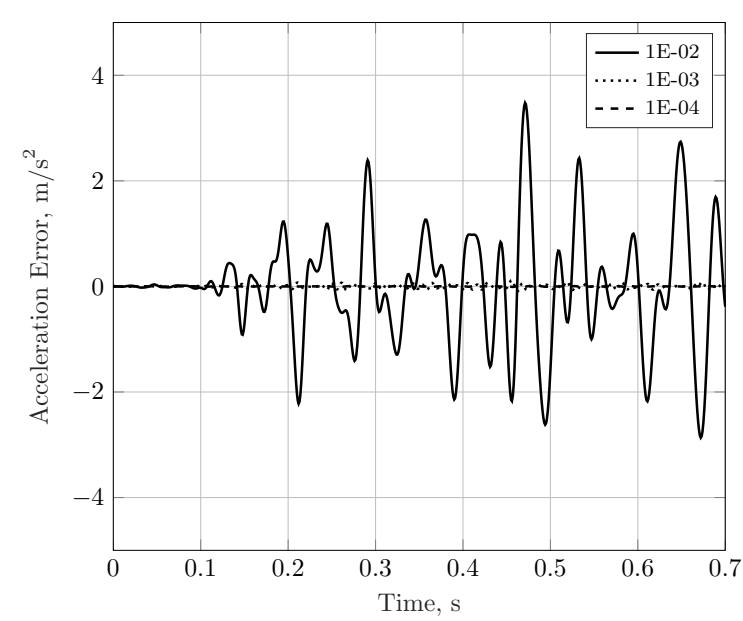

(b) Difference plot compared to the simulation with an integration error tolerance of $1 \times 10^{-5}$.

Figure 3.12: Simulated cockpit acceleration with various integration error tolerances. 
Table 3.17: Root mean square errors compared to simulation with a $1 \times 10^{-5}$ integration error tolerance with corresponding simulation time.

\begin{tabular}{ccccc}
\hline \hline & Sim Time & \multicolumn{3}{c}{ RMS Errors } \\
Error Tolerance & {$[\mathrm{s}]$} & Cockpit Accel. & MLG Stroke & MLG Force \\
\hline $1 \times 10^{-1}$ & 1.48 & $0.67 \mathrm{~g}$ & $468 \mu \mathrm{m}$ & $3.65 \mathrm{kN}$ \\
$1 \times 10^{-2}$ & 1.50 & $0.108 \mathrm{~g}$ & $51.6 \mu \mathrm{m}$ & $0.721 \mathrm{kN}$ \\
$1 \times 10^{-3}$ & 2.05 & $3.33 \times 10^{-3} \mathrm{~g}$ & $0.477 \mu \mathrm{m}$ & $0.0204 \mathrm{kN}$ \\
$1 \times 10^{-4}$ & 2.08 & $2.67 \times 10^{-4} \mathrm{~g}$ & $0.0353 \mu \mathrm{m}$ & $2.17 \times 10^{-3} \mathrm{kN}$ \\
$1 \times 10^{-5}$ & 2.73 & - & - & - \\
\hline \hline
\end{tabular}

It is concluded that an integration error tolerance of $1 \times 10^{-3}$ provides an acceptable trade-off between accuracy and computational efficiency. Smaller error tolerances result in relatively-small improvements in accuracy with as the cost of a longer simulation time. Although Table 3.17 shows a small change in the simulation time between the $1 \times 10^{-3}$ and $1 \times 10^{-4}$ integration error tolerances for this case of a nonlinear OP shock absorber, it was the author's experience that this difference was greater when using linear mechanical network shock absorbers.

\subsection{Initial Conditions: Landing Cases}

The basic set of conditions necessary for analysis of the landing loads are found in the regulatory requirements. The Regulations define the following scenarios: Level Landing Conditions (CARs 525.479), Tail-down Landing Conditions (CARs 525.481), One-gear Landing Conditions (CARs 525.483), and Side Load Conditions (CARs 525.485) [4. The requirements also state the necessity to test at a range of CG locations in order to obtain locations for which maximum design loads are reached. For the aircraft in this study, precise loading locations for fuel, passengers, and cargo are not known but needed in order to develop a range of CGs. However, the purpose of this study is not one where precise stressing of LG elements is required, such as for design, but rather to compare performance between shock absorber designs. Thus, only a nominal CG location is required and deemed sufficient for a comparative study.

The vertical speeds at landing for analysis are required to be $3.05 \mathrm{~m} \mathrm{~s}^{-1}$ at the MLM and $1.83 \mathrm{~m} \mathrm{~s}^{-1}$ at MTOM [4]. Ijff states that a larger forward speed increases spin-up time, 
which means a larger drag load is applied for a longer time, thus increasing the rotational moment and horizontal load [14]. However, Ijff ultimately concludes that only a single speed is needed in landing analysis as there is only a small change in the loads experienced over the typical landing speed range [14]. The CARs state that the landing forward speeds shall be between the stall speed at standard sea-level conditions, and the stall speed on a hot day at $23^{\circ} \mathrm{C}$ above standard for both Level and Tail-down Landing Conditions [4]. The forward speeds are the landing for this study were retrieved from the reference speeds for the aircraft given in reference [74].

Tail-down Landing conditions occur at either the stall angle or the angle for simultaneous ground contact of the MLG and tail structure. Since the stall angle is not known, the latter condition was selected and the value is given in Table 3.1. Thus, considering the relevant regulatory requirements and the guide for rational analysis from Ijff, a set of landing conditions was devised and is summarized in Table 3.18. It shall be noted that simulations of side-load and one-wheel landing need not be performed as the forces in these load cases are given in the Regulations as a percentage of the vertical loads obtained in the Level Landing Condition [4].

The purpose of the study is to compare the performance of various shock absorbers and not to ascertain loads for the stressing and design of the airframe. Thus, only a single scenario is necessary to compare the shock absorbers. The conditions corresponding to Case 4 (i.e. CARs 525.481 [4] for tail-down landing at MLM) shall be used for all simulations. Tail-down landing is the most common condition in practice and this condition also allows one to neglect the NLG parameters. This assumption is deemed valid as the NLG typically contacts the runway several seconds after the initial impact of the MLG and is outside of the typical landing impact window. All simulations were performed to observe the open-loop response, meaning that no controls or brakes were used for the duration of the simulation. 


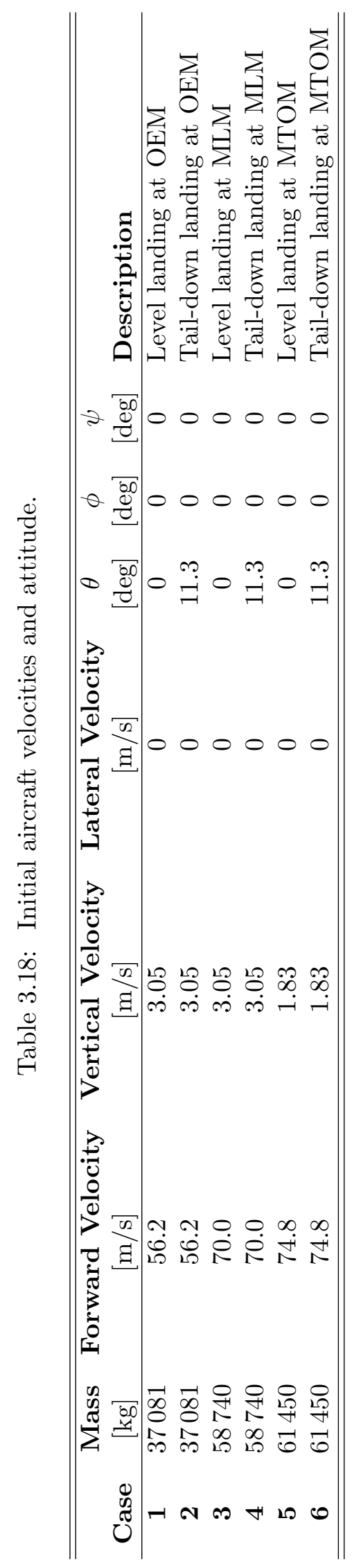




\subsection{Optimization Problem Setup}

There are two general goals of the optimization problem: to improve passenger comfort, and to improve the shock-strut performance. The quantification of these are detailed in the following two subsections.

\subsubsection{Comfort}

As detailed in Section 2.2.2, comfort under vibrational loading is dependent on both the magnitude and frequency content of an acceleration. A parameter that considers both the frequency and magnitude of an input acceleration is the DRI and was used as a single value to quantify comfort at landing; the DRI equation is derived in Section 2.2.2. The comfort was assessed at multiple locations throughout the fuselage. Thus, any comfort parameter in this study, including the DRI, was taken to be the arithmetic mean at the three fuselage stations (cockpit, mid-fuselage and aft-fuselage). The locations of these are given in Table 3.19 .

Table 3.19: Locations used to assess comfort.

\begin{tabular}{ccc}
\hline \hline & Fuselage Station, $x[\mathrm{~m}]$ & Node \\
\hline Cockpit & 2.00 & 11005 \\
Mid-fuselage & 15.0 & 11031 \\
Aft-fuselage & 27.0 & 11055 \\
\hline \hline
\end{tabular}

\subsubsection{Shock-Strut Performance}

Beyond contributing to comfort at landing, the shock-strut must efficiently absorb landing energy to avoid undue stressing of the airframe. A study by Li et al. [58, 59] quantified shock-strut performance using the peak vertical load, maximum stroke, and stroke efficiency. The stroke efficiency, $\eta_{s}$, is defined as

$$
\eta_{s}=\frac{\int_{0}^{s_{\max }} F(s) \mathrm{d} s}{s_{\max } F_{\max }}
$$

The maximum vertical force is used to size the structure adjacent to the LG attachment. Further, as indicated in Section 3.9, the peak vertical load is used in the side-load and one- 
wheel landing scenarios so minimizing the peak vertical force also minimizes the loads in other load cases. It was determined that the simulated maximum stroke length should not be included in the objective function as the maximum stroke length is a value that is fixed due to geometrical or performance constraints. For a linear shock-absorber model, such as a mechanical network, any solution that does not use the entire available stroke length is non-optimal as additional energy can be absorbed in the remaining stroke, or for the same energy absorbed, less force is required. Thus, including this metric encourages convergence to non-optimal solutions.

\subsubsection{Cost Function}

This optimization combines passenger comfort, quantified by the DRI, and the shock-strut performance, as quantified by the peak force and by the stroke efficiency. This forms a multi-objective optimization problem. In order to form a single objective optimization, scalarization factors must be established so the individual costs can be combined to form a single cost function. Ideally, these scalarization factors are such that a change in an input parameter will have the same change across all objectives. For this study, each cost will be scaled such that all three are of the same magnitude.

The DRI value is typically in the range of 2 to 4 and does not need further scaling. The stroke efficiency is typically between 0.5 and 1 and was multiplied by 2 and this produces typical scaled values in the range of 1 to 2 , which is in the same order of magnitude as the DRI. The peak force is typically 0.7 times the weight at landing [24] and, thus, the peak force (in N) was divided by the MLM (in $\mathrm{kg}$ ), $m_{L}$, to have a typical value around 7 . With these scalarization factors applied, all of the parameters have expected values of the same order of magnitude, thus providing similar representation in the cost function. The cost function, $f(\mathbf{x})$, is then given by

$$
f(\mathbf{x})=\frac{F_{\max }(\mathbf{x})}{m_{L}}+\operatorname{DRI}(\mathbf{x})-2 \eta_{s}(\mathbf{x})
$$

where $\mathbf{x}$ is the input parameter vector. The cost function was used in the optimization of any shock absorber and represents the combination of shock-strut performance and passenger 
comfort. 


\section{Chapter 4}

\section{Airframe Flexibility Effects}

\subsection{Flexibility Effects at Landing}

\subsubsection{Airframe Flexibility \\ Vertical Landing Gear Loads}

The literature review has shown that the inclusion of airframe flexibility may decrease the peak vertical loads during the landing impact (see Section 2.1.1). It was desired to observe the contributions of the wing flexibility, fuselage flexibility, and empennage flexibility that may alter the loading at landing. Simulations using an oleo-pneumatic shock absorber were performed at the MLM using a fully-rigid aircraft model, a model with flexible wings and rigid fuselage, a model with flexible wings and a flexible fuselage, and a fully-flexible model that includes flexibility of the empennage. The vertical load at the MLG for the various flexibility levels is plotted in Figure 4.1.

It is evident that the majority of the change in the loading is due to flexibility effects of the wings and fuselage, with negligible changes to the loading when including flexibility of the empennage. The inclusion of airframe flexibility both reduces the initial peak loading and results in greater variation in the instantaneous force about the nominal trend that is a consequence of modal excitations in the structure. It should be reiterated that the simulation occurs with the lift being equal to the weight and without the activation of any controls or brakes. As a result, the aircraft rebounds from the runway and this gives 


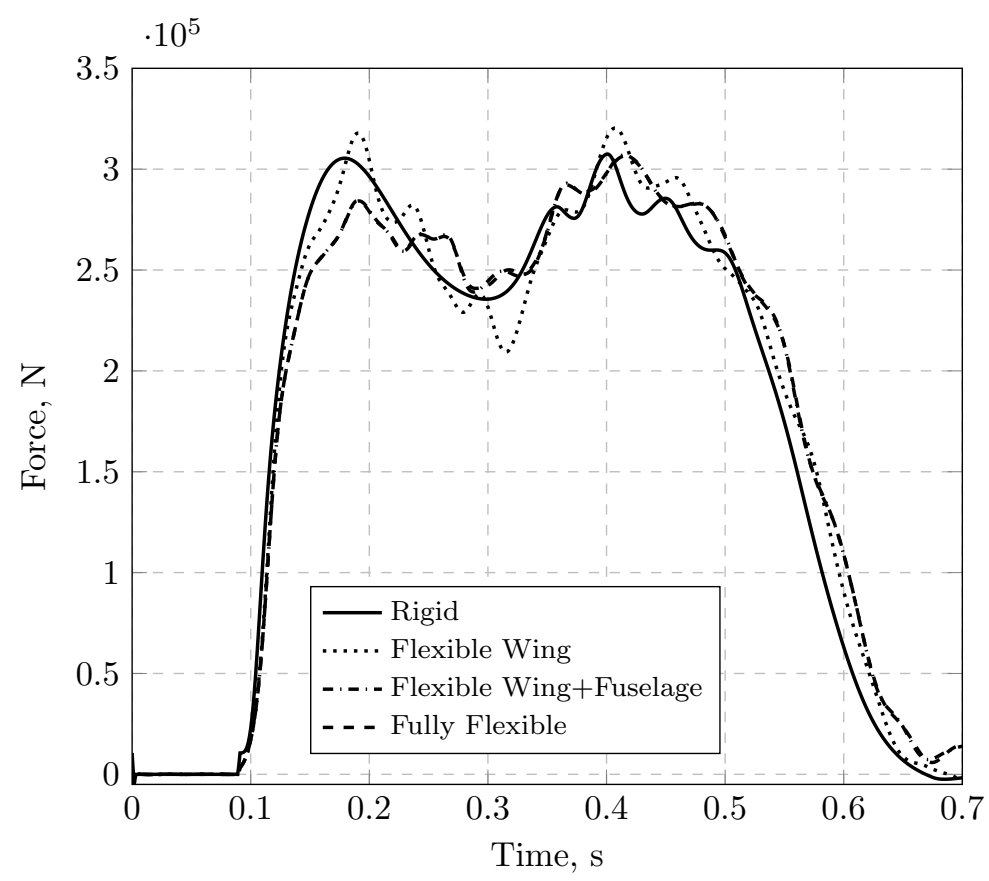

Figure 4.1: MLG force with varying levels of flexibility.

explanation to the behaviour towards the end of the time-histories in Figure 4.1.

\section{Accelerations in Fuselage}

It has been found in literature that the effect of airframe flexibility is commonly neglected in vibration control problems. However, it is conceivable that, since the loading regime changes when considering airframe flexibility, these effects will change the accelerations throughout the fuselage. To determine the effect of flexibility of each component, simulations with an oleo-pneumatic shock absorber were performed at the MLM using a fully-rigid model, a model with flexible wings and rigid fuselage, a model with flexible wings and a flexible fuselage, and a fully-flexible model. The accelerations in the cockpit for the various flexibility levels is plotted in Figure 4.2 .

In the rigid model, the acceleration in the cockpit follows the same trend as the input force. This is not the case for the flexible model. This phenomenon is explored further in Section 4.2. It can be seen in Figure 4.2 that with each level of flexibility, the response is quite different as a result of a different frequency response; this is a similar observation as made by Krüger in [47]. Since the acceleration response is different between each flexibility 


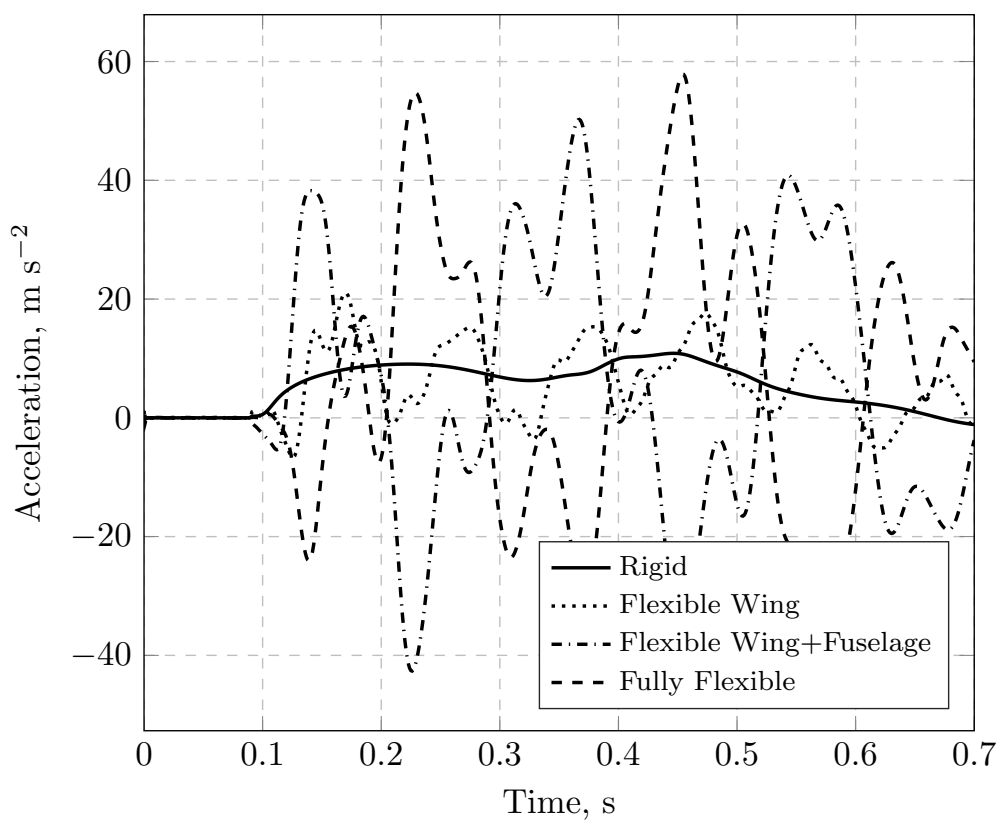

Figure 4.2: Cockpit acceleration with varying levels of flexibility.

level, so too will be the comfort response parameters. The comfort parameter values, as defined in Section 2.2.2, for each level of flexibility are given in Table 4.1 .

Despite the similar input loading regimes between the different flexible models, the comfort parameter values are quite different between the levels of flexibility. In general, the parameters tend to increase as the number of flexible components in the model is increased. This implies that each flexible component contributes additional eigenmodes with frequencies near the frequency content of the input loading or near resonant points of the response parameters. This result is intuitive as, in general, the FRF has a magnitude above the rigid-body response except for points of antiresonance. Since the frequency response is shown to be dependent on the flexibility levels, it is concluded that flexibility effects of all components must be considered for vibration control in an aircraft. It shall

Table 4.1: Comfort parameters in the cockpit for varying airframe flexibility levels.

\begin{tabular}{cccccc}
\hline \hline Flexibility Level & $\begin{array}{c}\text { DRI } \\
{[-]}\end{array}$ & $\begin{array}{c}\text { Peak Accel. } \\
{[\mathrm{g}]}\end{array}$ & $\begin{array}{c}\text { Peak Lumbar Accel. } \\
{[\mathrm{g}]}\end{array}$ & $\begin{array}{c}\text { BL PSD } \\
{\left[\mathrm{g}^{2} \mathrm{~Hz}^{-1}\right]}\end{array}$ & $\begin{array}{c}\text { Avg. Jerk } \\
{\left[\mathrm{g} \mathrm{s}^{-1}\right]}\end{array}$ \\
\hline Rigid & 1.19 & 1.11 & 1.05 & 0.00305 & 2.94 \\
Wings & 2.42 & 2.15 & 1.89 & 0.0274 & 52.9 \\
Wings \& Fuselage & 5.44 & 5.12 & 5.90 & 0.568 & 17.5 \\
Fully-Flexible & 6.53 & 5.90 & 7.09 & 0.462 & 74.9 \\
\hline
\end{tabular}


be noted that the comfort parameters referenced in the table are given for the cockpit only and will differ from the results of other studies given in Section 6.1 as those parameters are presented as the arithmetic mean of the comfort parameters in the cockpit, mid-fuselage, and aft-fuselage.

\subsubsection{Landing Gear Attachment Flexibility}

As discussed in Section 2.1.2, LG flexibility can affect the loading at landing. Literature states that these effects can be represented by an equivalent torsional spring at the attachment point, and the effects will have a significant effect on the torque at the attachment point. However, literature has shown that the attachment flexibility effects were negligible for the vertical LG force [29, 30, 27]. As the focus of the study is on the response of the vertical LG force and the accelerations throughout the fuselage, the effect of flexibility was investigated to confirm the conclusions in the literature.

The torsional stiffness of the equivalent spring at the wing-LG interface was arbitrarily selected to have a stiffness of $1 \times 10^{5} \mathrm{~N} \mathrm{~m} \mathrm{deg}^{-1}$, which results in a maximum spin-up deflection of $0.84 \mathrm{deg}$. To show the sensitivity of various response parameters of interest to the attachment stiffness, simulations were performed with a stiffness corresponding to half $(-50 \%)$ and double $(+100 \%)$ of the baseline value, and a rigid attachment. The response parameters include the maximum vertical force at the LG attachment, the average of the maximum acceleration at the cockpit, mid-fuselage and aft-fuselage, the maximum deflection angle of the MLG with respect to its equilibrium position, and the maximum torque at the MLG attachment point. The results are summarized in Table 4.2 .

The results of this study confirm the hypotheses of Section 2.1.2. The LG attachment flexibility has a significant effect on the spin-up angle and the torque at the LG attachment. However, the stiffness has a minor effect on the response of the accelerations and the vertical force at the LG attachment. Thus, it is concluded that the baseline stiffness value of $1 \times 10^{5} \mathrm{~N} \mathrm{~m} \mathrm{deg}^{-1}$ is sufficient to capture the spin-up and spring-back of the LG, as required by CARs 525.473(c)(2) [4]. Further refinement of the attachment stiffness is not necessary as the stiffness produces a minor effect on the response parameters of interest. 
Table 4.2: Percent differences of various response parameters compared to the baseline LG attachment stiffness.

\begin{tabular}{cccc}
\hline \hline & Half Stiffness & Double Stiffness & Rigid \\
\hline Max. Force & $-0.217 \%$ & $0.168 \%$ & $0.631 \%$ \\
Max. Avg. Acceleration & $1.41 \%$ & $-4.72 \%$ & $3.93 \%$ \\
Max. LG Deflection Angle & $166 \%$ & $-43.5 \%$ & $-100 \%$ \\
Max. Torque at LG Attachment & $32.9 \%$ & $13.1 \%$ & $-11.3 \%$ \\
\hline \hline
\end{tabular}

\subsection{Frequency Analysis}

The response of the structure to landing loads applied symmetrically at the MLG is required to observe the most-severe eigenmodes for passenger and pilot discomfort. Figure 4.3 provides the transfer frequency response function (FRF) to a $2 \times 10^{5} \mathrm{~N}$ vertical force applied symmetrically at each MLG attachment point $\left(4 \times 10^{5} \mathrm{~N}\right.$ force total), which is approximately $70 \%$ of the maximum landing weight and is the expected vertical force at landing [24]. The FRF is given at the same three fuselage stations used to assess passenger comfort to an input excitation at the MLG.

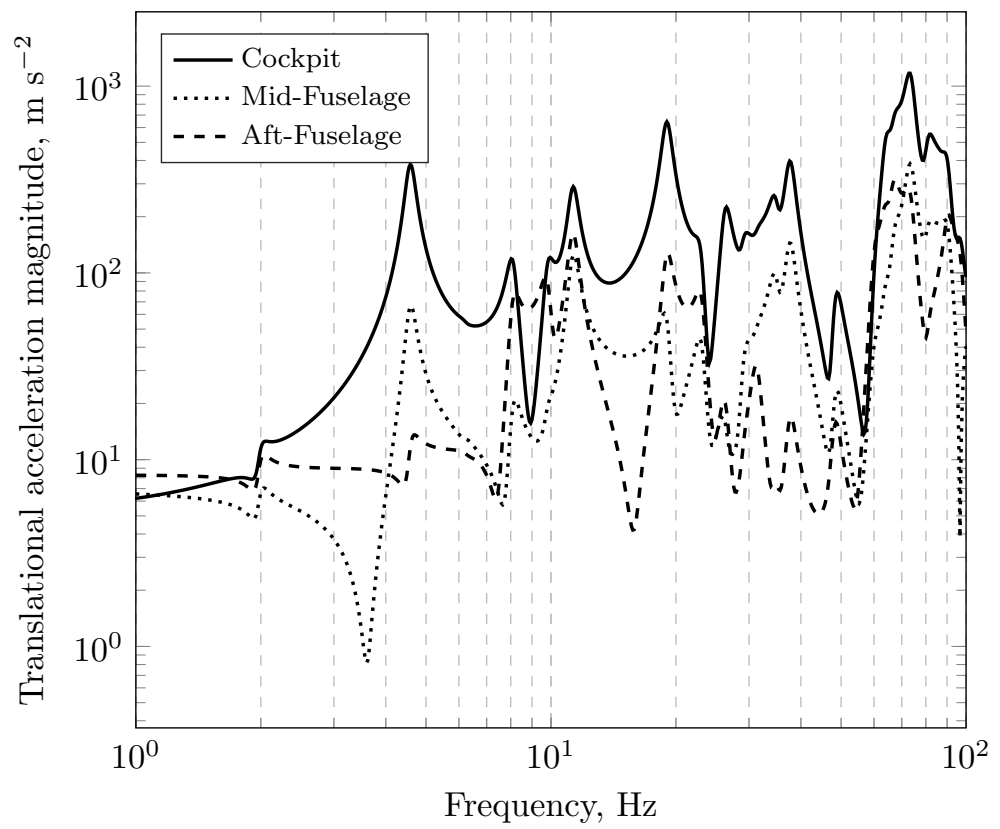

Figure 4.3: Translational acceleration magnitude FRF of excitation at MLG to various points along fuselage.

The frequency response of a rigid structure is constant and independent of the frequency. The acceleration at various points in the fuselage can be determined as a function of the 
Table 4.3: Acceleration at three fuselage stations in response to typical landing force for rigid airframe.

\begin{tabular}{ccc}
\hline \hline & Fuselage Station, $x[\mathrm{~m}]$ & Acceleration $\left[\mathrm{m} \mathrm{s}^{-2}\right]$ \\
\hline Cockpit & 2.00 & 4.50 \\
Mid-fuselage & 15.0 & 6.29 \\
Aft-fuselage & 27.0 & 7.95 \\
\hline \hline
\end{tabular}

input loading. The acceleration in the global $z$ direction results from the sum of that resulting from the translational acceleration and the rotational acceleration about the $\mathrm{CG}$ resulting from a force, $F$, as in

$$
a=\frac{F}{m}+\frac{F\left(x_{\mathrm{CG}}-x_{f}\right)}{I_{y y}}\left(x_{\mathrm{CG}}-x_{\mathrm{ref}}\right)=F\left(\frac{1}{m}+\frac{\left(x_{\mathrm{CG}}-x_{f}\right)\left(x_{\mathrm{CG}}-x_{\mathrm{ref}}\right)}{I_{y y}}\right)
$$

where $x_{\mathrm{CG}}=17.81 \mathrm{~m}$ and is the $x$-position of the centre of gravity, $x_{\text {ref }}$ is the $x$-position where the acceleration is calculated, and $x_{f}=18.74 \mathrm{~m}$ is the $x$ position of the applied force. At the MLM, the mass, $m$ is $58740 \mathrm{~kg}$ and the mass moment of inertia about the CG in the aircraft global axes is $I_{y y}=2.903 \times 10^{6} \mathrm{~kg} \mathrm{~m}^{2}$. For an input force $F=4 \times 10^{5} \mathrm{~N}$, the resulting accelerations at the three fuselage stations are given in Table 4.3 .

Comparing the acceleration magnitudes for the flexible airframe in Figure 4.3 to those for the rigid airframe in Table 4.3, it is evident that the accelerations are significantly different at higher frequencies. At low frequencies, the acceleration response is near that of a rigid airframe. However, as the frequency increases beyond the frequency of the first eigenmode of the structure, there are significantly higher acceleration magnitudes in the flexible airframe. This explains the observation in Section 4.1.1 where the landing forces are less in the flexible airframe but the accelerations are higher.

The FRF is integral to the evaluation of passenger comfort and for designing strategies to control vibratory loads in the airframe. The input-output PSD relationship states that the PSD of the output parameter, $\mathrm{PSD}_{\text {output }}$, is equal to the squared magnitude of the transfer function, TF, multiplied by the PSD of the input signal, $\mathrm{PSD}_{\text {input }}$, as in

$$
\mathrm{PSD}_{\text {output }}=(\mathrm{TF})^{2} \mathrm{PSD}_{\text {input }}
$$


The use of this relationship allows one to estimate and control the frequency content at a location of interest. In this case, the FRF magnitude plot acts as the transfer function. The FRF plot shows resonant points in the $4 \mathrm{~Hz}$ to $10 \mathrm{~Hz}$ range, which is generally associated with human discomfort [57]. Thus, one can form a control strategy in the LG to avoid output frequencies in the range of discomfort or near resonant frequencies of the structure.

\subsection{Observations and Conclusions}

This exercise examined the influence of the airframe flexibility effects in order to determine their significance during landing simulations. The flexible airframe model was not validated against flight test or ground vibration test data due to such data not being available and thus the results are dependent on the modelling assumptions. Since the model was developed using methods commonly seen in literature and industrial practice, it is expected that the model forms a first-order approximation with the results being typical of what would be observed for a regional jet aircraft class.

First considering the input vertical force applied to the aircraft, this investigation showed the need to consider flexibility effects as this influenced both the peak force and the loading regime when compared to the equivalent rigid model. A much greater difference was observed in terms of the acceleration response in the cockpit at landing. This large difference is explained by observing the acceleration frequency response to a vertical load applied at the MLG attachment point. The frequency response magnitude, in general, is greater than that of the rigid body response, and the difference is much more significant above $2 \mathrm{~Hz}$ (the frequency of the first flexible mode) and indicates the presence of power content in the frequency bands above $2 \mathrm{~Hz}$.

This exercise also observed the influence of the landing gear flexibility. An equivalent torsional spring was used at the attachment of the landing gear in order to capture these effects, which is a commonly-used method for a first-order approximation. Parameters such as torque at the LG attachment and the maximum deflection angle of the LG during spin-up showed a high sensitivity to the stiffness of the equivalent torsional spring. However, the vertical LG force and the response throughout the fuselage showed a small sensitivity. 
To conclude, CARs 525.473 (c)(4) states that landing analyses must consider the "Structural dynamic response of the airframe, if significant" [4]. Since this exercise demonstrated that airframe flexibility effects significantly altered the structural dynamic response, it is concluded that such effects must be included in this investigation. Further, the response parameters of interest to this study showed a small sensitivity to the flexibility of the LG attachment. However, these effects are included for the analysis to be compliant with CARs $525.473(\mathrm{c})(2)[4]$. 


\section{Chapter 5}

\section{Design and Synthesis of Shock}

\section{Absorbers}

\subsection{Baseline Oleo-pneumatic Performance}

The baseline performance of an OP shock absorber must be established to give a means of comparison for the other shock absorber designs. Given that the landing case in this study occurs symmetrically and the NLG does not contact the ground during the initial landing impact, NLG parameters were neglected from the analysis. The form of equations describing the OP force (see Eqs. 2.5 and (2.8) has two parameters that can be varied. Namely, these parameters are the air-spring coefficient, $F_{0}$, and the hydraulic damping coefficient, $C_{0}$. Therefore, optimization occurs in two-dimensions and a design of experiment (DOE) methodology was applied to visualize response surfaces in three-dimensions.

The cost function of the optimization problem is formed from the maximum LG force, the stroke efficiency, and the DRI. Response surfaces of the cost function and its three aforementioned constituents were plotted using a DOE methodology by forming a grid of 25 points evenly separated between the bounds in each dimension for a total of 625 test points. The air-spring coefficient was varied in the range from $10800 \mathrm{~N}$ to $28500 \mathrm{~N}$ and the

damping coefficient in the range from $5000 \mathrm{~N} \mathrm{~s}^{2} \mathrm{~m}^{-2}$ to $50000 \mathrm{~N} \mathrm{~s}^{2} \mathrm{~m}^{-2}$. The bounds on the air-spring coefficient were chosen to give a static deflection at the MTOM between $80 \%$ and 


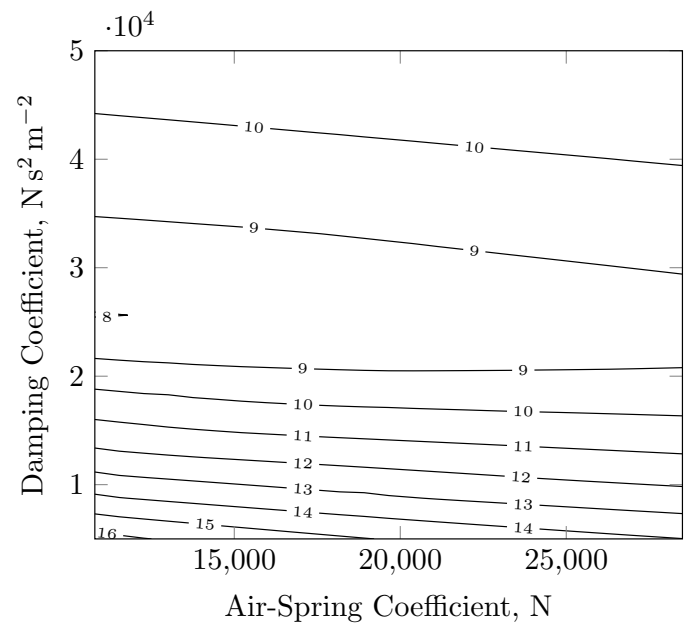

(a) Cost function response contour plot.

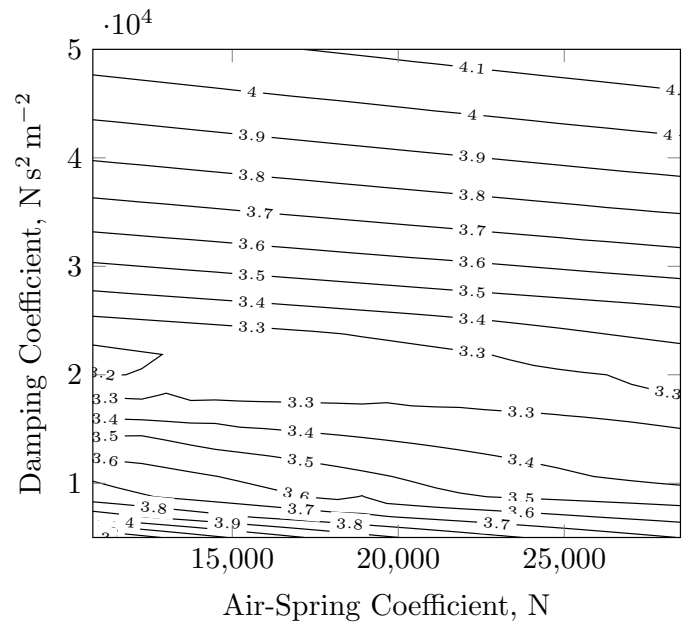

(c) DRI response contour plot.

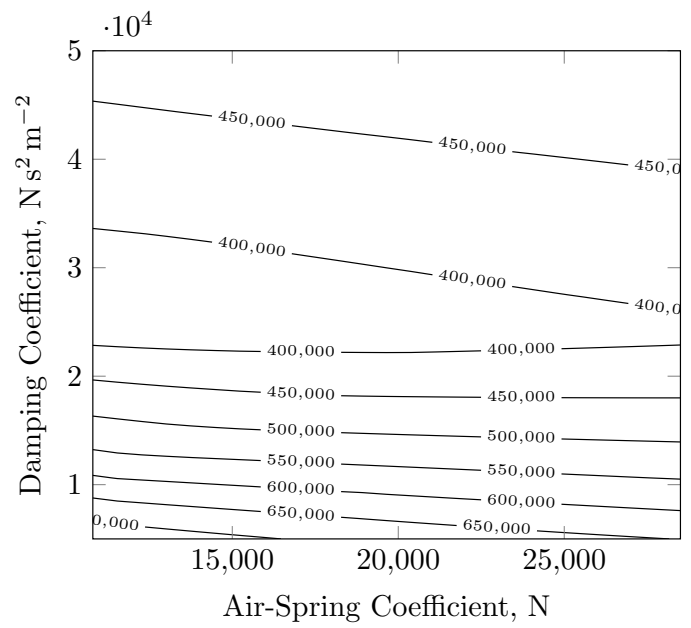

(b) Maximum force (in N) response contour plot.

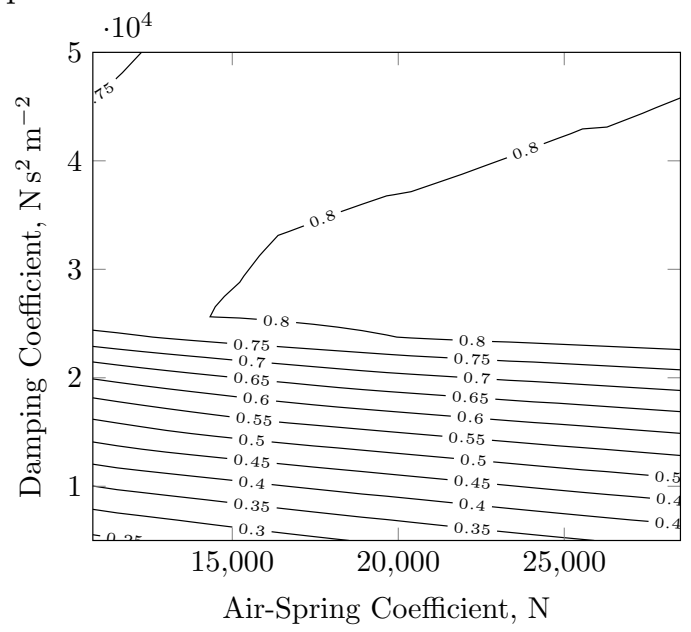

(d) Stroke efficiency response contour plot.

Figure 5.1: Response contour plots for OP shock absorber parameters.

$90 \%$ of the total stroke length, which is a typical range for transport-category aircraft [24].

The bounds on the damping coefficient were selected to be sufficiently wide to capture a minimum value. The resulting response contour plots are provided in Figure 5.1.

\subsubsection{Observations}

\section{Baseline Oleo-Pneumatic Performance}

The DOE study conducted on the baseline OP shock absorber both ensures that a true minimum was obtained within practical bounds and gives insight to the composition of the cost function by showing the optimal values of its constituents. Within these bounds, it was 
observed that the cost function has a minimum value just below 8, as seen in Figure 5.1a. The optimal point of the cost function was determined using patternsearch in MATLAB with the initial guess taken as the point with the lowest cost from the DOE grid and is given in Table 6.2 in Section 6.1. The resulting comfort parameters and strain energies are respectively given in Table 6.3 and Table 6.4 in Section 6.1. The optimizer converged to have a cost of 7.927 and thus it is concluded that a true minimum was obtained within the practical bounds.

The optimal values of the parameters forming the cost function can be observed to establish baseline optimal performance of the oleo-pneumatic shock absorber. First, in Figure $5.1 \mathrm{~b}$, it is observed that the smallest value corresponding to the peak force at the MLG has a value between $350 \mathrm{kN}$ to $400 \mathrm{kN}$. The peak force at the MLG tends to decrease as the air-spring force moves towards its minimum allowable value. In Figure $5.1 \mathrm{~d}$, the maximum value of the stroke efficiency is between 0.8 to 0.85 . The value tends to increase as the air-spring coefficient increases to its maximum value. Of note to this study is that the true-minimum of the DRI for the OP shock absorber is between 3.1 to 3.2 , as is evident in Figure 5.1c. The DRI tends to decrease as the air-spring coefficient decreases to its minimum allowable value at the boundary.

The optimal points for the cost, DRI, and maximum force are all at or near the boundary for the minimum allowable air-spring coefficient. Although this suggests the bounds may be too restrictive, the bounds are based on conventions for landing gear design from Currey [24]. These bounds are based on LG performance across a range of conditions, and not just taildown landing at MLM. For example, the air-spring force, as given by Eq. (2.8), follows a generally reciprocal relationship. If the air-spring coefficient is reduced, the static stroke will increase and approach the value of $s_{t}$. This results in both the air-spring force and its derivative to approach infinity, as in

$$
\begin{aligned}
\lim _{s \rightarrow s_{t}} F_{0}\left(1-\frac{s}{s_{t}}\right)^{-1.4} & =\infty \\
\lim _{s \rightarrow s_{t}} \frac{\mathrm{d}}{\mathrm{d} s}\left(F_{0}\left(1-\frac{s}{s_{t}}\right)^{-1.4}\right) & =\infty
\end{aligned}
$$


This has consequences for ground movement, such as taxiing, where small perturbations will result in a large change in force and does not allow for effective shock absorption. Thus, the minimum bound is deemed sufficient and need not be changed as this may only result in a slight improvement in performance. Similar behaviour is expected for other shock absorber designs, including mechanical networks. Thus, the conclusions of this study will not be altered such that the same restriction is imposed on all shock absorber designs.

\section{Frequency Content of Input Loading}

An understanding of the frequency content of input loading allows one to design control strategies. With knowledge of the FRF, one can apply the input-output PSD relationship to modify the frequency content of the loading at various fuselage stations in response to input at the LG. The PSD of the input loading from the OP baseline was found using a force window of data sampled at $1000 \mathrm{~Hz}$ and is shown in Figure 5.2 . In the figure, it is observed that most of the power of the input occurs in the frequency bands below $20 \mathrm{~Hz}$. This implies that frequency content above $20 \mathrm{~Hz}$ can generally be neglected. For example, zeros of the admittance function of a mechanical network should, in general, be placed below $20 \mathrm{~Hz}$.

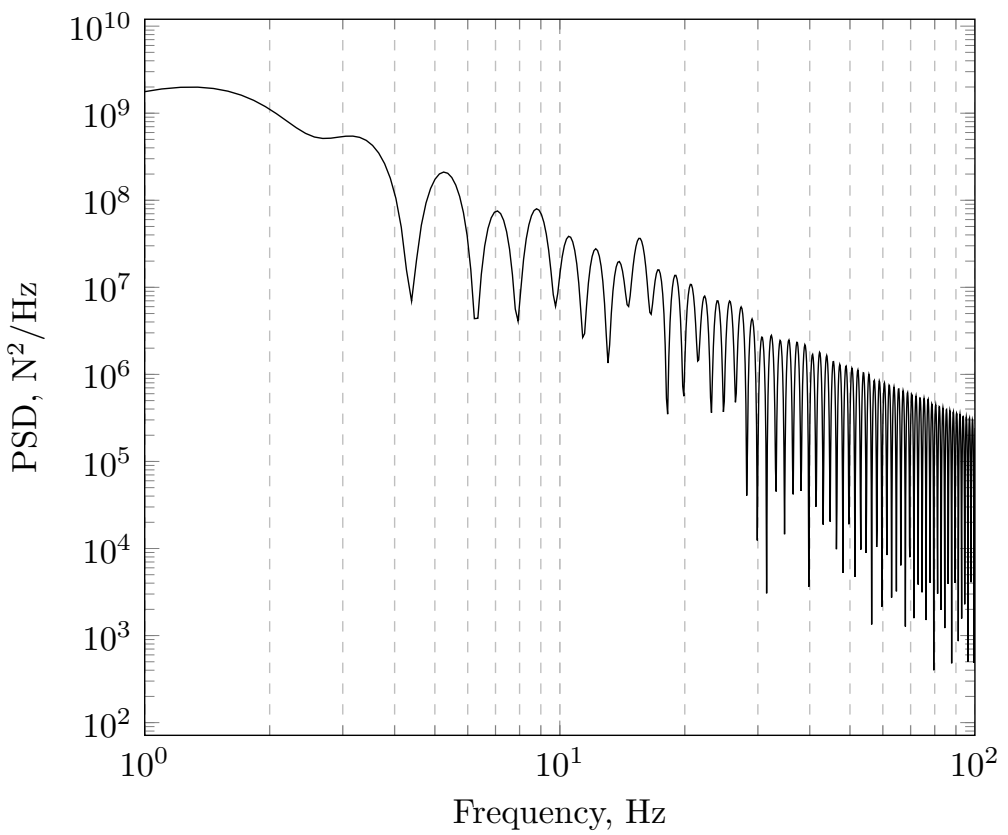

Figure 5.2: PSD of input force at the MLG for the OP baseline. 


\subsection{Optimization of Candidate Layouts}

The most common approach to the optimization of a mechanical network is to begin with a candidate arrangement and optimize the parameters with respect to a given cost function. Seven candidate mechanical network arrangements were retrieved from studies of vehicle suspensions and one arrangement was modified (arrangement L6 in Figure 5.3) for a total of eight candidate layouts in this study. All eight mechanical networks are given in Figure 5.3 . Arrangement L6-2 was modified from L6 by removing spring $k_{1}$ with reasoning for this is given in Section 5.2 .3 .

The corresponding admittance functions for the mechanical networks were derived and are listed as follows:

$$
\begin{aligned}
Q_{\mathrm{L} 1}(s) & =\frac{b_{1} c_{1}\left(k_{1}+k_{a}\right) s^{2}+b_{1} k_{1} k_{a} s+c_{1} k_{1} k_{a}}{s\left(c_{1} b_{1} s^{2}+k_{1} b_{1} s+k_{1} c_{1}\right)} \\
Q_{\mathrm{L} 2}(s) & =\frac{c_{1} b_{1} s^{2}+k_{a} b_{1} s+k_{a} c_{1}}{s\left(b_{1} s+c_{1}\right)} \\
Q_{\mathrm{L} 3}(s) & =\frac{b_{1} s^{2}+c_{1} s+k_{a}}{s} \\
Q_{\mathrm{L} 4}(s) & =\frac{b_{1}\left(k_{1}+k_{a}\right) s^{2}+c_{1}\left(k_{1}+k_{a}\right) s+k_{1} k_{a}}{s\left(b_{1} s^{2}+c_{1}+k_{1}\right)} \\
Q_{\mathrm{L} 5}(s) & =\frac{b\left(k_{1}+k_{a}\right)\left(c_{1}+c_{2}\right) s^{2}+\left(b_{1} k_{1} k_{a}+c_{1} c_{2}\left(k_{1}+k_{a}\right)\right) s+c_{1} k_{1} k_{a}}{s\left(b_{1}\left(c_{1}+c_{2}\right) s^{2}+\left(b_{1} k_{2}+c_{1} c_{2}\right) s+k_{1} c_{1}\right)} \\
Q_{\mathrm{L} 6}(s) & =\frac{b_{1} c_{2}\left(k_{1}+k_{a}\right) s^{2}+\left(b_{1} k_{1} k_{a}+c_{1} c_{2}\left(k_{1}+k_{a}\right)\right) s+\left(c_{1}+c_{2}\right) k_{1} k_{a}}{s\left(b_{1} c_{2} s^{2}+\left(b_{1} k_{1}+c_{1} c_{2}\right) s+k_{1}\left(c_{1}+c_{2}\right)\right)} \\
Q_{\mathrm{L} 6-2}(s) & =\frac{b_{1} c_{2} s^{2}+\left(c_{1} c_{2}+b_{1} k_{a}\right) s+k_{a}\left(c_{1}+c_{2}\right)}{s\left(b_{1} s+\left(c_{1}+c_{2}\right)\right)} \\
Q_{\mathrm{L} 7}(s) & =\frac{b_{1} c_{1} s^{2}+b_{1} k_{1} c_{1}\left(k_{1}+k_{a}\right) s+k_{1} k_{a}}{s\left(c_{1} s+k_{1}\right)}
\end{aligned}
$$

It is noted that Eq. (5.3c) and Eq. (5.3h) do not form proper transfer functions since the order of the numerator is greater than that of the denominator. In order to allow for simulation using a proper transfer function, the following transformation can be applied:

$$
F(s)=\frac{s}{s} V(s) Q(s)=A(s) \frac{Q(s)}{s}
$$

where $A(s)$ is the Laplace-transformed stroke acceleration. This forms a transfer function 
L1

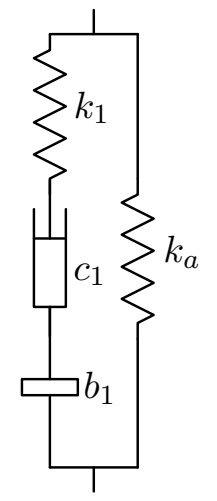

L5

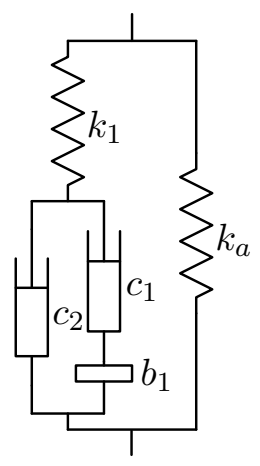

L2

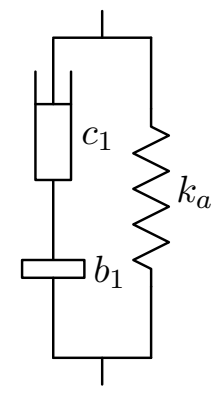

L6

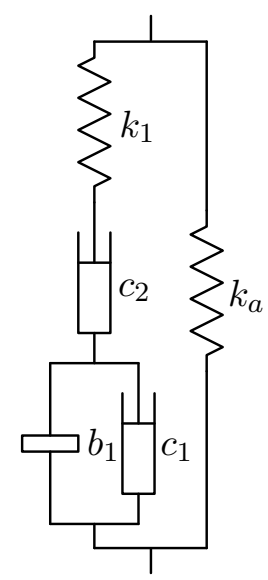

L3
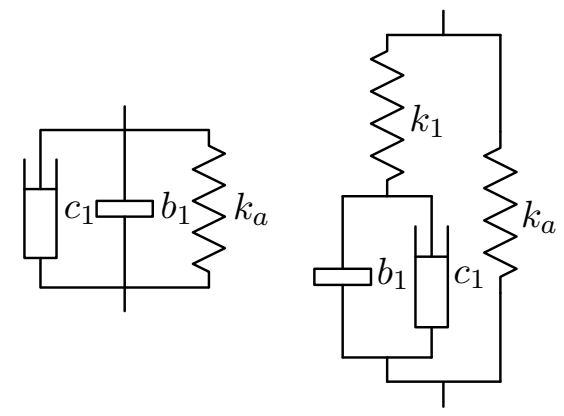

L6-2
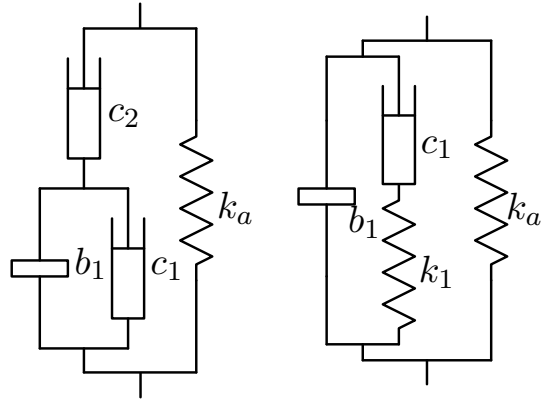

Figure 5.3: Candidate mechanical network arrangements. 
of the input stroke acceleration to output force and does not alter the locations of the poles and zeros.

One requirement of a candidate mechanical network is that it must contain a spring element to statically support the aircraft's weight. For transport category aircraft, the static stroke is typically $80 \%$ to $90 \%$ of the total stroke length [24]. The value of the spring constant, $k_{a}$, necessary for this was fixed to one that gives a static deflection of $85 \%$ of the total stroke length at the MTOM; a similar approach was used by Smith and Wang [3]. For a total stroke of $0.5 \mathrm{~m}$, a MTOM, $m_{0}$, of $61000 \mathrm{~kg}$, and assuming both MLG support $90 \%$ of the aircraft's weight (the static MLG loads vary between $89 \%$ to $94.5 \%$ of the weight [74]), the spring constant is

$$
k_{a}=\frac{0.9 m_{0} g}{(2)(0.85) s_{t}}=633610 \mathrm{~N} \mathrm{~m}^{-1}
$$

With the value of $k_{a}$ fixed, the remaining stiffness, damping, and inertance constants can be optimized with respect to the cost function given in Section 3.10.3. The following subsections outline the optimization procedure.

\subsubsection{Optimization Algorithm}

Two optimization algorithms were used from the same starting point. The first algorithm is fminsearch in MATLAB, which uses a Nelder-Mead simplex search method. A simplex search is prone to convergence at a local minimum near the initial guess. With the initial guess near a point believed to be a global minimum of the DRI, the use of a simplex search is believed to converge to a local minimum of the cost function that favours the DRI. This algorithm, however, is unbounded and may converge to unfeasible points.

The second algorithm is patternsearch in MATLAB, which is based on an adaptive mesh and can be bounded. This algorithm is not gradient based and explores around the starting point such that it is not as prone to converging to a local minimum as is a simplex search. This algorithm is believed to find a true minimum within the optimization bounds. Further discussion on the optimizer behaviour is contained in Section 5.2.3.

The converged points of both algorithms are compared based on their cost, and preference shall be given to points with lower stiffness, damping, and inertance constants. When 
these constants have lower values, they can be assumed to be smaller and of a lower weight, thereby improving the feasibility of the point.

\section{Optimization Bounds}

Bounds were placed on the stiffness, damping, and inertance values for the patternsearch algorithm such that the final points are physically realizable or feasible. Stiffness elements were constrained to have a maximum value corresponding to the equivalent stiffness of a steel rod with diameter $0.05 \mathrm{~m}$ and length $0.5 \mathrm{~m}$. To determine the upper bound of the damping constant, consider first the dashpot in Figure 5.4

The volumetric flow rate of the fluid displaced by the piston with a speed, $v$, and radius, $R$, is

$$
Q=v \pi R^{2}
$$

The pressure drop, $\Delta p$, across the channel through which the fluid flows is found using the Hagen-Poiseuille Equation, in the following modified form given by White in [87]

$$
\Delta p=\frac{128 Q L}{\pi d^{4}} \mu
$$

The equivalent damping coefficient, $c$, is then the ratio of the equivalent force due to the pressure drop to the speed of the piston, as in

$$
c=\frac{128 L A^{2} \mu}{\pi d^{4}}
$$

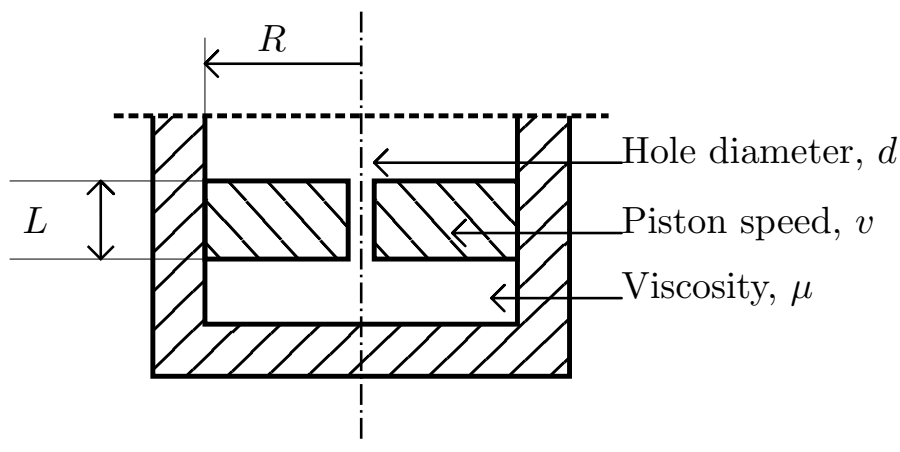

Figure 5.4: Diagram of a dashpot. 
Assuming a MIL-H-5606 hydraulic fluid at $15^{\circ} \mathrm{C}$ with a viscosity, $\mu$, of $12.7 \times 10^{-3} \mathrm{~Pa}-\mathrm{s}$ (as from [88]), a piston with a radius of $8 \mathrm{~cm}$, a channel length, $L$, of $5 \mathrm{~cm}$, and assuming the smallest practical hole diameter, $d$, that can be manufactured is $1 \mathrm{~mm}$, the theoretical maximum damping coefficient is

$$
c=\frac{128(0.05)\left(\pi 0.08^{2}\right)^{2}(0.0127)}{\pi(0.001)^{4}}=1.05 \times 10^{7} \mathrm{~N} \mathrm{~s} \mathrm{~m}^{-1}
$$

Accordingly, the upper bound of the damping coefficient is $10^{7} \mathrm{~N} \mathrm{~s} \mathrm{~m}^{-1}$, which represents a practical maximum given the desire to occupy a small volume in the landing gear and with consideration to the limits of manufacturability. Finally, Smith states that the mass of a mechanical inerter is approximately 300 times less than the inertance constant [2]. To avoid adding excessive mass to the aircraft, the maximum inertance constant was constrained to $10^{4} \mathrm{~N} \mathrm{~s}^{2} \mathrm{~m}^{-1}$, corresponding to an inerter with a mass of $33 \mathrm{~kg}$ [73lb]. The inequality constraints on the stiffness, damping, and inertance constants are as follows:

$$
\begin{gathered}
0 \mathrm{~N} \mathrm{~m}^{-1}<k_{i} \leq 10^{9} \mathrm{~N} \mathrm{~m}^{-1} \\
0 \mathrm{~N} \mathrm{sm}^{-1}<c_{i} \leq 10^{7} \mathrm{~N} \mathrm{~s} \mathrm{~m}^{-1} \\
0 \mathrm{~N} \mathrm{~s}^{2} \mathrm{~m}^{-1}<b_{i} \leq 10^{4} \mathrm{~N} \mathrm{~s}^{2} \mathrm{~m}^{-1}
\end{gathered}
$$

\section{Initial Guess}

Knowing the form of the admittance function for each candidate arrangement, parameters were selected to place a conjugate-pair zero at $8 \mathrm{~Hz}$. This method is believed to place the initial point near a global minimum of the DRI, which has a natural frequency of $8.4 \mathrm{~Hz}$ (see Figure 2.4 for the Bode magnitude of the DRI). The initial parameter values are provided in Table 5.1 .

\subsubsection{Results}

The results of the optimization, including the optimal points and the corresponding comfort parameter values and strain energies, are given in Section 6.1. Observations of the optimizer 
Table 5.1: Initial guesses for the optimization of the candidate mechanical networks.

\begin{tabular}{ccccc}
\hline \hline & $\begin{array}{c}\text { Stiffness Elements } \\
{\left[\mathrm{N} \mathrm{m}^{-1}\right]}\end{array}$ & \multicolumn{3}{c}{ Damping Elements } \\
& $k_{1}$ & $c_{1}$ & $c_{2}$ & $\begin{array}{c}\text { Inertance Elements } \\
{\left[\mathrm{N} \mathrm{s} \mathrm{s}^{-2} \mathrm{~m}^{-1}\right]}\end{array}$ \\
\hline L1 & $10^{8}$ & $10^{6}$ & - & $b_{1}$ \\
L2 & - & $10^{5}$ & - & 100 \\
L3 & - & $10^{3}$ & - & 300 \\
L4 & $10^{6}$ & 500 & - & 160 \\
L5 & $10^{6}$ & $10^{5}$ & 100 & 100 \\
L6 & $2 \times 10^{6}$ & 100 & $10^{5}$ & 153 \\
L6-2 & - & 100 & $8 \times 10^{4}$ & 190 \\
L7 & $10^{5}$ & $10^{4}$ & - & 500 \\
\hline \hline
\end{tabular}

behaviour and the converged transfer functions are made in the following sections as these are necessary to synthesize the custom transfer function in Section 5.3 .

\subsubsection{Observations}

\section{Optimizer Behaviour}

It was observed that the patternsearch tended towards an infinite spring stiffness when a spring element is in series with damping or inertance elements (i.e. for arrangements L1, L4, L5, L6, and L7). This trend can be explained by observing the behaviour of the transfer function for an arrangement consisting of a spring, $k_{1}$, in series with a damper, $c_{1}$, and these in parallel with a spring, $k_{a}$, necessary to provide static support. This arrangement has an admittance given by

$$
\frac{k_{a}}{s}+\frac{1}{\frac{s}{k_{1}}+\frac{1}{c_{1}}}=\frac{\left(k_{a} c_{1}+c_{1} k_{1}\right) s+k_{1} k_{a}}{s\left(c_{1} s+k_{1}\right)}
$$

When $k_{1}$ approaches infinity, this becomes a parallel arrangement of a spring and damper.

$$
\lim _{k_{1} \rightarrow \infty} \frac{\left(k_{a} c_{1}+c_{1} k_{1}\right) s+k_{1} k_{a}}{s\left(c_{1} s+k_{1}\right)}=\frac{c_{1} s+k_{a}}{s}
$$

Similarly, an arrangement consisting of a spring, $k_{1}$, in series with an inerter, $b_{1}$, and 
these in parallel with a spring, $k_{a}$, has an admittance given by

$$
\frac{k_{a}}{s}+\frac{1}{\frac{s}{k_{1}}+\frac{1}{b_{1} s}}=\frac{\left(k_{a}+k_{1}\right) b_{1} s^{2}+k_{1} k_{a}}{s\left(b_{1} s^{2}+k_{1}\right)}
$$

When $k_{1}$ approaches infinity, this becomes a parallel arrangement of a spring and inerter.

$$
\lim _{k_{1} \rightarrow \infty} \frac{\left(k_{a}+k_{1}\right) b_{1} s^{2}+k_{1} k_{s}}{s\left(b_{1} s^{2}+k_{1}\right)}=\frac{b_{1} s^{2}+k_{a}}{s}
$$

For the arrangements with a spring in series with an inerter or damper, the order of the denominator is greater than that of the numerator by one and the Bode slope as $s$ approaches infinity is non-zero and negative. As $k_{1}$ approaches infinity, a pole of the transfer function moves towards infinity, essentially reducing the order of the denominator. Therefore, it is concluded that including spring elements in series with damping or inertance elements tends to increase the order of the denominator of the transfer function.

In order to maximize stroke efficiency or reduce the peak loading, the ideal force versus stroke curve is one that is constant-valued. Since admittance functions with higher-ordered numerators tend to reduce the order of the response, an admittance function that has an equal-ordered numerator and denominator is ideal while remaining a proper transfer function. However, a constant force versus stroke behaviour is not the ideal behaviour when comfort parameters are considered. A constant force versus stroke curve has an instantaneous force onset, which will result in a large jerk and greater perceived discomfort. Therefore, the cost function represents a trade-off between shock-strut performance and passenger comfort. The weighting of these within the cost function will consequently affect the location of the global minimum. It was observed that the current weighting in the cost function favours the shock-strut performance.

Optimizations used two algorithms: an unconstrained simplex search using fminsearch and a constrained global pattern search using patternsearch in MATLAB. The starting values for the mechanical networks were selected to be near the global minimum of the DRI, which is expected to be near a local minimum of the cost function. It was generally observed that the fminsearch algorithm converged to a local minimum that favours pas- 
senger comfort and patternsearch converged to a minimum with a lower cost favouring shock-strut performance within practical parameter bounds. In general, patternsearch converged to the highest allowable spring stiffness for arrangements consisting of springs in series with other elements so the result from the fminsearch was used.

An example of an arrangement exhibiting this behaviour is L6, which converged to a local minimum that favoured passenger comfort when using fminsearch and a second minimum with lower cost when using patternsearch. The second minimum tended towards an infinite value for spring stiffness $k_{1}$. To observe the effect of an infinite stiffness, arrangement L6-2 was formed by removing $k_{1}$ from L6. Arrangement L6-2 had the lowest cost of all candidate shock absorbers and has similar performance to the OP baseline. L6-2 has an admittance given by a proper transfer function with a complex conjugate zero near $2 \mathrm{~Hz}$, thus resulting in an improvement in the DRI over the OP baseline.

\section{Behaviour of Optimized Transfer Functions}

The Bode magnitude diagrams of all optimized transfer functions are given in Figure 5.5 . The shock absorbers can be grouped by the form of their admittance function. Arrangements L1, L4, L5, and L6 are strictly proper transfer functions where the order of the numerator is one less than that of the denominator and their Bode magnitude plots are shown in Figure 5.5a. Arrangements L2 and L6-2 are proper transfer functions where the order of the numerator equals that of the denominator and their Bode magnitude plots are shown in Figure 5.5b. Finally, arrangements L3 and L7 are improper transfer functions where the order of the numerator is greater than that of the denominator and their Bode magnitude plots are shown in Figure 5.5c.

Arrangements L1, L4, L5, and L6 were in the form of a strictly proper transfer function and favoured comfort. All arrangements have conjugate-pair zeros between $9 \mathrm{~Hz}$ to $10 \mathrm{~Hz}$ with low damping (i.e. $\zeta<0.1$ ). L2 and L6-2 favour shock-strut performance over comfort and resemble spring-damper behaviour at high and low frequencies but have a conjugatepair zero near $2 \mathrm{~Hz}$. Finally, layouts L3 and L7 are in the form of an improper transfer function that does not have favourable performance in both categories of comfort and shockstrut performance. Considering these observations, it is concluded that a zero near $2 \mathrm{~Hz}$ 
approximates the ideal spring-damper behaviour and when that zero is a conjugate-pair zero, it provides some attenuation of structural modes to improve passenger comfort. Further, a conjugate-pair zero with low damping near $10 \mathrm{~Hz}$ provides attenuation of the frequencies near the resonant point of the DRI and provides the greatest benefit to passenger comfort.

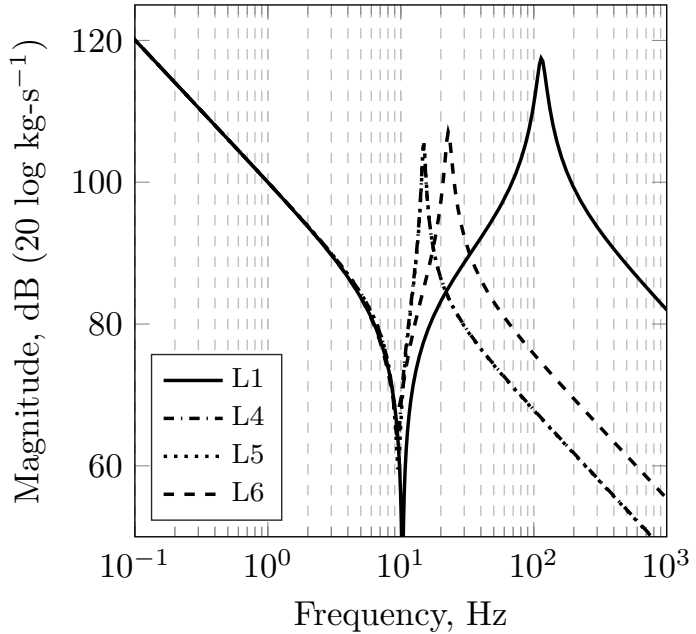

(a) Bode magnitude of arrangements favouring comfort.

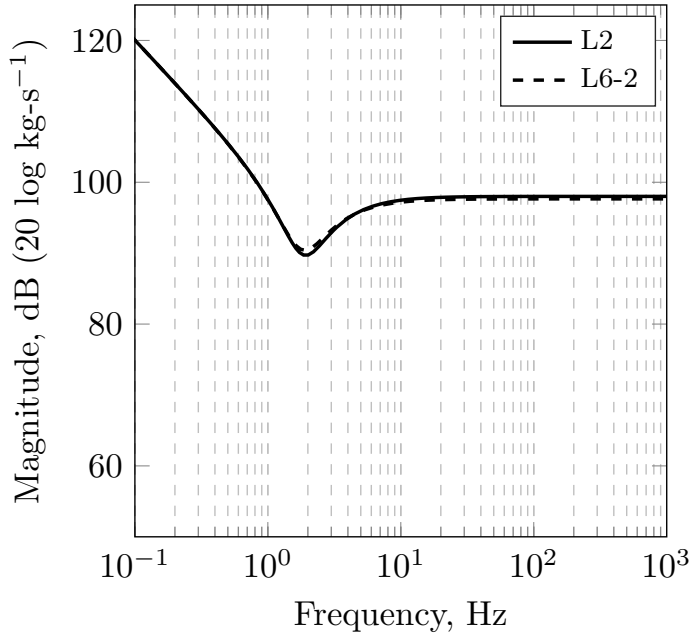

(b) Bode magnitude of arrangements favouring shock-strut performance.

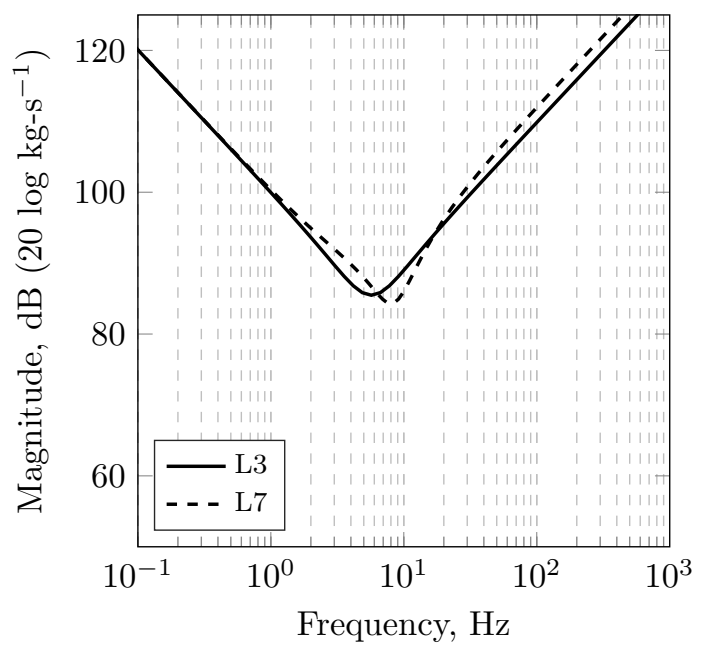

(c) Bode magnitude of arrangements L3 and L7.

Figure 5.5: Bode magnitude plots of all shock absorbers at converged point. 


\subsection{Synthesis of Mechanical Network with Idealized Response}

Instead of beginning from a given candidate mechanical network, one can design a mechanical network with a prescribed frequency response and then optimize the parameters with respect to a cost function. One can create a desired form of an admittance function considering the observations of the frequency content of the input loading discussed in Section 5.1.1, the frequency response of the airframe given in Section 4.2, and the behaviour of the candidate mechanical networks in Section 5.2.3. An admittance is sought with two conjugate-pair zeros to attenuate structural modes in the range generally associated with passenger discomfort. Further, it is desired that the admittance resemble spring-damper behaviour at high and low frequencies. An admittance of the following form accomplishes this:

$$
Q(s)=\frac{(s+a)\left(s^{2}+\omega_{1}^{2}\right)\left(s^{2}+\omega_{2}^{2}\right)}{s\left(d_{5} s^{4}+d_{4} s^{3}+d_{3} s^{2}+d_{2} s+d_{1}\right)}
$$

The impedance of $Q(s)$ is given by

$$
Z(s)=\frac{s\left(d_{5} s^{4}+d_{4} s^{3}+d_{3} s^{2}+d_{2} s+d_{1}\right)}{(s+a)\left(s^{2}+\omega_{1}^{2}\right)\left(s^{2}+\omega_{2}^{2}\right)}
$$

In Eq. 5.15, the $\frac{(s+a)}{s}$ factor approximates a spring and damper behaviour at high and low frequencies. $\left(s^{2}+\omega_{1}^{2}\right)$ and $\left(s^{2}+\omega_{2}^{2}\right)$ are conjugate-pair zeros for notch-filter behaviour. Finally, the $\left(d_{5} s^{4}+d_{4} s^{3}+d_{3} s^{2}+d_{2} s+d_{1}\right)$ term is required so the admittance is positive real and it is the same order as the combination of the conjugate-pair zeros so the high and low frequency behaviour is maintained. A two-terminal mechanical network consisting of springs, dampers, and inerters can be synthesized from a positive real function [2]. Thus, the following set of conditions is necessary to ensure $Q(s)$ is positive real:

1. If $d_{5}=0, d_{4} \neq 0$ so the difference in the highest power in the numerator and denominator is at most one;

2. $\left\{\omega_{1}, \omega_{2}, a, d_{1}, d_{2}, d_{3}, d_{4}, d_{5}\right\} \geq 0$

3. $\left\{\omega_{1}, \omega_{2}, a, d_{1}, d_{2}, d_{3}, d_{4}, d_{5}\right\} \in \mathbb{R}$;

4. $d_{1} \neq 0$ to prevent multiple poles at zero; 
5. $d_{1}, d_{2}, d_{3}, d_{4}, d_{5}$ are such that the roots do not have positive real parts.

First, consider a general positive real function, $z^{\prime}(s)$, that has a conjugate-pair pole

$$
z^{\prime}(s)=\frac{N(s)}{\left(s^{2}+\omega^{* 2}\right) D(s)}
$$

where $N(s)$ and $D(s)$ are polynomials of the appropriate degree. The conjugate-pair pole is removed by partial fraction decomposition

$$
z^{\prime}(s)=\frac{k_{1}}{s+j \omega^{*}}+\frac{k_{2}}{s-j \omega^{*}}+z_{1}^{\prime}(s)
$$

where $k_{1}$ is the residue of the pole at $s=-j \omega^{*}$ and $k_{2}$ the residue of the pole at $s=j \omega^{*}$. Since $z^{\prime}(s)$ is positive real, $k_{1}$ and $k_{2}$ are positive real and $k_{1}=k_{2}$ [89]. The remainder function, $z_{1}^{\prime}(s)$, is positive real and has the same poles as $z^{\prime}(s)$ but with removable singularities at $s= \pm j \omega^{*}$. Thus,

$$
z_{1}^{\prime}(s)=\frac{N(s)}{\left(s^{2}+\omega^{* 2}\right) D(s)}-\frac{2 k_{1} s}{s^{2}+\omega^{* 2}}=\frac{N^{\prime}(s)}{D(s)}
$$

This observation is applied to Eq. (5.16) with Brune's synthesis [69]. Since there are no poles at zero or infinity, the first step is to remove poles on the imaginary axis.

$$
Z(s)=\frac{2 K_{1} s}{s^{2}+\omega_{1}^{2}}+\frac{2 K_{2} s}{s^{2}+\omega_{2}^{2}}+z_{1}(s)
$$

where $z_{1}(s)$ is the remainder function and has the same poles as $Z(s)$ less $\left(s^{2}+\omega_{1}^{2}\right)$ and $\left(s^{2}+\omega_{2}^{2}\right)$ and is expressed as

$$
\begin{aligned}
& z_{1}(s)=\frac{s\left(d_{5} s^{4}+d_{4} s^{3}+d_{3} s^{2}+d_{2} s+d_{1}\right)}{(s+a)\left(s^{2}+\omega_{1}^{2}\right)\left(s^{2}+\omega_{2}^{2}\right)}-\frac{2 K_{1} s}{s^{2}+\omega_{1}^{2}}-\frac{2 K_{2} s}{s^{2}+\omega_{2}^{2}} \\
& z_{1}(s)=\frac{N^{\prime}(s)}{s+a}
\end{aligned}
$$

where $N^{\prime}(s)$ must be a polynomial of order 1. Eq. 5.22) is first substituted into Eq. 5.20, then observing the equivalency of the numerator in Eq. 5.16) and the expansion of the 
numerator in Eq. 5.20

$$
\begin{aligned}
& s\left(d_{5} s^{4}+d_{4} s^{3}+d_{3} s^{2}+d_{2} s+d_{1}\right) \\
= & \left(2 K_{1} s\right)(s+a)\left(s^{2}+\omega_{2}^{2}\right)+\left(2 K_{2} s\right)(s+a)\left(s^{2}+\omega_{1}^{2}\right)+N^{\prime}(s)\left(s^{2}+\omega_{1}^{2}\right)\left(s^{2}+\omega_{2}^{2}\right)
\end{aligned}
$$

Therefore, $N^{\prime}(s)$ must be of the following form:

$$
N^{\prime}(s)=K_{3} s
$$

where $K_{3}$ is constant valued. The decomposed form of Eq. (5.16) is

$$
Z(s)=\frac{2 K_{1} s}{s^{2}+\omega_{1}^{2}}+\frac{2 K_{2} s}{s^{2}+\omega_{2}^{2}}+\frac{K_{3} s}{s+a}
$$

The $\frac{2 K_{i}}{\left(s^{2}+\omega_{i}^{2}\right)}$ terms can be realized by a parallel arrangement of a spring and inerter

$$
\frac{2 K_{i} s}{s^{2}+\omega_{i}^{2}}=\frac{s}{b_{i} s^{2}+k_{i}}
$$

The spring and inertance constants are given by

$$
\begin{aligned}
k_{i} & =\frac{\omega_{i}^{2}}{2 K_{i}} \\
b_{i} & =\left(2 K_{i}\right)^{-1}
\end{aligned}
$$

for $i=1,2 . \frac{K_{3} s}{s+a}$ can be realized by the parallel arrangement of a spring and damper

$$
\frac{K_{3} s}{s+a}=\frac{s}{c_{1} s+k_{3}}
$$

The spring and damping constants are given by

$$
\begin{aligned}
k_{3} & =\frac{a}{K_{3}} \\
c_{1} & =K_{3}^{-1}
\end{aligned}
$$


The final form of the impedance is

$$
Z(s)=\frac{s}{b_{1} s^{2}+k_{1}}+\frac{s}{b_{2} s^{2}+k_{2}}+\frac{s}{c_{1} s+k_{3}}
$$

The corresponding admittance is

$$
\begin{gathered}
Q(s)=\left(\frac{s}{b_{1} s^{2}+k_{1}}+\frac{s}{b_{2} s^{2}+k_{2}}+\frac{s}{c_{1} s+k_{3}}\right)^{-1} \\
Q(s)= \\
\frac{\left(b_{1} s^{2}+k_{1}\right)\left(b_{2} s^{2}+k_{2}\right)\left(k_{3}+c_{1} s\right)}{s\left(b_{1} b_{2} s^{4}+\left(b_{1}+b_{3}\right) c_{1} s^{3}+\left(b_{1} k_{3}+b_{1} k_{2}+b_{2} k_{1}+b_{2} k_{3}\right) s^{2}+\left(c_{1} k_{1}+c_{1} k_{2}\right) s+k_{1} k_{2}+k_{1} k_{3}+k_{2} k_{3}\right)}
\end{gathered}
$$

The physical representation of this admittance function is shown in Figure 5.6 and shall hereafter be referred to as layout Syn1. It is important to note that this arrangement is not unique and is one of several possibilities. For example, a term with impedance in the form of $\frac{s}{d_{1} s+d_{2}}$ was taken to be a parallel arrangement of a spring and damper. However, this can be realized with a series arrangement of a damper, $c$, and inerter, $b$, in parallel with a spring, $k$, which has impedance $c b \frac{s}{b s+c(1+k b)}$. The inclusion of additional elements allows greater control of the impedance at the cost of increased complexity.

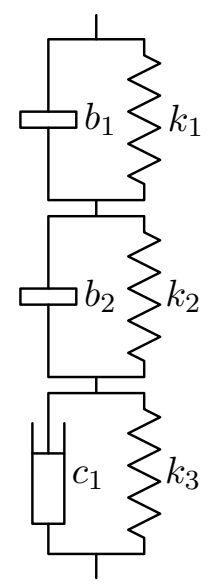

Figure 5.6: Mechanical network layout of Syn1. 


\subsubsection{Optimization}

\section{Constraints}

The optimization problem for Syn1 has the following set of constraints:

$$
\begin{aligned}
598410 \mathrm{Nm}^{-1} & \leq k_{1,2,3} \leq 10^{9} \mathrm{~N} \mathrm{~m}^{-1} \\
0 \mathrm{~N} \mathrm{~s} \mathrm{~m}^{-1} & <c_{1} \leq 10^{7} \mathrm{~N} \mathrm{~s} \mathrm{~m}^{-1} \\
0 \mathrm{~N} \mathrm{~s}^{2} \mathrm{~m}^{-1} & <b_{1,2} \leq 10^{4} \mathrm{~N} \mathrm{~s}^{2} \mathrm{~m}^{-1} \\
598410 \mathrm{Nm}^{-1} & \leq\left(k_{1}^{-1}+k_{2}^{-1}+k_{3}^{-1}\right)^{-1} \leq 673211 \mathrm{~N} \mathrm{~m}^{-1}
\end{aligned}
$$

The constraints of Eqs. (5.33a to (5.33c are the same as the candidate layouts. The nonlinear constraint of Eq. (5.33d) is necessary to ensure the landing gear can statically support the aircraft within the typical range of $80 \%$ to $90 \%$ static deflection at MTOM [24]. In addition, the following linear inequality constraints were implemented to control the placement of the conjugate-pair zeros:

$$
\begin{gathered}
(2 \cdot 2 \pi)^{2} \leq \frac{k_{1}}{b_{1}} \leq(6 \cdot 2 \pi)^{2} \\
(6.01 \cdot 2 \pi)^{2} \leq \frac{k_{2}}{b_{2}} \leq(12 \cdot 2 \pi)^{2}
\end{gathered}
$$

The constraint in Eq. (5.34a) places the first conjugate-pair zero in the range of $2 \mathrm{~Hz}$ to $6 \mathrm{~Hz}$, which corresponds to structural resonance. The constraint of Eq. 5.34b) places the second conjugate-pair zero in the range of $6.01 \mathrm{~Hz}$ to $12 \mathrm{~Hz}$, which corresponds to both structural resonance and the resonant point of the DRI.

\section{Optimization Algorithm}

Optimization occurs in six dimensions with nonlinear constraints. A multi-start algorithm was used to develop a set of local minima, from which a final point was selected. The starting points were randomly generated within the bounds of Eqs. (5.33a) to (5.34b) and then passed to patternsearch for optimization. 


\subsubsection{Results}

The results of the optimization, including the optimal point and the corresponding comfort parameter values and strain energies, are given in Section 6.1. 


\section{Chapter 6}

\section{Results and Discussion}

\subsection{Results}

\subsubsection{Converged Points}

Optimizations were performed on the parameters of the eight candidate mechanical networks using both of the fminsearch and patternsearch algorithms in $M A T L A B$, as described in Section 5.2.1. The converged points of both algorithms and the selected point with justification for the selection are provided in Table 6.1. The converged points and corresponding cost of all shock absorbers, including the OP shock absorber and the synthesized mechanical network, are summarized in Table 6.2 . 


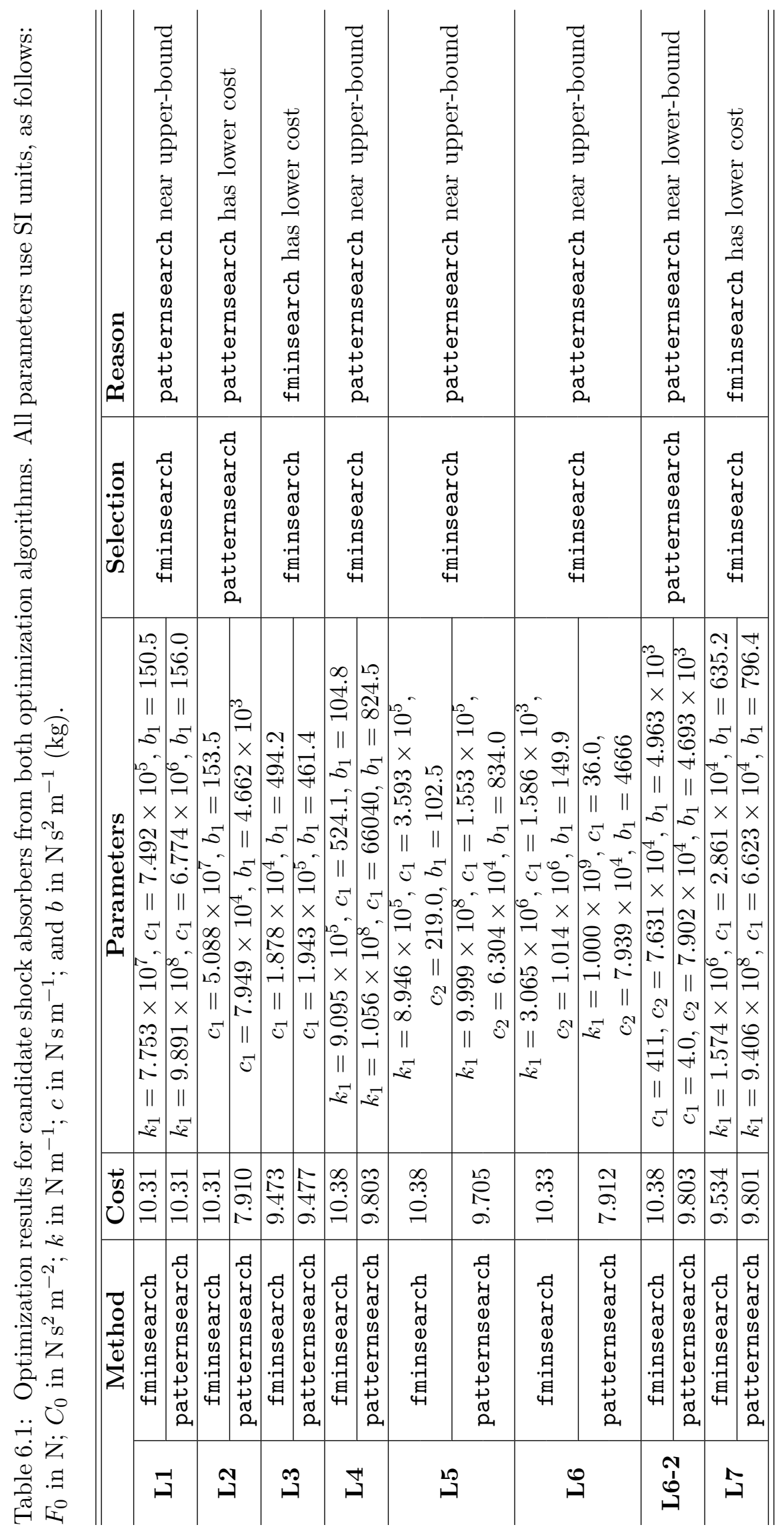


Table 6.2: Optimization results for all shock absorbers from best optimization algorithm. All parameters use SI units, as follows: $F_{0}$ in $\mathrm{N} ; C_{0}$ in $\mathrm{N} \mathrm{s}^{2} \mathrm{~m}^{-2} ; k$ in $\mathrm{N} \mathrm{m}^{-1} ; c$ in $\mathrm{N} \mathrm{s} \mathrm{m}^{-1}$; and $b$ in $\mathrm{N} \mathrm{s}^{2} \mathrm{~m}^{-1}(\mathrm{~kg})$.

\begin{tabular}{|c|c|c|c|c|c|}
\hline & $\begin{array}{c}\text { Cost } \\
{[-]}\end{array}$ & $\begin{array}{c}\text { DRI } \\
{[-]}\end{array}$ & $\begin{array}{l}\text { Max. Force } \\
{[\mathrm{N}]}\end{array}$ & $\begin{array}{c}\text { Stroke Eff. } \\
{[-]}\end{array}$ & Notes \\
\hline OP & 7.927 & 3.296 & 364600 & 0.7877 & $F_{0}=10805, C_{0}=25294$ \\
\hline L1 & 10.31 & 2.603 & 515600 & 0.5329 & $\begin{array}{l}k_{1}=7.753 \times 10^{7}, c_{1}=7.492 \times 10^{5}, \\
b_{1}=150.5\end{array}$ \\
\hline L2 & 7.910 & 3.202 & 378500 & 0.8674 & $c_{1}=7.949 \times 10^{4}, b_{1}=4.662 \times 10^{3}$ \\
\hline L3 & 9.473 & 2.882 & 467100 & 0.6804 & $c_{1}=1.878 \times 10^{4}, b_{1}=494.2$ \\
\hline L4 & 10.38 & 2.694 & 515100 & 0.5396 & $\begin{array}{l}k_{1}=9.095 \times 10^{5}, c_{1}=524.1 \\
b_{1}=104.8\end{array}$ \\
\hline L5 & 10.38 & 2.689 & 514900 & 0.5384 & $\begin{array}{l}k_{1}=8.946 \times 10^{5}, c_{1}=3.593 \times 10^{5} \\
c_{2}=219.0, b_{1}=102.5\end{array}$ \\
\hline L6 & 10.33 & 2.633 & 516000 & 0.5423 & $\begin{array}{l}k_{1}=3.065 \times 10^{6}, c_{1}=1.586 \times 10^{3} \\
c_{2}=1.014 \times 10^{6}, b_{1}=149.9\end{array}$ \\
\hline L6-2 & 7.900 & 3.207 & 379000 & 0.8791 & $\begin{array}{l}c_{1}=411, c_{2}=7.631 \times 10^{4} \\
b_{1}=4.963 \times 10^{3}\end{array}$ \\
\hline L7 & 9.534 & 2.979 & 468600 & 0.7108 & $\begin{array}{l}k_{1}=1.574 \times 10^{6}, c_{1}=2.861 \times 10^{4} \\
b_{1}=635.2\end{array}$ \\
\hline Syn1 & 7.790 & 2.889 & 383500 & 0.8142 & $\begin{array}{l}k_{1}=1.499 \times 10^{6}, k_{2}=2.967 \times 10^{6}, \\
k_{3}=1.499 \times 10^{6}, c_{1}=53280 \\
b_{1}=9345, b_{2}=722.9\end{array}$ \\
\hline
\end{tabular}

\subsubsection{Comfort Parameters}

The acceleration time-histories at three fuselage stations (cockpit, mid-fuselage, and aftfuselage) were recorded during the landing impact simulation. These were used in the calculation of various human comfort parameters. In all cases, the presented comfort parameter is the arithmetic mean at three fuselage stations.

Five comfort parameters were investigated in this study to quantify comfort and human perception of the landing loads corresponding to the loads from an optimized shock absorber. The values of these comfort parameters are given in Table 6.3. 
Table 6.3: Average comfort parameters at three fuselage stations for optimized shock absorbers.

\begin{tabular}{cccccc}
\hline \hline & $\begin{array}{c}\text { DRI } \\
{[-]}\end{array}$ & $\begin{array}{c}\text { Peak Seat Accel. } \\
{[\mathrm{g}]}\end{array}$ & $\begin{array}{c}\text { Peak Lumbar Accel. } \\
{[\mathrm{g}]}\end{array}$ & $\begin{array}{c}\text { BL PSD } \\
{\left[\mathrm{g}^{2} \mathrm{~Hz}^{-1}\right]}\end{array}$ & $\begin{array}{c}\text { Avg. Jerk } \\
{\left[\mathrm{g} \mathrm{s}^{-1}\right]}\end{array}$ \\
\hline OP & 3.296 & 3.302 & 3.767 & 0.1458 & 63.15 \\
L1 & 2.603 & 2.628 & 2.686 & 0.02527 & 22.51 \\
L2 & 3.202 & 2.598 & 2.923 & 0.1015 & 36.11 \\
L3 & 2.882 & 2.542 & 2.580 & 0.03934 & 15.13 \\
L4 & 2.694 & 2.551 & 2.625 & 0.02705 & 17.86 \\
L5 & 2.689 & 2.539 & 2.616 & 0.02703 & 17.96 \\
L6 & 2.633 & 2.730 & 2.749 & 0.02605 & 15.69 \\
L6-2 & 3.209 & 2.595 & 2.931 & 0.09899 & 36.05 \\
L7 & 2.979 & 2.614 & 2.721 & 0.04267 & 16.14 \\
Syn1 & 2.890 & 2.413 & 2.635 & 0.06200 & 17.00 \\
\hline \hline
\end{tabular}

\subsubsection{Strain Energy}

The strain energy time-history is recorded in MSC Adams, from which the maximum value of the strain energy can be determined. The values corresponding to the simulation of each shock absorber in this study are given in Table 6.4.

Table 6.4: Sum of peak forces at each landing gear attachment and peak strain energy.

\begin{tabular}{ccc}
\hline \hline & $\begin{array}{c}\text { Peak Force } \\
{[\mathrm{N}]}\end{array}$ & $\begin{array}{c}\text { Peak Strain Energy } \\
{[\mathrm{N} \mathrm{m}]}\end{array}$ \\
\hline OP & 364600 & 8853 \\
L1 & 515600 & 6727 \\
L2 & 378500 & 7394 \\
L3 & 467100 & 7793 \\
L4 & 515100 & 7175 \\
L5 & 514900 & 7598 \\
L6 & 516000 & 7401 \\
L6-2 & 379000 & 7059 \\
L7 & 468600 & 8472 \\
Syn1 & 383500 & 6428 \\
\hline \hline
\end{tabular}




\subsection{Discussion}

\subsubsection{Airframe Flexibility Effects}

The first step in this study was to examine the importance of airframe flexibility effects in capturing airframe dynamics at landing. A flexible airframe model was developed from information available in the public domain using techniques commonly found in literature and industrial applications. The results of this Thesis are ultimately dependent on the assumptions used in creating the model. In the absence of ground vibration test or landing flight test data to tune and validate the model, the flexible model represents a first-order approximation to capture the expected effects for a typical regional jet such as the Airbus A220-300. This study examined the influence of including airframe flexibility on the LG force time-history and the vibration response at landing in terms of the acceleration in the cockpit.

Airframe flexibility essentially behaves like a system of springs, masses, and dampers between the LG attachment and the CG of the aircraft. Accordingly, it was expected that this would absorb energy and reduce the magnitude of the peak force from the LG. This was observed in the simulations where there was a reduction in the peak force from the fully-flexible model when compared to a fully-rigid model. It is expected that a greater difference would be present for other aircraft classes, such as unmanned aerial vehicles, where the structures are often more flexible, and for aircraft where the MLG attachment point is farther laterally along the wingspan.

Despite the minor, albeit important, change in the MLG force time-history, a significant change was observed in the dynamics throughout the airframe, as exemplified by the acceleration time-history in the cockpit. The acceleration time-history for the rigid model generally followed the same trend as the input force at the LG attachment. However, the same was not observed for the fully-flexible model where the peak acceleration was not only larger, but the acceleration time-history was oscillatory, which was not the case for the rigid model. This can be explained by observing the frequency response of the airframe and the input power auto-spectrum. The frequency response of a rigid structure is constant, and the rigid body response of a flexible structure is the value found at a frequency of $0 \mathrm{~Hz}$. 
Thus, with the knowledge of the frequency response of the airframe as well as the input PSD, it was expected that greater accelerations would be observed throughout the airframe by applying the input-output PSD relation. This study demonstrated the importance of including airframe flexibility effects both for observing the input forces and the resulting structural dynamic response. Accordingly, airframe flexibility effects were considered for the other studies of this Thesis.

\subsubsection{Optimized Mechanical Networks}

The purpose of this study was to demonstrate the potential improved ability of mechanical networks to control vibration at landing touchdown compared to an OP baseline shock absorber. Thus, it is only necessary to prove the optimality of the OP baseline and any mechanical network design that has a lower cost function value than the baseline is deemed to have accomplished the purpose of this Thesis. Accordingly, it should be noted that the presented final points for all mechanical networks may only be local minima are not claimed to be the global minima. The performance of the OP baseline was demonstrated to be the global minimum within practical bounds, which allows for a valid comparative study between an OP baseline and mechanical networks. Thus, if the performance of a mechanical network at a local minimum exceeds that of the OP baseline, for which a global optimum was proven within practical bounds, it can be definitively concluded that the theoretical mechanical network performance exceeds that of the OP baseline and further global optimization is not necessary.

The candidate layouts in Section 5.2 demonstrate that for this problem, only one objective could be achieved where either improved shock-strut performance over the OP baseline is possible, or significantly reduced DRI is possible, but not both. Then, using the theorem of Smith [2], one can synthesize a mechanical network to achieve any positive real admittance. The synthesized mechanical network demonstrates one possible admittance and the corresponding mechanical network that can achieve both similar or improved shock-strut performance and improved comfort over the OP baseline.

The synthesized mechanical network has two conjugate-pair zeros with $\omega_{n_{1}}=2.01 \mathrm{~Hz}$, $\zeta_{1}=0, \omega_{n_{2}}=10.2 \mathrm{~Hz}$, and $\zeta_{2}=0$, as is evident in Figure 6.1. One can add additional 
conjugate-pair zeros through the series connection of spring-inerter parallels, thus forming an immittance function [71]. However, with additional elements, concerns arise for the total weight and for space constraints. Further, an immittance function has conjugate-pair poles between the conjugate-pair zeros where the output force would go to infinity, and this raises difficulty generating a robust set of poles and zeros that are valid across a range of aircraft weight configurations. This can be managed by controlling the damping at conjugate-pair poles by including damping elements in the network at the expense of increased weight and complexity.

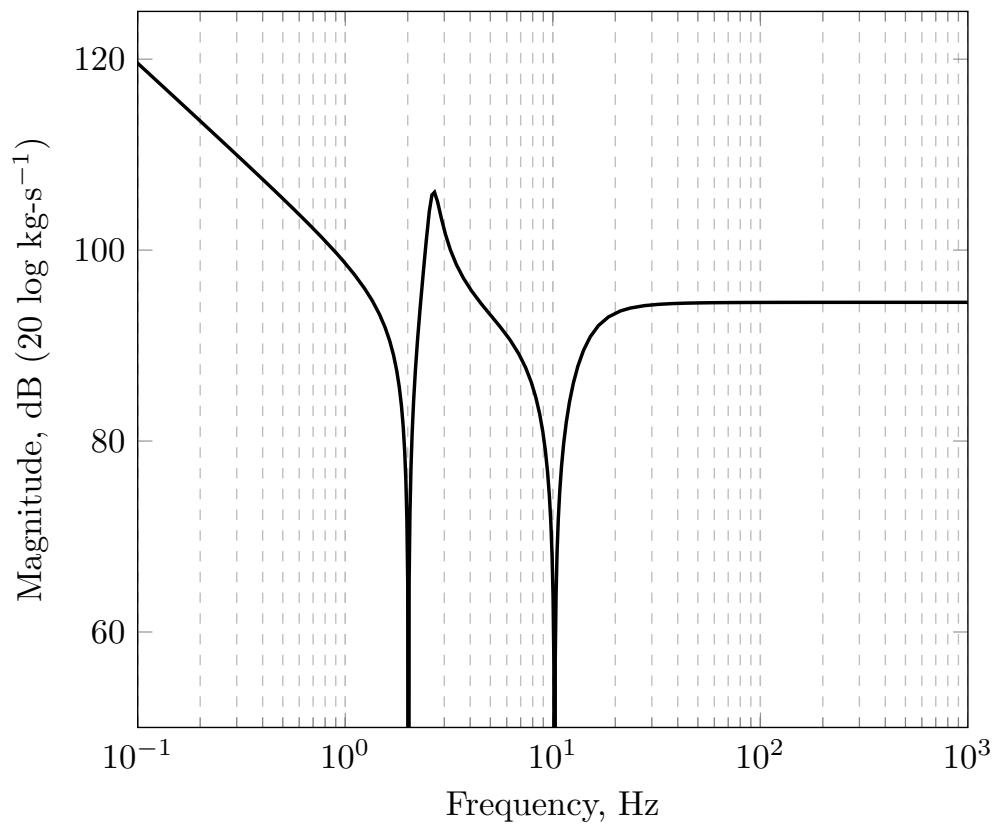

Figure 6.1: Bode magnitude plot of Syn1.

\subsubsection{Strain Energy}

The OP shock absorber had the lowest peak force out of all shock absorbers in this study. However, as this load is applied dynamically, it does not necessarily correlate to the stressing of the airframe. In order to quantify the total stressing, the peak strain energy during landing impact was observed. This considers inertia relief effects and the way in which the load is applied. The baseline OP loads resulted in greater peak strain energy. The ability of mechanical networks to filter frequency content both in specific bands and in higher frequencies allows the network to avoid the excitation of specific modes. A side effect of 
controlling the frequency content of the input loading was lower peak strain energy and, thus, lower airframe stressing.

It should be noted that, although important, the landing loads do not generally form the design load case used for the sizing of major aircraft components. Currey indicates that the load factor, or reaction factor, during landing is generally used to size the engine mounts and areas adjacent to the LG attachment 24] and Pérez at al. indicate that landing loads may form the design case for the fore- and aft-fuselage, and for wing-down bending [13]. Thus, minimizing both the peak force at the LG attachment and peak acceleration at specific points are crucial for component sizing and weight reduction more-so than minimizing the peak strain energy. Further, reducing the peak vertical force also reduces the forces used in other regulatory landing load cases. For example, the loads used in CARs 525.479(d) for drag loads, CARs 525.483 for one-gear landing loads, and CARs 525.485 for side loads are given as a percentage of the peak vertical force in the level landing condition. Accordingly, the peak force at the attachment was included in the cost function instead of the strain energy.

However, the peak force at the MLG is less than the load experienced statically for all arrangements in this study. The weight of the aircraft at the MTOW is $669 \mathrm{kN}$; assuming both MLG combine to support $90 \%$ of the static weight, the total vertical static load on the MLG is $602 \mathrm{kN}$. This result is expected as landing load factors in the range of 0.7 to 1.5 are typical for transport-category aircraft [24]. Since this aircraft model has a relatively large stroke, load factors near 0.7 were expected for optimized shock absorbers. As the peak vertical force is less than the static load, greater concern is placed on controlling the accelerations at specific points, such as along the fuselage or at the engines, in order to improve comfort or reduce the effective dynamic load. With knowledge of the frequency response of the structure, it can be concluded that a mechanical network can be synthesized for structural weight savings by controlling the frequency content of the input load such that accelerations are minimized at specific points through the aircraft. 


\subsubsection{Passenger and Crew Comfort}

The admittance functions that resulted in the best overall performance in improving comfort had a conjugate-pair zero in the range of $9 \mathrm{~Hz}$ to $10 \mathrm{~Hz}$ and were in the form of a strictlyproper transfer function such that high-frequency content is filtered. This admittance has the behaviour of a band-stop filter combined with a first-order low-pass filter. A stop-band in the $2 \mathrm{~Hz}$ to $12 \mathrm{~Hz}$ range both serves to avoid the peaks of the FRF (see Fig. 4.3) and the frequency range associated with human discomfort. The low-pass filter avoids highfrequency loading such that there is not a sudden load rise.

To quantify the overall comfort across all considered comfort parameters, parameters were normalized with respect to the highest value. Arrangement L5 resulted in the lowest average value and therefore is concluded to have the best comfort at touchdown for passengers and crew. The baseline OP shock absorber had the highest value across all considered comfort parameters and resulted in the least comfort at touchdown. L5, L6 and Syn1 have a DRI lower than 3.1 and this value is shown in Figure $5.1 \mathrm{c}$ to be the best value that can be achieved by the OP baseline regardless of the weighting in the cost function. As described in Sec. 5.2.3. there is a trade-off between shock absorber performance and passenger comfort, so the weighting of the cost function affects the location of the optimal point. Since the optimal points for L5, L6 and Syn1 result in a DRI lower than the true minimum for the OP baseline, it is concluded that the inclusion of inerters in mechanical networks can result in improved passenger and crew comfort.

Despite the high peak observed in the FRF near $35 \mathrm{~Hz}$, a conjugate-pair zero near that frequency does not have a significant benefit. As discussed in Sec. 5.1.1, the frequency content of the input loading is insignificant above $20 \mathrm{~Hz}$. Thus, conjugate-pair zeros in the $2 \mathrm{~Hz}$ to $12 \mathrm{~Hz}$ range have the greatest benefit for passenger comfort as this corresponds to excitable resonant points considering both the FRF and input PSD. 


\section{Chapter 7}

\section{Conclusions}

A fully-flexible airframe model for the multibody dynamic simulation of landings was generated using information available in the public domain. The inclusion of a fully-flexible airframe model was demonstrated to alter the structural dynamic response of the airframe when compared to the rigid equivalent model. Accordingly, the flexible model was used as the platform to analyze the ability of shock absorbers to control the structural dynamic response in this study.

A positive real impedance function can be formed from a mechanical network consisting of an arrangement of springs, dampers, and inerters to modify the frequency content of the input loads, thus improving the perceived passenger comfort and the structural dynamic response for a given objective. All mechanical networks in this study improved all considered human comfort parameters compared to an oleo-pneumatic shock absorber baseline. Therefore, mechanical networks can be synthesized with similar or improved shock-strut performance compared to oleo-pneumatic shock absorbers, with the added capability to control the frequency content of the input loads.

When considering passenger comfort or accelerations throughout an aircraft at landing, it is crucial to include airframe flexibility effects to capture the frequency response of the airframe to the input loading. With knowledge of the frequency response of the structure, the synthesized mechanical network can also control the acceleration response at various points along the structure for benefits including improved passenger and crew comfort at landing, and weight savings. 


\subsection{Contributions}

This Thesis makes the following contributions:

1. A flexible aircraft model was developed from information available in the public domain using a low-cost method.

2. The influence of airframe flexibility on response parameters, including landing gear loads and acceleration throughout the aircraft, was demonstrated using various levels of airframe flexibility.

3. A cost function was generated for the simultaneous optimization of shock-strut performance and passenger comfort.

4. A DOE methodology was applied to establish the baseline performance of a conventional oleo-pneumatic shock absorber.

5. The response through a flexible airframe and corresponding comfort parameters were shown to depend both on the magnitude and frequency content of the input loading.

6. Strategies were devised to modify the frequency content and magnitude of input loading, with vibrations quantified by human comfort metrics. This was accomplished in the following two ways:

(a) The parameters of candidate mechanical network layouts available in literature were optimized and were found to have either similar or improved shock-strut performance, or improved comfort compared to the oleo-pneumatic baseline. Both goals could not be achieved simultaneously by a candidate layout.

(b) A custom one-port (two-terminal) mechanical network including an inerter was synthesized to have a desired frequency response that has spring and damper behaviour at high and low frequencies and avoids resonant frequencies of the aircraft structure and the response comfort parameter. The custom mechanical network was shown to provide both similar or improved shock-strut performance and improved comfort compared to the oleo-pneumatic baseline. 


\subsection{Publications}

The following publications and presentations were generated from the work of this Thesis.

\section{Conference Presentations and Proceedings}

T. A. Stachiw, F. Khouli, R. G. Langlois, and F. F. Afagh, "The Effect of Airframe Flexibility on Dynamic Landing Gear Loads," presented at the CASI AERO 2019, Montreal, QC, 2019.

T. A. Stachiw, F. Khouli, R. G. Langlois, and F. F. Afagh, "The Use of an Inerter in an Aircraft Landing Gear Suspension for Improved Passenger and Crew Comfort at Touchdown," in AIAA SciTech 2020, Orlando, FL, 2020, AIAA-2020-1681. doi: 10.2514/6.20201681

\section{Journal Articles - In Review}

T. A. Stachiw, F. Khouli, R. G. Langlois, and F. F. Afagh, "Landing Gear Mechanical Network Synthesis for Improving Comfort at Landing Considering Aircraft Flexibility," Journal of Aircraft

\subsection{Future Work}

The following list outlines areas for future improvement of the work in the field of landing loads analysis and vibration control in the aircraft:

- Include other loading conditions in the analyses, including level landing and ground roll, which require consideration of the NLG parameters and altering the boundary conditions for the frequency response of the airframe.

- The effects of weight configurations, loading conditions, and initial conditions can be explored to evaluate the robustness of the mechanical network parameters as the current study explores a single weight and landing condition.

- A fully-flexible LG model can be included instead of LG flexibility effects represented by an equivalent torsional spring at the LG-wing attachment point. This will result 
in a stiffness that is dependent on the stroke position and increases as the stroke compresses.

- Aeroelastic effects at landing can be explored as the structural deformations caused by the landing impact can alter the local lift distribution along the wing.

- Active and semi-active shock absorbers have been explored for vibration control in rigid aircraft but the influence of a flexible airframe on their performance can be explored.

- The passive mechanical networks were shown to reduce the peak strain energy during landing by avoiding input loading frequencies near the resonant points of the airframe. Using the methodologies of Bronstein et al. [21] and Cumnuantip and Krüger [22, the stressing of the fore- and aft-fuselage can be evaluated under these different loading conditions to evaluate the potential for weight reductions. 


\section{Bibliography}

[1] Transportation Safety Board of Canada, "Statistical summary: Air transportation occurrences in 2018," Jul. 2019.

[2] M. Smith, "Synthesis of mechanical networks: The inerter," IEEE Transactions on Automatic Control, vol. 47, no. 10, pp. 1648-1662, Oct. 2002.

[3] M. C. Smith and F.-C. Wang, "Performance benefits in passive vehicle suspensions employing inerters," in Vehicle System Dynamics, vol. 42, no. 4, 2004, pp. 235-257.

[4] Transport Canada, "Canadian Aviation Regulations: Part V - Airworthiness Chapter 525 - Transport Category Aeroplanes," 2019.

[5] F. E. Cook and B. Milwitzky, "Effect of interaction of landing-gear behavior and dynamic loads in a flexible airplane structure," techreport NACA-TR-1278, Jan. 1956.

[6] Landing Gear Design Loads, no. 484. Advisory Group for Aeospace Research and Development, 1990.

[7] W. Krüger, I. Besselink, D. Cowling, D. Doan, W. Kortüm, and W. Krabacher, "Aircraft landing gear dynamics: Simulation and control," Vehicle System Dynamics, vol. 28, no. 2-3, pp. 119-158, Aug. 1997.

[8] J. Pritchard, "Overview of landing gear dynamics," Journal of Aircraft, vol. 38, no. 1, pp. 130-137, Jan. 2001.

[9] M. C. C. Bampton and R. R. J. Craig, "Coupling of substructures for dynamic analyses." AIAA Journal, vol. 6, no. 7, pp. 1313-1319, Jul. 1968. 
[10] K. H. Lyle, K. E. Jackson, and E. L. Fasanella, "Simulation of aircraft landing gears with a nonlinear dynamic finite element code," Journal of Aircraft, vol. 39, no. 1, pp. 142-147, Jan. 2002.

[11] C. E. Cesnik, R. Palacios, and E. Y. Reichenbach, "Reexamined structural design procedures for very flexible aircraft," Journal of Aircraft, vol. 51, no. 5, pp. 1580-1591, Sep. 2014.

[12] K. B. Lee, S. H. Jeong, J. Y. Cho, J. H. Kim, and C. Y. Park, "Hard-landing simulation by a hierarchical aircraft landing model and an extended inertia relief technique," International Journal of Aeronautical and Space Sciences, vol. 16, no. 3, pp. 394-406, Sep. 2015.

[13] J. L. Pérez, L. H. Benítez, M. Oliver, and H. Climent, "Survey of aircraft structural dynamics non-linear problems and some recent solutions," The Aeronautical Journal, vol. 115, no. 1173, pp. 653-668, Nov. 2011.

[14] J. Ijff, "Analysis of dynamic aircraft landing loads, and a proposal for rational design landing load requirements," PhD Thesis, Delft University of Technology, Jun. 1972.

[15] G. R. Doyle, "A review of computer simulations for aircraft-surface dynamics," Journal of Aircraft, vol. 23, no. 4, pp. 257-265, 1985.

[16] W. R. Krüger, "A multi-body approach for modelling manoeuvring aeroelastic aircraft during preliminary design," in Proceedings of the Institution of Mechanical Engineers, Part G: Journal of Aerospace Engineering, vol. 222, no. 6. SAGE Publications, Jun. 2008, pp. 887-894.

[17] P. V. Thomas, M. S. A. ElSayed, and D. Walch, "Review of model order reduction methods and their applications in aeroelasticity loads analysis for design optimization of complex airframes," Journal of Aerospace Engineering, vol. 32, no. 2, p. 04018156 , Mar. 2019. 
[18] G. Ghiringhelli and M. Boschetto, "Design landing loads evaluation by dynamic simulation of flexible aircraft," in Landing Gear Design Loads, no. 484. Advisory Group for Aeospace Research and Development, 1990.

[19] D. L. Brutto, F. Mastroddi, and V. D'Errioo, "Ground loads calculation of an aircraft flexible model," in MSC. ADAMS European Users Conference, 2002.

[20] P. D. Khapane, "Simulation of asymmetric landing and typical ground maneuvers for large transport aircraft," Aerospace Science and Technology, vol. 7, no. 8, pp. 611-619, Dec. 2003.

[21] M. Bronstein, E. Feldman, R. Vescovini, and C. Bisagni, "Assessment of dynamic effects on aircraft design loads: The landing impact case," Progress in Aerospace Sciences, vol. 78, pp. 131-139, Oct. 2015.

[22] S. Cumnuantip and W.R. Krüger, "Assessment of dynamic landing loads by a hybrid multibody / full finite element simulation approach," in German Aerospace Congress 2018. Deutsche Gesellschaft für Luft- und Raumfahrt - Lilienthal-Obert e.V., 2018.

[23] A. Castrichini, J. E. Cooper, T. Benoit, and Y. Lemmens, "Gust and ground loads integration for aircraft landing loads prediction," Journal of Aircraft, vol. 55, no. 1, pp. 184-194, Jan. 2018.

[24] N. S. Currey, Aircraft Landing Gear Design: Principles and Practices. American Institute of Aeronautics and Astronautics, 1988.

[25] B. Milwitzky and F. E. Cook, "Analysis of landing-gear behavior," techreport NACATN-2755, Aug. 1952.

[26] D. Yadav and R. P. Ramamoorthy, "Nonlinear landing gear behavior at touchdown," Journal of Dynamic Systems, Measurement, and Control, vol. 113, no. 4, p. 677, 1991.

[27] W. R. Krüger and M. Morandini, "Recent developments at the numerical simulation of landing gear dynamics," CEAS Aeronautical Journal, vol. 1, no. 1-4, pp. 55-68, May 2011. 
[28] R. Lernbeiss and M. Plöchl, "Simulation model of an aircraft landing gear considering elastic properties of the shock absorber," Proceedings of the Institution of Mechanical Engineers, Part K: Journal of Multi-body Dynamics, vol. 221, no. 1, pp. 77-86, Mar. 2007.

[29] X.-H. Wei, C.-L. Liu, X.-C. Song, H. Nie, and Y.-Z. Shao, "Drop dynamic analysis of half-axle flexible aircraft landing gear," Journal of Vibroengineering, vol. 16, no. 1, 2014.

[30] X. Wei, C. Liu, X. Liu, H. Nie, and Y. Shao, "Improved model of landing-gear drop dynamics," Journal of Aircraft, vol. 51, no. 2, pp. 695-700, Mar. 2014.

[31] P. D. Khapane, "Simulation of landing gear dynamics using flexible multi-body methods," in 25th International Congress of the Aeronautical Sciences, vol. 6, Hamburg, Germany, 2006, pp. 3698-3707.

[32] F. Caputo, A. D. Luca, A. Greco, S. Maietta, A. Marro, and A. Apicella, "Investigation on the static and dynamic structural behaviors of a regional aircraft main landing gear by a new numerical methodology," Frattura ed Integrità Strutturale, vol. 12, no. 43, pp. 191-204, Dec. 2017.

[33] R. D. Leo, A. D. Fenza, M. Barile, and L. Lecce, "Drop test simulation for an aircraft landing gear via multi-body approach," Archive of Mechanical Engineering, vol. 61, no. 2, pp. 287-304, Aug. 2014.

[34] Y. Guan, Z. Xue, M. Li, and H. Jia, "A numerical-experimental method for drop impact analysis of composite landing gear," Shock and Vibration, vol. 2017, pp. 1-11, 2017.

[35] P. Nguyen, S. Mak, and J. Panza, "Simulation of landing events for an unconventional UAV landing gear system using transient dynamics approach," in $4^{\text {rth }}$ AIAA/ASME/ASCE/AHS/ASC Structures, Structural Dynamics, and Materials Conference. American Institute of Aeronautics and Astronautics, May 2006. 
[36] W. R. Krüger and S. Cumnuantip, "A hybrid approach for the analysis of aircraft ground loads," in International Forum on Aeroelasticity and Structural Dynamics, 2019 .

[37] E. Denti and D. Fanteria, "Models of wheel contact dynamics: An analytical study on the in-plane transient responses of a brush model," Vehicle System Dynamics, vol. 34, no. 3, pp. 199-225, Sep. 2000.

[38] A. Alroqi and W. Wang, "Comparison of aircraft tire wear with initial wheel rotational speed," International Journal of Aviation, Aeronautics, and Aerospace, 2015.

[39] R. H. Daugherty, "A study of the mechanical properties of modern radial aircraft tires," Hampton, Virginia, techreport NASA/TM-2003-212415, May 2003.

[40] R. F. Smiley and W. B. Horne, "Mehanical properties of pneumatic tires with special reference to modern aircraft tires," Tech. Rep. Technical Note 4110, 1958.

[41] R. Kiébré, "Contribution to the modelling of aircraft tyre-road interaction," phdthesis, Université de Haute Alsace - Mulhouse, Dec. 2010.

[42] E. Fiala, "Seitenkraften am rollenden luftreifen," VDI, vol. 96, pp. 973-979, 1954.

[43] MSC Software Corporation, Using Aircaft Tire Models, 2019.

[44] H. Pacejka, Tire and Vehicle Dynamics, 3rd ed. Elsevier Science \& Technology, 2012.

[45] M. van Slagmaat, "Tire models in aircraft landing gear simulation," Vehicle System Dynamics, vol. 21, no. sup001, pp. 108-115, Jan. 1991.

[46] M. Castellani, J. E. Cooper, and Y. Lemmens, "Flight loads prediction of high aspect ratio wing aircraft using multibody dynamics," International Journal of Aerospace Engineering, vol. 2016, pp. 1-13, 2016.

[47] W. Krüger, "DESIGN AND SIMULATION OF SEMI-ACTIVE LANDING GEARS FOR TRANSPORT AIRCRAFT," Mechanics of Structures and Machines, vol. 30, no. 4, pp. 493-526, Jan. 2002. 
[48] H. Wang, J. Xing, W. Price, and W. Li, "An investigation of an active landing gear system to reduce aircraft vibrations caused by landing impacts and runway excitations," Journal of Sound and Vibration, vol. 317, no. 1-2, pp. 50-66, Oct. 2008.

[49] M. Zapateiro, F. Pozo, H. R. Karimi, and N. Luo, "Semiactive control methodologies for suspension control with magnetorheological dampers," IEEE/ASME Transactions on Mechatronics, vol. 17, no. 2, pp. 370-380, Apr. 2012.

[50] S. Sivakumar and A. Haran, "Mathematical model and vibration analysis of aircraft with active landing gears," Journal of Vibration and Control, vol. 21, no. 2, pp. 229$245,2015$.

[51] M. Zarchi and B. Attaran, "Performance improvement of an active vibration absorber subsystem for an aircraft model using a bees algorithm based on multi-objective intelligent optimization," Engineering Optimization, vol. 49, no. 11, pp. 1905-1921, Jan. 2017.

[52] — - "Improved design of an active landing gear for a passenger aircraft using multi-objective optimization technique," Structural and Multidisciplinary Optimization, vol. 59, no. 5, pp. 1813-1833, Dec. 2018.

[53] H. Yazici and M. Sever, "Observer based optimal vibration control of a full aircraft system having active landing gears and biodynamic pilot model," Shock and Vibration, vol. 2016, 2016.

[54] W. Abbas, O. Abouelatta, M. El-Azab, M. Elsaidy, and A. Megahed, "Optimization of biodynamic seated human models using genetic algorithms," Engineering, vol. 2, no. 9, pp. 710-719, 2010.

[55] H. Ciloglu, "Experimental and numerical investigation of the dynamic seat comfort in aircrafts," Master's thesis, University of Ontario Institute of Technology, 2013.

[56] H. Ciloglu, M. Alziadeh, A. Mohany, and H. Kishawy, "Assessment of the whole body vibration exposure and the dynamic seat comfort in passenger aircraft," International Journal of Industrial Ergonomics, vol. 45, pp. 116-123, Feb. 2015. 
[57] ISO-2631-1, Mechanical vibration and shock - Evaluation of human exposure to wholebody vibration, International Organization for Standardization, Geneva, Switzerland, 1997.

[58] Y. Li, J. Z. Jiang, P. Sartor, S. A. Neild, and H. Wang, "Including inerters in aircraft landing gear shock strut to improve the touch-down performance," Procedia Engineering, vol. 199, pp. 1689-1694, 2017.

[59] Y. Li, J. Z. Jiang, S. A. Neild, and H. Wang, "Optimal inerter-based shock-strut configurations for landing-gear touchdown performance," Journal of Aircraft, vol. 54, no. 5, pp. 1901-1909, Sep. 2017.

[60] R. Peterson and C. Bass, "Shock mitigation for the human on high speed craft: Development of an impact injury design rule," in RTO-MP-AVT-110: Habitability of Combat and Transport Vehicles: Noise, Vibration and Motion, 2004.

[61] P. De Alwis, "Methods for shock and vibration evaluation applied on offshore power boats," Master's thesis, Kth Royal Institute of Technology, 2014.

[62] ISO-2631-5, Mechanical vibration and shock - Method for evaluation of vibration containing multiple shocks, International Organization for Standardization, Geneva, Switzerland, 2004.

[63] "Detail specification: Seat system, upward ejection, aircraft, general specification for," Tech. Rep. MIL-DTL-9479E, 2007.

[64] W. A. Fladung, "Windows used for impact testing," in SPIE The International Society for Optical Engineering, 1997, pp. 1662-1666.

[65] S. J. Swift, M. C. Smith, A. R. Glover, C. Papageorgiou, B. Gartner, and N. E. Houghton, "Design and modelling of a fluid inerter," International Journal of Control, vol. 86, no. 11, pp. 2035-2051, Nov. 2013.

[66] Y. Hu, M. Z. Chen, and Z. Shu, "Passive vehicle suspensions employing inerters with multiple performance requirements," Journal of Sound and Vibration, vol. 333, no. 8, pp. 2212-2225, Apr. 2014. 
[67] X. Dong, Y. Liu, and M. Z. Q. Chen, "Application of inerter to aircraft landing gear suspension," in Proceedings of the $34^{\text {th }}$ Chinese Control Conference, Jul. 2015, pp. 2066-2071.

[68] Y. Li, C. Howcroft, S. A. Neild, and J. Z. Jiang, "Using continuation analysis to identify shimmy-suppression devices for an aircraft main landing gear," Journal of Sound and Vibration, vol. 408, pp. 234-251, Nov. 2017.

[69] O. Brune, "Synthesis of a finite two-terminal network whose driving-point impedance is a prescribed function of frequency," Journal of Mathematics and Physics, vol. 10, no. 1-4, pp. 191-236, Apr. 1931.

[70] M. Z. Chen and M. C. Smith, "Electrical and Mechanical Passive Network Synthesis," in Recent Advances in Control and Information Sciences. Springer-Verlag London Limited, 2008.

[71] C. L. Wadhwa, Network analysis and synthesis. Anshan, 2008.

[72] A. Morelli and M. C. Smith, Passive Network Synthesis: An Approach to Classification. SIAM - Society for Industrial and Applied Mathematics, 2019.

[73] M. S. A. Elsayed, R. Sedaghati, and M. Abdo, "Accurate stick model development for static analysis of complex aircraft wing-box structures," AIAA Journal, vol. 47, no. 9, pp. 2063-2075, Sep. 2009.

[74] Airbus Canada Limited Partnership, Airport planning publication. Airbus Canada Limited Partnership, 2019.

[75] European Aviation Safety Agency, "Type-certificate data sheet for pw1500g series engines," 2018.

[76] P. Jackson, Ed., All the World's Aircraft: Development \& Production 2018 - 2019. Jane's Information Group, 2019, ch. Aircraft - Fixed-Wing - Civil - Airbus A220.

[77] J. Roskam, Airplane Design Part V: Component Weight Estimation. Design, Analysis and Research Corporation, 1999. 
[78] The Goodyear Tire \& Rubber Co., "Global aviation tires," 2002.

[79] The Goodyear Tire \& Rubber Company, "Global aviation tires," Jun. 2018.

[80] Society of Automotive Engineers Inc., Vehicle Dynamics Terminology, Jan. 2008.

[81] Reed Business Information, "Cs100 cutaway drawing," 2017.

[82] R. Cirillo, "Detailed and condensed finite element models for dynamic analysis of a business jet aircraft," Ph.D. dissertation, Politecnico Di Milano, 2011.

[83] W. Krüger, "Integrated design process for the development of semi-active landing gears for transport aircraft," phdthesis, Universität Stuttgart, Dec. 2000.

[84] ASM International, Properties and Selection: Nonferrous Alloys and Special-Purpose Materials, 10th ed., 1990, vol. 2. [Online]. Available: http://asm.matweb.com/search/ SpecificMaterial.asp?bassnum=MA7075T6

[85] T. J. Yager and J. L. McCarty, "Friction characteristics of three 30 x 11.5-14.5, type viii, aircraft tires with various tread groove patterns and rubber compounds," Tech. Rep. TP 1080, 1977.

[86] MSC Software Corporation, Welcome to the C++ Version of the Adams Solver, 2019.

[87] F. M. White, Fluid Mechanics, M. Lange, Ed. McGraw-Hill, 2011.

[88] MIL-H-5606H, Military Specification: Hydraulic Fluid, Petroleum Base; Aircraft, Missile, and Ordnance, 1994.

[89] B. Peikari, Fundamentals of Network Analysis and Synthesis. Englewood Cliffs, N.J.: Prentice-Hall, 1974. 


\title{
Appendix A
}

\section{Tire and Road Property Files}

\author{
A.1 Nose Landing Gear

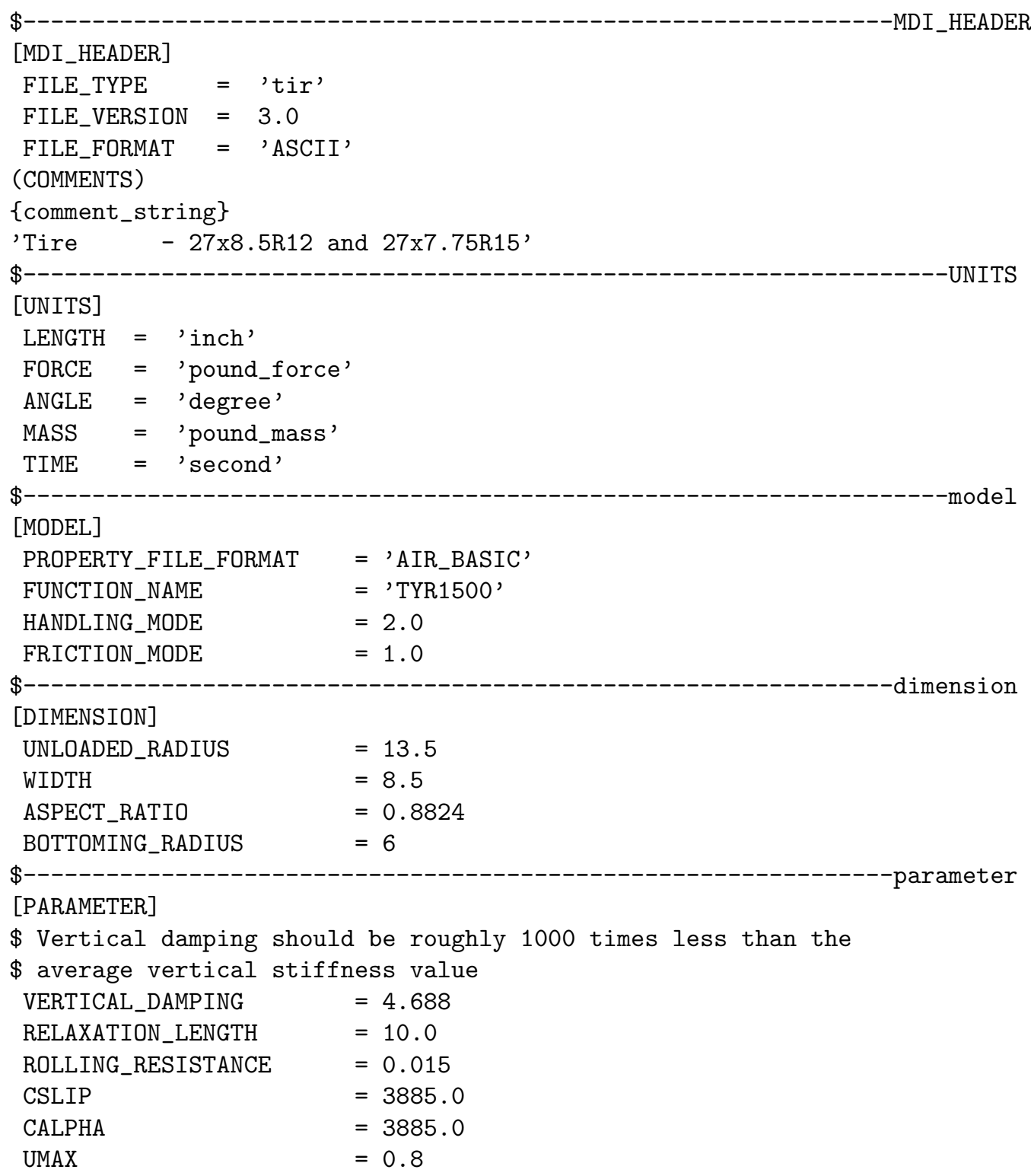




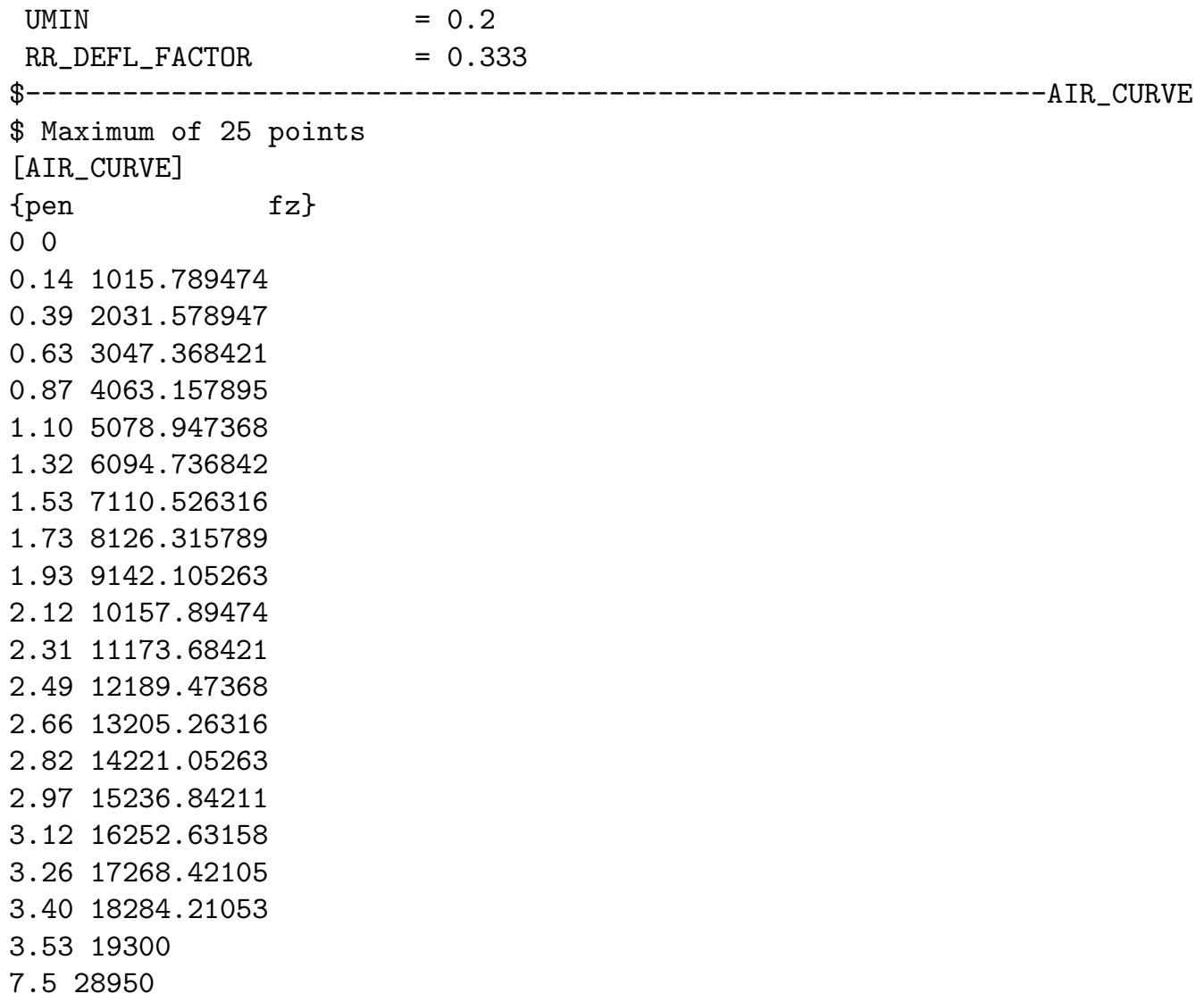

\section{A.2 Main Landing Gear}

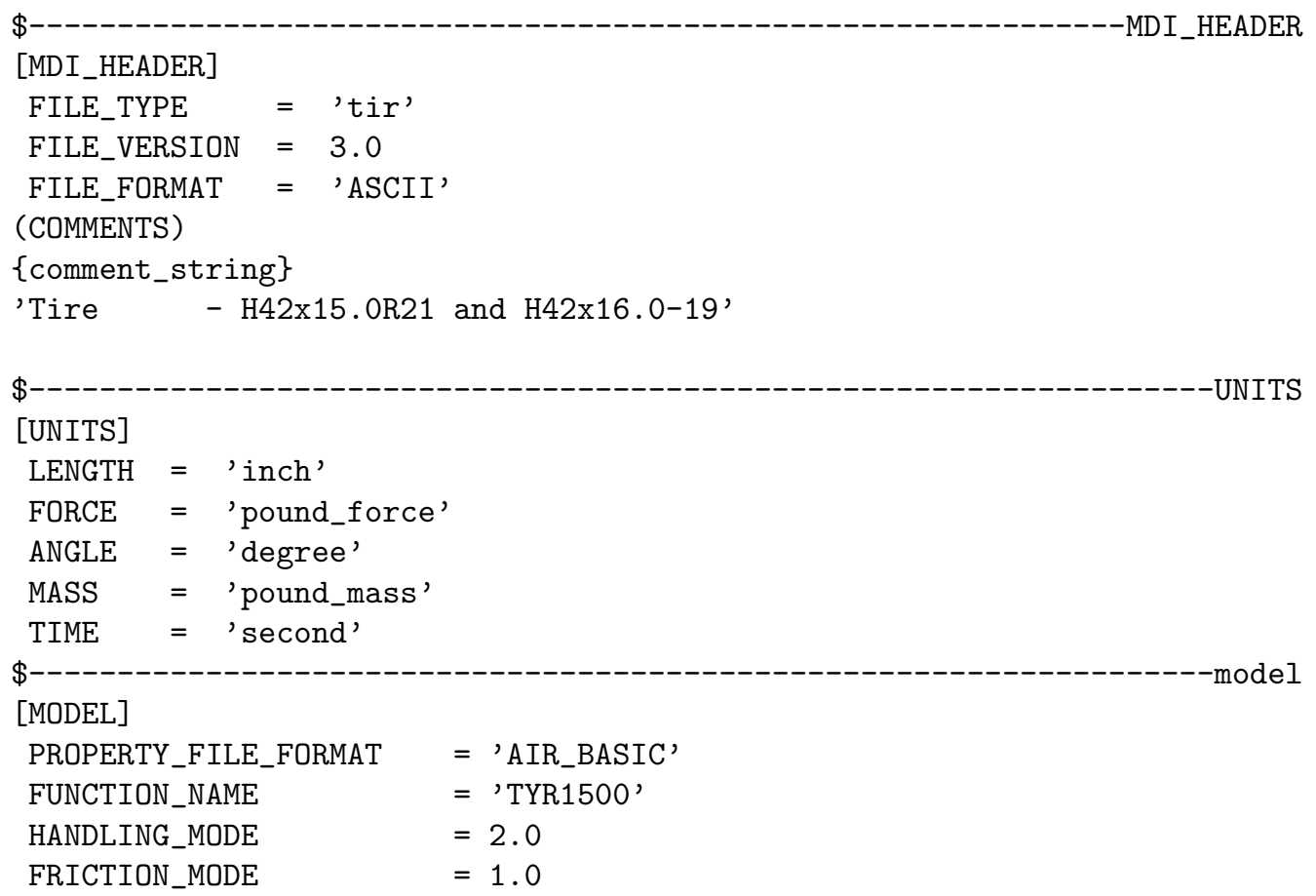




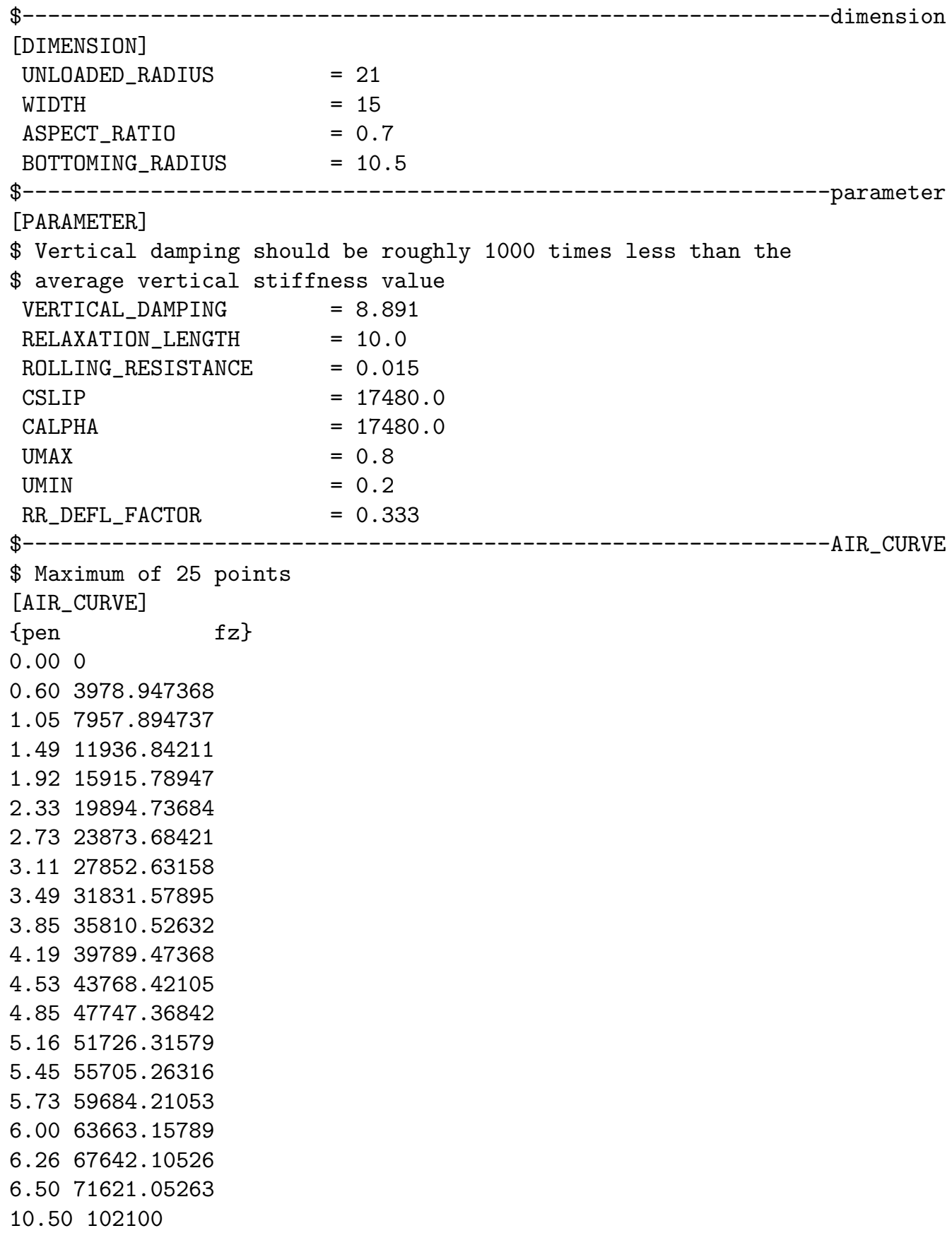

\section{A.3 Road Property File}

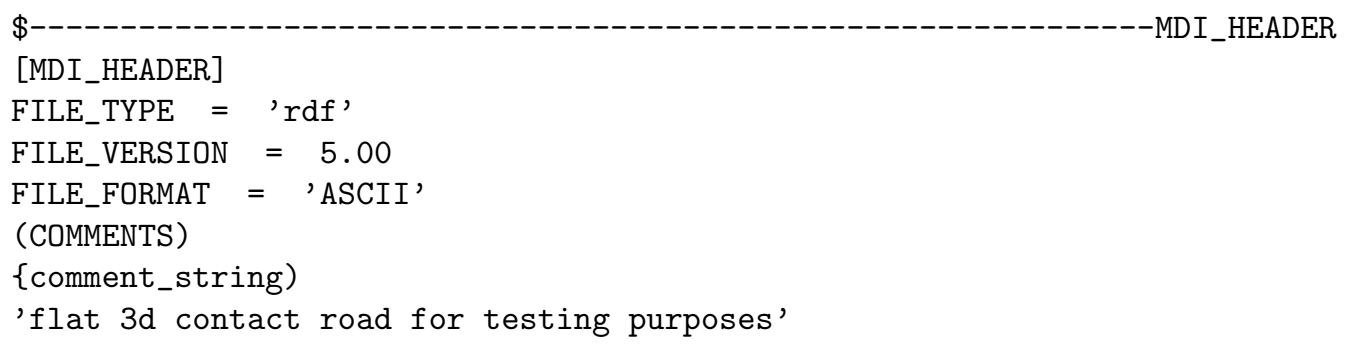




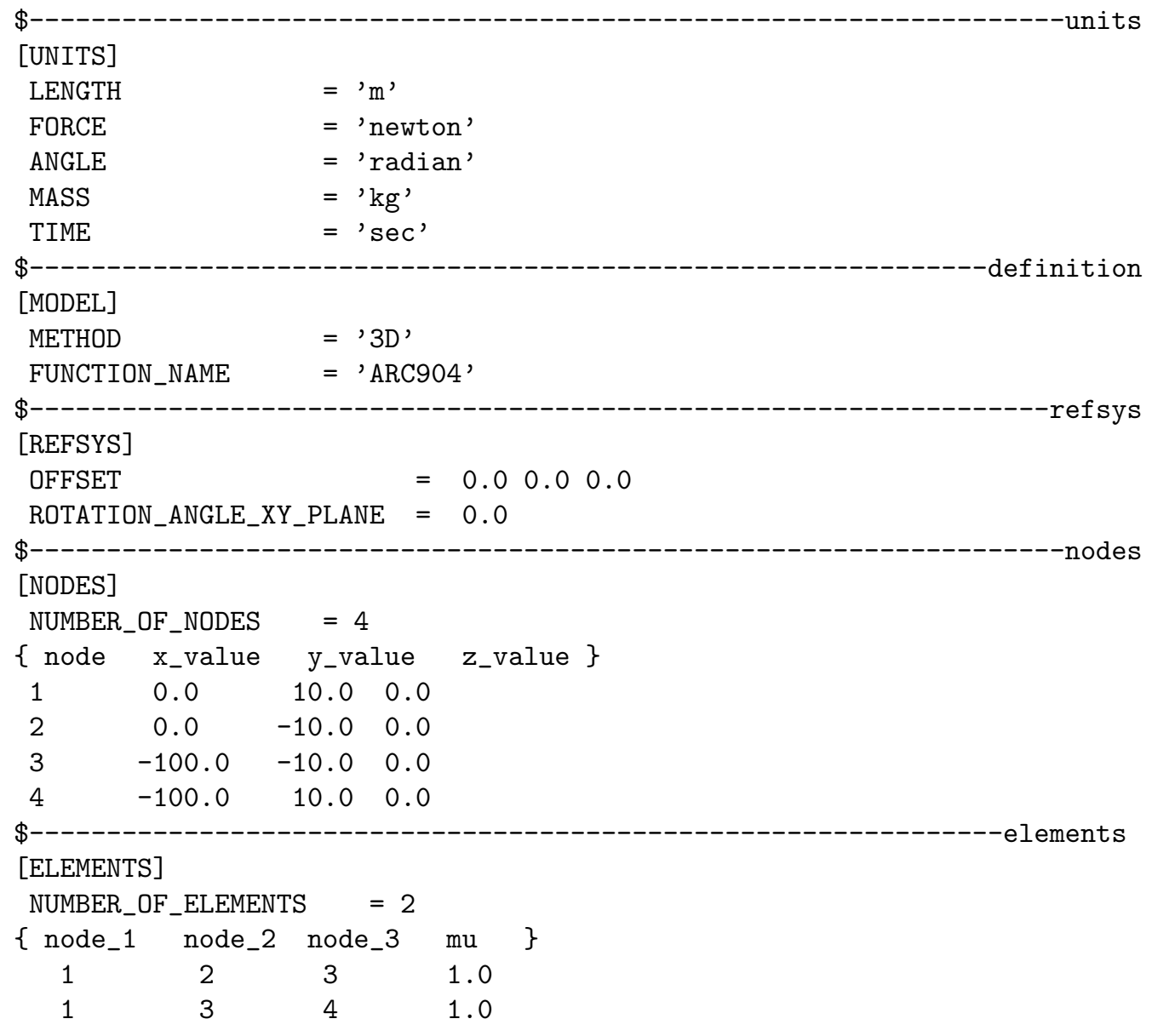

